University of Louisville ThinkIR: The University of Louisville's Institutional Repository

Electronic Theses and Dissertations

8-2019

\title{
Behavioral and cognitive correlates of intolerance of uncertainty in children with and without anxiety disorders.
}

Colette Marie Gramszlo

University of Louisville

Follow this and additional works at: https://ir.library.louisville.edu/etd

Part of the Clinical Psychology Commons

\section{Recommended Citation}

Gramszlo, Colette Marie, "Behavioral and cognitive correlates of intolerance of uncertainty in children with and without anxiety disorders." (2019). Electronic Theses and Dissertations. Paper 3279.

https://doi.org/10.18297/etd/3279

This Doctoral Dissertation is brought to you for free and open access by ThinkIR: The University of Louisville's Institutional Repository. It has been accepted for inclusion in Electronic Theses and Dissertations by an authorized administrator of ThinkIR: The University of Louisville's Institutional Repository. This title appears here courtesy of the author, who has retained all other copyrights. For more information, please contact thinkir@louisville.edu. 


\title{
BEHAVIORAL AND COGNITIVE CORRELATES OF INTOLERANCE OF UNCERTAINTY IN CHILDREN WITH AND WITHOUT ANXIETY DISORDERS
}

\author{
By \\ Colette Marie Gramszlo \\ B.A., Johns Hopkins University, 2013 \\ M.S., University of Louisville, 2016
}

\begin{abstract}
A Dissertation
Submitted to the Faculty of the

College of Arts and Sciences of the University of Louisville in Partial Fulfillment of the Requirements

for the Degree of
\end{abstract}

\begin{abstract}
Doctor of Philosophy
in Clinical Psychology
\end{abstract}

Department of Psychological and Brain Sciences

University of Louisville

Louisville, Kentucky

August, 2019 



\title{
BEHAVIORAL AND COGNITIVE CORRELATES OF INTOLERANCE OF UNCERTAINTY IN CHILDREN WITH AND WITHOUT ANXIETY DISORDERS
}

\author{
By \\ Colette Marie Gramszlo \\ B.A., Johns Hopkins University, 2013 \\ M.S., University of Louisville, 2016 \\ A Dissertation Approved on
}

June 25, 2018

by the following Dissertation Committee:

Dissertation Director
Janet Woodruff-Borden, Ph.D.

Cara Cashon, Ph.D.

Judith Danovitch, Ph.D.

Cheri Levinson, Ph.D.

Christine Brady, Ph.D. 


\section{DEDICATION}

To Eric, Roxie, and Melanie, whose love has been a steadying force and a constant source of motivation. 


\section{ACKNOWLEDGEMENTS}

Thank you to my mentor, Dr. Janet Woodruff-Borden, for her endless encouragement and guidance throughout my time as a graduate student. Her creativity and leadership have been a model for my professional development and I am grateful for the time and energy she has invested in my academic future. Thank you to Dr. Cara Cashon, for her invaluable input on collection and analysis of this project's data; to Dr. Cheri Levinson, for her thoughtful feedback on this and previous projects; to Dr. Judith Danovitch, for her insight on theoretical aspects of this work; and to Dr. Christine Brady, for her generous support and advice, clinically and academically. Finally, thank you to Judy Mier-Chairez and Angela Lee for their gracious assistance with this project and for their humor and friendship. 


\section{ABSTRACT \\ BEHAVIORAL AND COGNITIVE CORRELATES OF INTOLERANCE OF UNCERTAINTY IN CHILDREN WITH AND WITHOUT ANXIETY DISORDERS

\author{
Colette Marie Gramszlo
}

June $25^{\text {th }}, 2018$

Intolerance of Uncertainty (IU) has long been identified as a proximal risk factor for the development of anxiety disorders, and more recently has been implicated in the development of emotional disorders broadly. However, little is known about how IU and psychopathology symptoms relate, limiting the degree to which IU can be identified prior to the development of emotional disorders and targeted during the intervention of disorder symptoms. The current study reviews several areas of literature to inform a model by which IU impacts anxiety symptoms. First, uncertainty processing and the development of uncertainty processing in childhood are reviewed. Next, IU is reviewed and model of the impact of IU on uncertainty processing is proposed. Finally, childhood IU is reviewed and current gaps in the childhood IU literature are identified. The current study hypothesized that IU contributes to uncertainty avoidance, which is reflected by cognitive and behavioral processes associated with decision-making under uncertainty. Specifically, this study tested the hypothesis that children with higher IU demonstrate less efficient information processing and decision-making, particularly in the presence of ambiguous information. Further, this study tested the hypotheses that the relation between IU and disorder symptoms would be moderate by individual differences in 
higher order cognitive control processes implicated in decision-making. The study recruited 47 children, 23 with anxiety disorders and 24 without, to test these hypotheses. Children completed a decision-making computer task and children and their parents completed questionnaires. Overall, the results partially supported the study hypotheses. IU predicted greater reaction time (RT) during the task but RT was not greater in the presence of ambiguous, as compared to neutral or threatening, stimuli for children with high IU. IU predicted greater distraction from the task target and distraction was increased in the presence of ambiguous stimuli for children with high IU. Accuracy was not related to IU. Exploratory analyses indicated that children with high IU demonstrated greater RT variability compared to children with low IU, and greater distractibility in earlier, compared to later, task trials. Results are discussed in terms of theoretical and clinical implications for future study and intervention of IU. 


\section{TABLE OF CONTENTS}

ACKNOWLEDGEMENTS $\ldots \ldots \ldots$

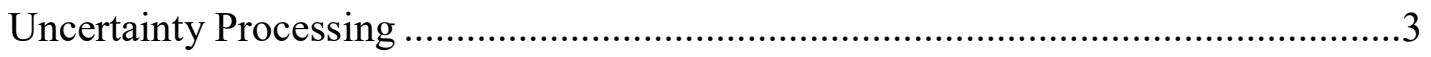

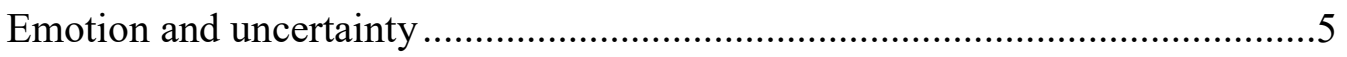

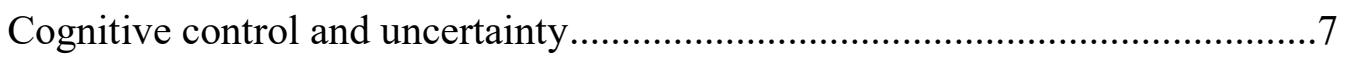

Childhood Uncertainty Processing ................................................................

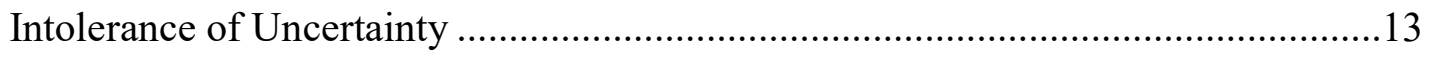

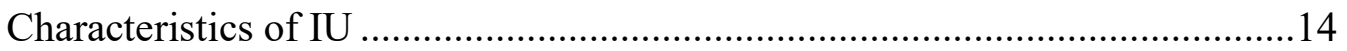

Individual differences in uncertainty processing ......................................16

Integrating uncertainty processing and IU ............................................ 19

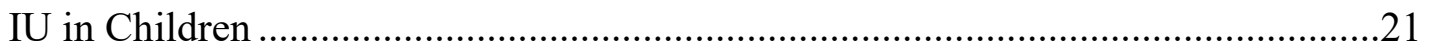

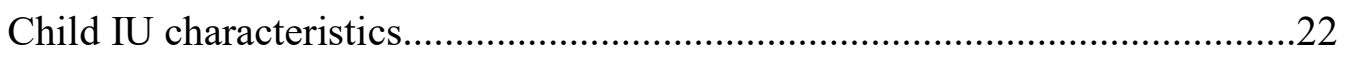

Individual differences in uncertainty processing among children ...................23

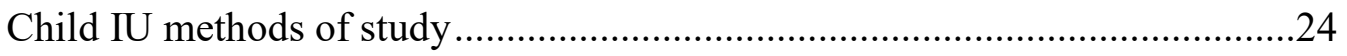

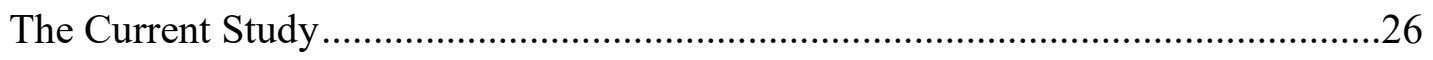

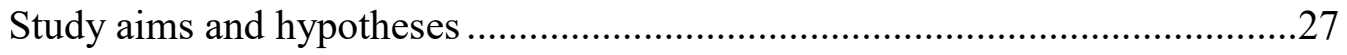

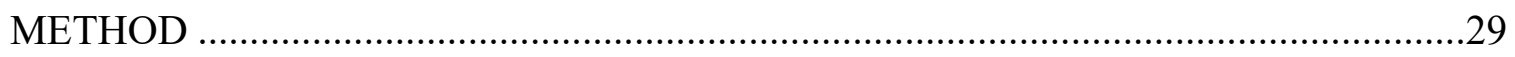




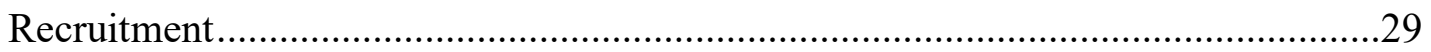

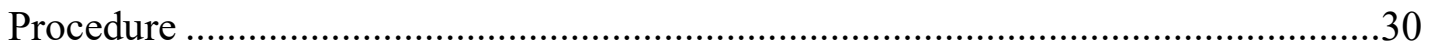

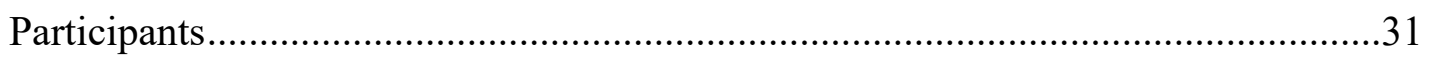

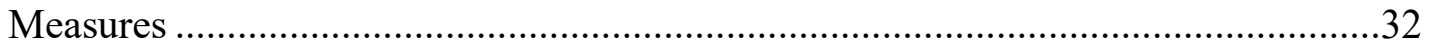

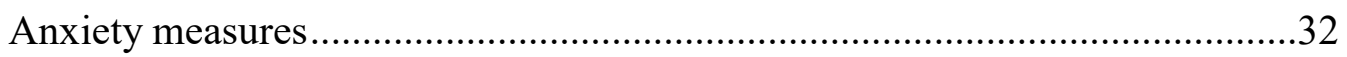

Executive function measure ...............................................................34

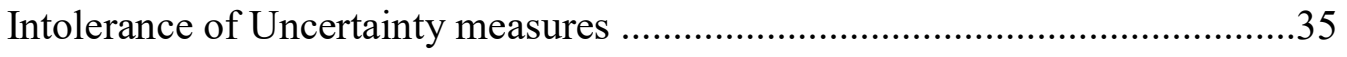

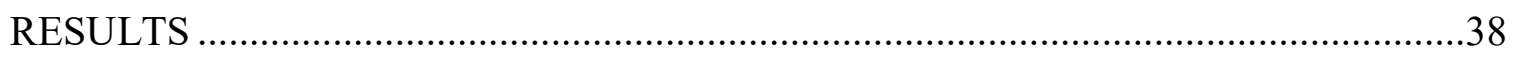

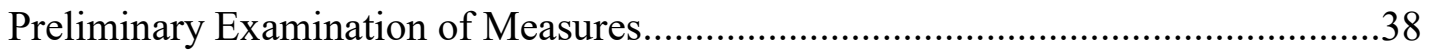

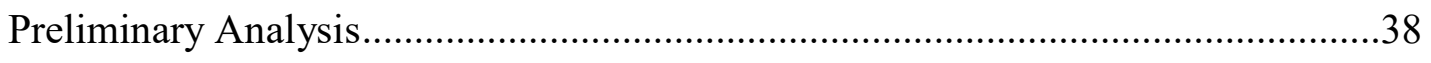

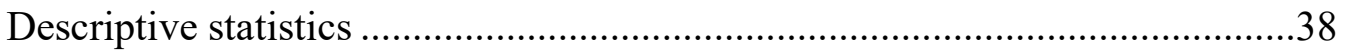

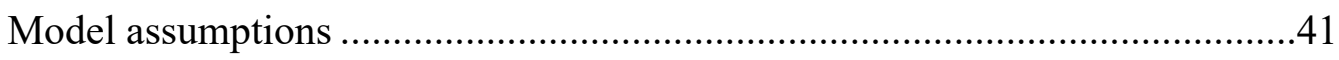

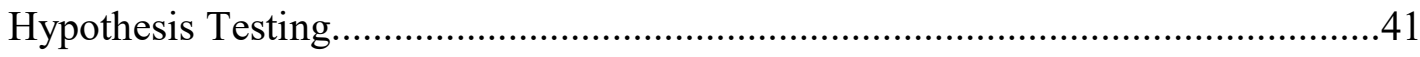

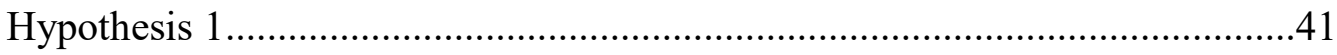

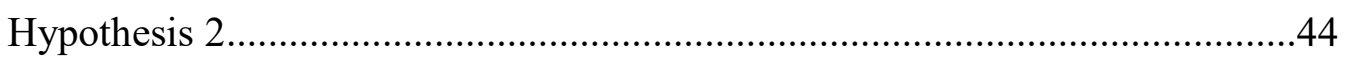

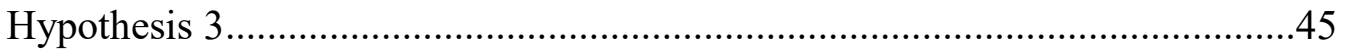

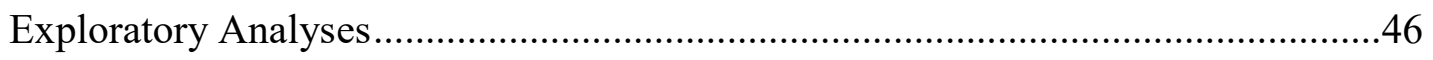

Anxiety disorder symptoms ...........................................................46

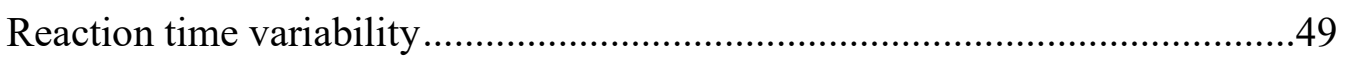

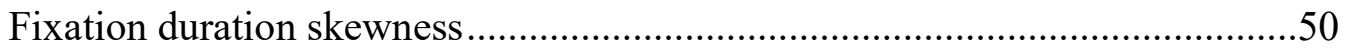

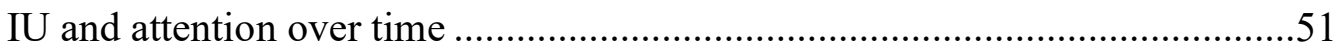

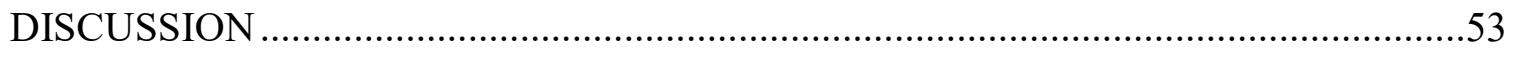

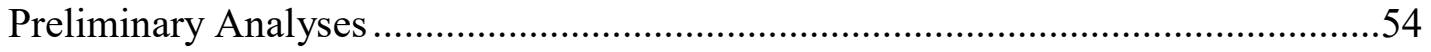




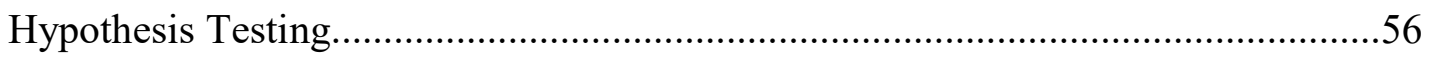

Behavior and IU during decision-making.......................................................56

Behavior and anxiety symptoms during decision-making ................................59

Attention and IU during decision-making .......................................................60

Attention and anxiety symptoms during decision-making ..............................63

IU, cognitive control, and anxiety symptoms ...................................................64

Implications for the Impact of IU on Development and Anxiety Symptoms .............66

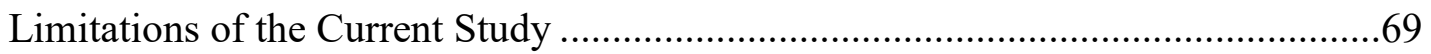

Summary and Future Directions ........................................................................

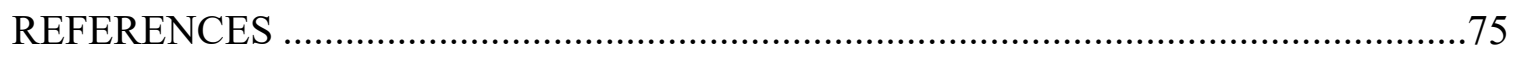

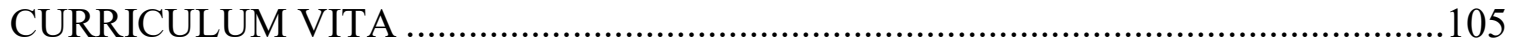




\section{LIST OF TABLES}

TABLE

PAGE

1. Sample Characteristics and Independent Samples $T$ Tests Comparing Children with and without Anxiety Disorders on Study Measures ............................................. 39

2. Correlation Coefficients Between IUS-C, Task Outcomes, and Covariates ............. 42

3. Correlation Coefficients between Study Measures and Covariates ........................... 43

4. Correlation Coefficients between Anxiety Symptom Measures, Task Outcomes, and

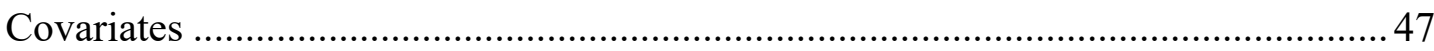

5. Correlations Coefficients between IUS-C and Task Outcomes by Group ................ 48 


\section{LIST OF FIGURES}

FIGURE $\quad$ PAGE

1. An illustration of the conditions under which uncertainty arises and is resolved ........9

2. A proposed model of the conditions under which maladaptive uncertainty processing

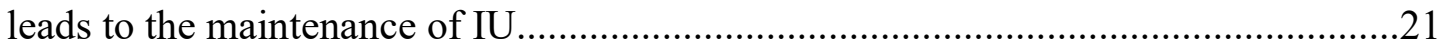

3. Graphical representation of dwell duration proportion predicted by condition for high

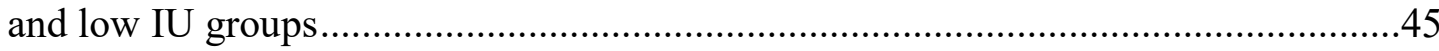

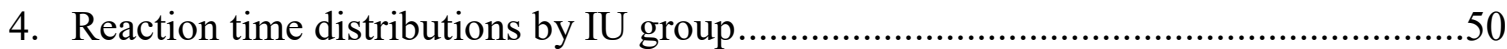

5. Fixation duration distribution for high and low worry groups ................................51

6. Graphical representation of dwell duration proportion in ambiguous conditions predicted by IU group by time 


\section{INTRODUCTION}

Uncertainties, large and small, are a constant presence in daily life, and the resolution of uncertainty is a fundamental task of the human brain. We are driven to reduce uncertainty as it arises through cognitive and emotional processes that facilitate decision-making behaviors, whether determining what to eat for dinner or which career to pursue. For some, however, uncertainty presents a unique challenge. Intolerance of Uncertainty (IU) is defined as the inability to endure the unpleasant responses triggered by the perceived absence of sufficient information (Carleton, 2016). IU is dispositional, and individuals with high IU experience aversive reactions to uncertainty across contexts. Elevated levels of IU have been identified across a wide variety of psychiatric disorders, including anxiety, post-traumatic stress, obsessive/compulsive, eating and mood disorders.

While IU appears to precede the onset of psychopathology symptoms, it is unclear why this relation exists. Current research in this area has relied primarily on questionnaires measuring beliefs and opinions regarding uncertainty, limiting our knowledge of the neurobiological and behavioral characteristics of those with high IU. The introduction of the Research Domain Criteria (RDoC) has highlighted the need to integrate research concerning core domains of neurobehavioral function, such as affect and cognition, with clinical research to clarify the fundamental mechanisms of psychopathology (Sanislow et al., 2010) and allow basic science research to directly 
inform the study and treatment of psychopathology (Cuthbert \& Insel, 2013). However, no models have linked IU to psychopathology with regard to these core domains.

Examining IU among youth, who are still developing the ability to process uncertainty, may inform models of IU as a predictor of psychopathology. In childhood, uncertainty presents an opportunity to learn new information, challenge existing beliefs about the world, and practice problem-solving skills. For individuals with high IU, uncertainty is unacceptable, distressing, paralyzing and ultimately avoided. Children with high IU likely limit their exposure to uncertainty, hindering their uncertainty processing development. Avoidance of uncertainty at a young age may contribute to maladaptive uncertainty processing strategies, which ultimately allows psychopathology symptoms to emerge. Newly created, age appropriate measurement tools (e.g., Intolerance of Uncertainty Scale for Children) have allowed IU to be identified in children as young as seven (Comer et al., 2009), but there remains a paucity of research concerning IU in childhood and the characteristics of children with high IU in uncertain environments.

Given the increasing interest in IU as a transdiagnostic construct with clinical utility (Shihata, McEvoy, Mullan, \& Carleton, 2016), a clearer picture of the behavioral and cognitive correlates of IU during the development of uncertainty processing (i.e., in childhood) is necessary at this time to understand how IU relates to the emergence of psychopathology. Uncertainty processing and the development of this processing will first be reviewed as a background on relevant methods and systems. IU literature will be reviewed and a model of the maintenance of IU will be proposed. Childhood IU literature will then be reviewed, along with an overview of the limits and future directions of this 
work. The current study aimed to begin addressing these limitations by investigating uncertainty processing among youth with and without anxiety disorders.

\section{Uncertainty Processing}

Uncertainty refers to the realization that there is insufficient information in the present environment to make predictions about the future (Yu \& Dayan, 2005), and the brain relies on external and internal information to resolve uncertainty as it arises. External information includes environmental cues - the facial expression of a stranger or the perceived speed of a car coming toward you. Internally, emotional arousal, emotional valence, and related bodily sensation provide informational cues. This bottom-up information interacts with top-down predictions about the future to determine whether sufficient certainty exists. When top-down predictions (e.g., hearing a fire alarm and predicting that the building is on fire) are violated by bottom-up information (e.g., no smoke or heat are present), uncertainty arises (Yu \& Dayan, 2003).

Several related terms are used across uncertainty and IU literature: expected uncertainty, unexpected uncertainty, ambiguity, risk, probability and value. Uncertainty is said to be expected when a cue relating to an outcome is unreliable. For instance, when a car's left-hand turn signal flashes, there is a good chance that the driver will soon make a left turn. However, the driver may have signaled too soon, and there exists some expected uncertainty regarding when the driver will turn left. The degree of expected uncertainty, sometimes termed risk, may fluctuate depending on certain conditions, such as the geographic location or the speed of the driver. If, however, the driver turns right, unexpected uncertainty, or ambiguity, exists (Bland \& Schaefer, 2012). In the case of unexpected uncertainty, the cue itself has changed and a belief has been violated (Cohen 
\& Aston-Jones, 2005). Expected and unexpected uncertainty activate separable neural substrates, with expected uncertainty activating regions associated with error detection and unexpected uncertainty activating regions associated with novelty detection, providing evidence that humans process these two types of uncertainty in distinct ways (Payzan-LeNestour, Dunne, Bossaerts, \& O’Doherty, 2013).

Uncertainty is resolved through decision-making, and decisions represent responses to uncertainty. Decision-making is defined as the selection of a response, following a cue, based on both the predicted value and the computed probability of the outcome associated with that response (FeldmanHall, Glimcher, Baker, \& Phelps, 2016). Uncertainty, as described above, arises when the response paired with a stimulus is an unreliable or volatile predictor of an outcome. Decision-making is a temporal process, and the selection of a response to uncertainty is based on knowledge of past responses and previously learned causal statistics within the environment (Huettel, Song, \& McCarthy, 2005). If a child is cued by their teacher to note an upcoming exam, that child may decide whether or not to study based on how much studying was required to do well on past exams. Decision-making requires future based processing as well. Selecting "study" as a response to "upcoming test" also depends on how risky it will be to do poorly on this specific upcoming exam, and how rewarding it will be to do well.

Decision science has traditionally studied responses to uncertainty by examining which options are selected, how accurately decisions are made, and how quickly those decisions are made (Behrens, Woolrich, Walton, \& Rushworth, 2007). New models of decision-making reflect a recent paradigm shift within the field toward the cognitive processes underlying decision-making, including "basic perceptual, attentional, memory 
and aggregation processes" (Oppenheimer \& Kelso, 2015, p. 277) in addition to observable behavior under uncertainty. Emotion and cognitive control are two key processes elicited by uncertainty and involved in the resolution of uncertainty through decision-making.

Emotion and uncertainty. Uncertainty and emotions intersect at multiple points during decision-making, both arising from and contributing to decisions, and affecting thoughts and behaviors associated with decision-making (Lerner, Li, Valdesolo, \& Kassam, 2015). Of note, the terms affect and emotion are used somewhat interchangeably throughout this proposal to reflect the linguistic choices of different authors. Though the two do differ somewhat, with affect referring more to psycho-physiological experiences and emotions being social constructions of those experiences, they are largely synonymous (Russell, 2003). Uncertainty in decision-making interacts with both emotional arousal and emotional valence. Arousal refers to the amount of experienced affect, while valence refers to the kind of affective state (Winkielman, Knutson, Paulus, $\&$ Trujillo, 2007). Emotions can also be integral to decision-making, arising directly from a situation, or incidental to decision-making, arising from one situation and affecting decisions made about another.

Uncertainty increases emotional arousal and increases in specific emotions reciprocally increase the perception of uncertainty. In a series of four studies examining the interaction of emotion and uncertainty, Bar-Anan, Wilson and Gilbert (2009) showed participants film clips aimed at eliciting positive or negative affect. Participants in the uncertainty condition were prompted to state phrases such as "I'm not sure what's happening" while viewing the clips, while those in the certainty condition stated phrases 
such as "I understand" and "I see what's happening." Participants in the uncertainty condition reported more extreme affect related to the clips, despite having received the same objective amount of information. This suggests that despite the true availability of information in an environment, the perception of uncertainty elicits increased affect. The authors hypothesize that perceived uncertainty may elicit affect to make goal-relevant cues in the environment more salient, so that they can be attended to and used as additional information to resolve uncertainty (Bar-Anan, Wilson, \& Gilbert, 2009).

Tiedens and Linton (2001) explored the interaction of uncertainty, emotion and information processing in a series of experiments. In the first experiment, undergraduates were induced to feel positive or negative emotions using an emotional memories task, then asked to make predictions about the future and rate their subjective certainty about these predictions. They found differences in the effect of emotional valence on decisions by demonstrating that participants who were primed to feel positive emotions (i.e., happy) were more certain about their predictions, while participants primed to feel negative emotions (i.e., anxious) were less certain. In a second experiment, they found that emotional valence also affected depth of thought under uncertainty, by showing that participants induced to feel happy, and thus more certain about their decisions, were more likely to rely on less effortful cognitive processing during decision-making, while participants induced to feel anxious, and thus less certain, were more likely to rely on effortful and controlled cognitive processing (Larissa Z. Tiedens, 2001).

Importantly, the mood induction portion of each experiment was incidental to the second portion of the experiment involving information processing and decision-making. An individual does not need to feel uncertainty about the decision itself to experience 
uncertainty while making a decision, and it is hypothesized that individuals who experience more negative affect in general are also more likely to perceive uncertainty across environments and experiences. Tiedens and Linton's (2001) experiments also demonstrate that anxiety, a specific negative mood state, facilitates controlled processing of information during decision-making. Anxiety elicits the perception of uncertainty, which then triggers a methodical analysis of all available information to create certainty about a decision (Larissa Z. Tiedens, 2001).

Cognitive control and uncertainty. Cognitive control refers to higher order, topdown processes responsible for goal-directed activity. Humans typically conserve cognitive resources by operating through automatic processing unless triggered to switch toward controlled processing (Mushtaq, Bland, \& Schaefer, 2011). Triggers that initiate controlled cognitive processing include the detection of errors (Braver, Gray, \& Burgess, 2012; Yeung \& Cohen, 2006), conflict between competing responses (Botvinick, Braver, Barch, Carter, \& Cohen, 2001), and changes in the prediction of error likelihood (Brown \& Braver, 2005). Broadly, cognitive control takes over when existing models of the environment do not match incoming information, indicating that there is a mismatch between available representations of the environment and the actual environment, leading automatic processing to yield undesirable outcomes (e.g., errors). This mismatch represents uncertainty about the environment, and controlled cognitive processing allows for new representations to be learned so that individuals can adapt their behavior in the future (Mushtaq et al., 2011).

Emotion acts as a catalyst for cognitive control processes. Errors, and the uncertainty they signal, are aversive in nature, and conflicts arising between personal 
goals and outcomes elicit negative affect (e.g., wanting to do well in a job interview and not receiving a job offer; Fritz \& Dreisbach, 2013). This negative affect plays a causal role in the recruitment of cognitive control, allowing an individual to alter behavior, thereby decreasing the likelihood of repeating errors and increasing certainty about future outcomes (Inzlicht, Bartholow, \& Hirsh, 2015). Cognitive control also reciprocally impacts emotional experiences through emotion regulation (Lerner et al., 2015; Ochsner $\&$ Gross, 2005). Emotion regulation encompasses both effortful increases and decreases in affect, through cognitive and behavioral strategies (Lewis, 2013).

Despite findings that both emotion and cognitive control are key to uncertainty processing, only one study has examined the effects of emotion regulation on uncertainty processing. In two experiments, participants watched movie clips which induced either fear or disgust and were prompted to adaptively regulate this emotion through cognitive reappraisal, maladaptively regulate through emotional suppression, or not regulate at all. During decision-making tasks following the movie clips, participants who used cognitive reappraisal demonstrated significantly less aversion to uncertainty and performed better on the tasks than participants who suppressed their emotion or did not use an emotion regulation strategy (Heilman, Crişan, Houser, Miclea, \& Miu, 2010). These results suggest that individuals who adaptively down-regulate emotions as they arise are less averse to uncertainty and more efficient at resolving uncertainty.

Figure 1 summarizes this review of uncertainty processing. (1) When an individual becomes aware that either the information available in the present environment or the individual's existing representations about information in the present environment are insufficient to make decisions about the future (2) uncertainty arises. This uncertainty 
can be expected or unexpected, and people track the causal statistics of events to inform processing of uncertainty. Both varieties of uncertainty increase learning rates by facilitating (3) emotional processing and (4) cognitive control to form new representations or update old representations about the environment and to regulate the emotions elicited by uncertainty. The adaptive regulation of affect by higher order processes allows for certainty to be reached. Human resolution of uncertainty has thus far been studied in the context of decision-making paradigms. (5) Decision-making is determined by the interaction of emotional, or affective, processing and controlled, or deliberative, processing.

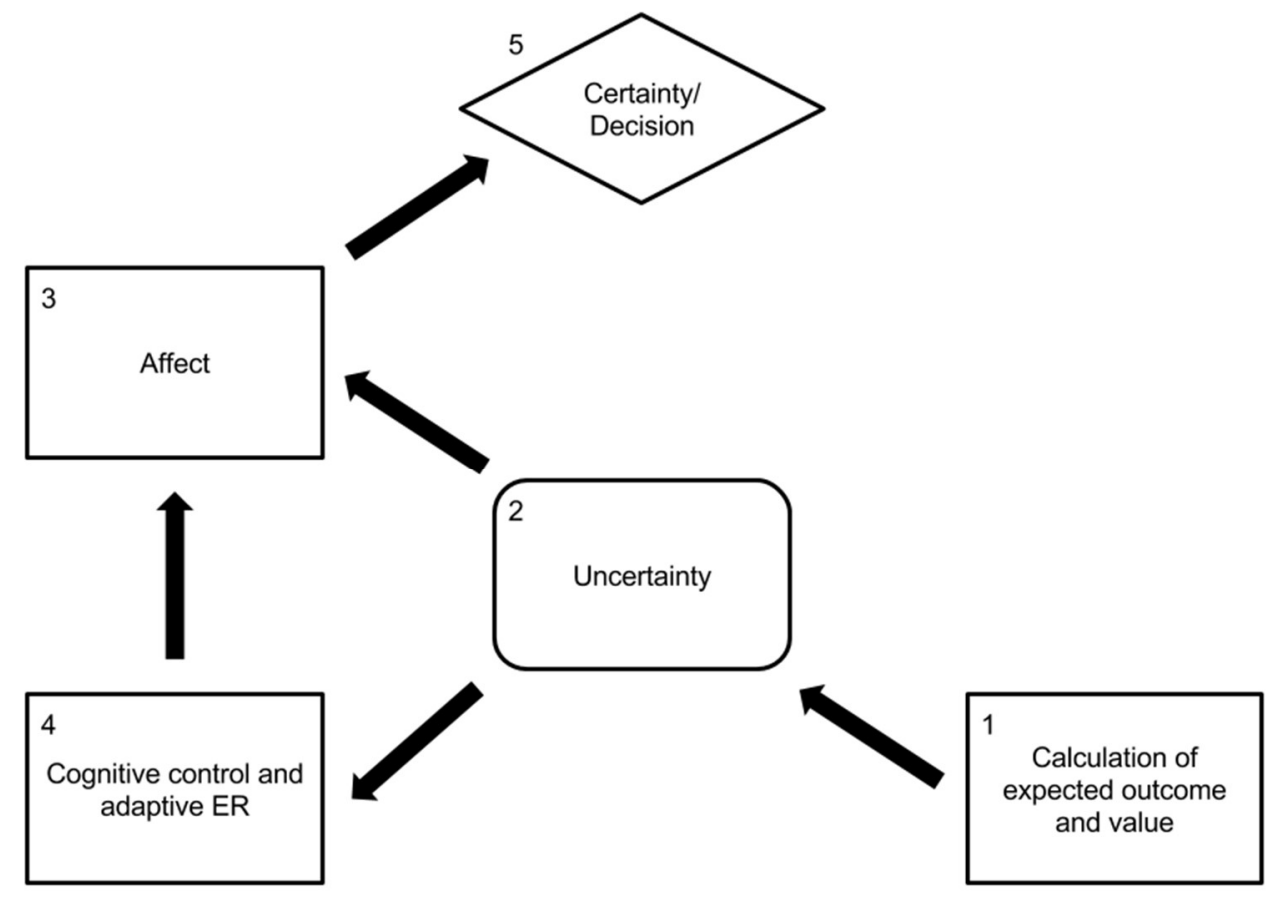

Figure 1. An illustration of the conditions under which uncertainty arises and is resolved.

\section{Childhood Uncertainty Processing}

Children differ in both their understanding of uncertainty and their ability to resolve it. In middle childhood, children begin to accurately monitor uncertainty (Roderer 
$\&$ Roebers, 2010) and learn that they can use information in the present environment to make decisions about the future (Lagattuta \& Sayfan, 2011). Adults tend to allocate attention toward goal-relevant cues in uncertain environments, but young children are less able to identify, and therefore less able to attend to, goal-relevant cues. Rather, they scan environments broadly, largely guided by bottom-up information processing, due to immature, or weak, cognitive control (Chevalier \& Blaye, 2009; Chrysikou, Weber, \& Thompson-Schill, 2014). While this makes children slower, less accurate and less efficient at certain decision-making tasks, young children benefit from less cognitive control. Weaker cognitive control encourages exploration and manipulation of environments, allowing children to learn statistical regularities in the environment and form top-down representations (Chevalier, 2015). As cognitive control develops, children learn the meaning of certain cues and increasingly pay attention to these cues, reciprocally allowing knowledge to build. Ambiguity poses particular difficulty for children, compared to adults, as they are beginning to develop knowledge of cues but still depend on environmental salience to guide actions. While older children can infer goals from subtler cues, cue transparency influences reaction time (RT) and accuracy through adulthood (Logan \& Schneider, 2006). Results of eye tracking studies have demonstrated that as children age they are less likely to evaluate all available information, and more likely to base decisions on only relevant information within uncertain environments (Lagattuta \& Sayfan, 2013).

Cognitive control undergoes tremendous development throughout childhood, continuing into young adulthood. Cognitive control is difficult for young children, and the development of such control is reflected in increasing speed, accuracy and efficiency 
of complex tasks as children age (Diamond, 2014). Development of cognitive control is driven by early growth of the prefrontal cortex (PFC), and subsequent pruning of unnecessary synapses in later childhood, which allows focalization of function to emerge. For example, young children show neural activation in areas unrelated to cognitive control on controlled tasks, which decreases into adulthood (Durston et al., 2006). Thus, cognitive control has been described as a diffuse, "unitary construct" which becomes differentiated with age (Carlson, Zelazo, \& Faja, 2013).

Cognitive control is commonly categorized into three core executive functions (EFs): inhibition, including behavioral inhibition and cognitive inhibition, working memory, and cognitive flexibility (Miyake et al., 2000). The development of cognitive control is characterized by increases in each of these areas, such that children are more impulsive and inattentive as compared to adults. Working memory and inhibition undergo the greatest development during preschool years (approximately ages three through six), while more focalized development of controlled attention, organization and flexibility occur during school-age years (approximately ages seven through 13; Carlson et al., 2013). During early childhood and preschool years, behavior is driven more by environmental stimuli than goals, but this balance changes through middle childhood and adolescents, such that adult behavior is more resistant to distraction from environmental stimuli and guided by internally held goals.

Evidence suggests that aspects of cognitive control associated with affect reach developmental maturity later than aspects associated with affectively-neutral cognitive control (Zelazo \& Müller, 2010). Performance on tasks designed to elicit affect during decision-making, such as the Iowa Gambling Task, develops slowly into adulthood, 
whereas performance on affectively-neutral EF tasks, such as Backward Digit Span, reaches adult levels in adolescence (Prencipe et al., 2011). Further, individual differences in affectively-relevant EFs are more stable than affectively-neutral EFs across development (Zelazo \& Carlson, 2012). On affective decision-making tasks, the ability to learn from negative emotional cues (e.g., the aversive affect associated with an error) and change one's behavior accordingly develops with age. Adults are more sensitive to the affective response associated with errors, which allows them to learn about the causal statistics of the environment more quickly and make more advantageous decisions than children under uncertainty (Cauffman et al., 2010). Middle childhood and adolescence represent an important period of maturation for emotional processes related to goaldirected behavior.

Adults learn to avoid negative outcomes more quickly due to the development of cognitive control broadly, and to the development of emotion regulation specifically. Emotion regulation develops linearly from middle childhood into adulthood. Cognitive reappraisal, for example, a skill which is associated with the ability to tolerate stressful events and processes emotions adaptively, increases through young adulthood (Gullone, Hughes, King, \& Tonge, 2010). The use of emotional suppression, a maladaptive emotion regulation associated with reduced positive affect and the maintenance of negative emotionality, decreases linearly through childhood and into adulthood as adaptive emotion regulation skills come online (Gullone et al., 2010).

Prior to adolescence, children learn to effectively identify and resolve uncertainty. Weaker cognitive control in childhood allows young children to explore their environment and facilitates learning, but also makes them less efficient at decision- 
making. As inhibitory and attentional control mature, children are more likely to attend to environmental cues that are relevant to their goals and use these cues as information to make decisions. With age, children are more able to learn from the negative emotions associated with uncertainty, down-regulate these emotions effectively, and make more efficient and accurate decisions as a result. Avoidance of uncertainty in childhood may limit the development of decision-making skills and contribute to rigid, maladaptive patterns of responding to uncertainty.

\section{Intolerance of Uncertainty}

IU was originally proposed by Freeston and colleagues as part of an effort to elucidate the cognitive processes associated with generalized anxiety disorder (GAD; Freeston, Rhéaume, Letarte, Dugas, \& Ladouceur, 1994). IU was measured in this seminal study through the Intolerance of Uncertainty Scale (IUS), whose items were created based on clinical observations of individuals with GAD (Birrell, Meares, Wilkinson, \& Freeston, 2011). The IUS measures cognitive, emotional and behavioral reactions to uncertainty with items such as, "Uncertainty stops me from having a strong opinion" and "Uncertainty makes life intolerable" (Freeston et al., 1994). The IUS and the IUS short form, a 12 question adaptation of the original 27 item measure, continue to be the only measures of IU (Carleton, Norton, \& Asmundson, 2007). Given the way the IUS was developed, early studies of IU focused exclusively on GAD and worry. Indeed, though IU is now linked to a wide range of disorders, it consistently demonstrates a unique and robust link to both worry and GAD (Dugas, Freeston, \& Ladouceur, 1997; Gentes \& Ruscio, 2011). 
As studies of IU have expanded their scope past worry and GAD, the definition has been altered to accommodate updated findings. Following results demonstrating that individuals with high IU are more likely to interpret ambiguous situations as threatening, as compared to both positive and negative situations, IU was defined as a "cognitive vulnerability" (Koerner \& Dugas, 2008). Koerner and Dugas (2008) proposed that, as a cognitive vulnerability, IU is a causal risk factor for the development of emotional disorders, contributes to the etiology of these disorders directly, and is malleable but dispositional. IU is separable from personality traits and temperamental risk factors (e.g., neuroticism, negative affect) and other cognitive risk factors (e.g., anxiety sensitivity, fear of negative evaluation) and predicts disorder symptoms above and beyond these related factors (Boelen \& Reijntjes, 2009). IU mediates the relation between neuroticism and disorder symptoms such as worry, agoraphobic cognitions, and depression (McEvoy \& Mahoney, 2012) and represents a "lower order" factor as compared to higher order factors such as neuroticism (Carleton, 2016). IU is thus described as the "filter" through which psychopathology arises (Shihata et al., 2016). The most updated descriptions of IU seek to incorporate this cognitive hypothesis with findings that individuals with high IU exhibit physiological, behavioral and emotional differences as well. Carleton (2016a) thus proposes that "IU is an individual's dispositional incapacity to endure the aversive response triggered by the perceived absence of salient, key, or sufficient information, and sustained by the associated perception of uncertainty" (p. 31).

Characteristics of IU. Though IU has received much attention in anxiety disorders literature, elevated levels of IU have been identified among individuals with obsessive-compulsive disorder (OCD; Tolin, Abramowitz, Brigidi, \& Foa, 2003), 
posttraumatic stress disorder (PTSD; Fetzner, Horswill, Boelen, \& Carleton, 2013) and major depressive disorder (MDD; Gentes \& Ruscio, 2011). Thus, theories of IU posit that it is a transdiagnostic factor associated with emotional disorders broadly (Einstein, 2014). Indeed, reductions in IU through treatment are associated with reductions in overall impairment associated with emotional disorders (Boswell, Thompson-Hollands, Farchione, \& Barlow, 2013).

Examinations of IU in relation to similar constructs have allowed characteristics of those with IU to emerge. High IU demonstrates a unique association with repetitive negative thinking, as compared to similar cognitive processes such as perfectionism and perceived control (Buhr \& Dugas, 2006; McEvoy \& Mahoney, 2013). For instance, in the case of anxiety disorders, IU's relation to symptom severity is mediated by worry, whereas IU's relation to depressive symptoms is mediated by rumination (Yook, Kim, Suh, \& Lee, 2010). Reductions in IU predict reductions in worry over time, providing evidence that among adults the inability to tolerate uncertainty may cause worry (Bomyea et al., 2015). High IU is also associated with a reduced ability to extinguish learned fear associations, such that individuals with high IU maintain fear responses during extinction paradigms while those with low IU do not (Morriss, Christakou, \& van Reekum, 2016).

Birrell, Meares, Wilkinson and Freeston (2011) point out in their review that researchers have focused on validating the construct of IU, with little attention to the phenomenology and development of IU. Indeed, IU as a construct did not develop through investigations of the nature of uncertainty, and the nature of distress caused by this uncertainty, but through observations of those with an active and specific emotional disorder. Carleton's (2016a) definition highlights the etiological nature of IU by 
proposing that IU arises through distress to responses elicited by uncertainty, and is maintained through the continued perception of uncertainty. Dispositional IU likely contributes to individual differences in uncertainty processing, which then impact the development of psychopathology.

Individual differences in uncertainty processing. Emotions are both information and informational regulators (Lench, Flores, \& Bench, 2011). Fear and anxiety are more closely associated with uncertainty than other emotions such as happiness or anger, and thus fear and anxiety facilitate the acquisition of information under uncertainty (Frey, Hertwig, \& Rieskamp, 2014). This relation is reciprocal, as previously described, and perceived uncertainty also increases affect (Bar-Anan et al., 2009). Some have proposed that individual differences in uncertainty tolerance underlie all clinically significant experiences of anxiety (Carleton, 2012). The Uncertainty and Anticipation Model of Anxiety (UAMA) proposes a neurobiological and psychological framework through which individual differences in physiology, emotion, behavior and cognition interact to explain anxious reactions to uncertainty (Grupe \& Nitschke, 2013). Though this model does not explicitly address IU, Grupe and Nitschke (2013) suggest that IU may represent the collection of "exaggerated physiological and subjective emotional responses to uncertainty" (p. 10). It can be hypothesized, then, that individual differences in emotional experiences and emotional processing, as in the case of emotional disorders, are likely linked to individual differences in uncertainty processing. Thus, the following section reviews individual differences in uncertainty processing. Given the specific link between anxiety and uncertainty, this section focuses on these individual differences in uncertainty processing within anxiety and anxiety disorders. 
Individual differences in emotion under uncertainty. Emotions are a necessary

and integral aspect of decision-making under uncertainty (Lerner et al., 2015).

Individuals with high IU require more information before reaching a decision

(Ladouceur, Talbot, \& Dugas, 1997) and may experience increases in affect under

uncertainty, above and beyond the increased affect experienced by those with low IU, as

a means of increasing the salience of relevant cues in the environment. Adults with high

IU interpret ambiguous information as more threatening than overtly positive, negative or

neutral information. This suggests that among adults with high IU, uncertainty itself may

serve as a fear cue, which increases negative affect specifically (Oglesby, Raines, Short,

Capron, \& Schmidt, 2016). Only one study of emotion and IU has differentiated between

expected and unexpected uncertainty. High IU individuals relative to low IU individuals

showed increased negative affect and biased threat appraisals toward unexpected

uncertainty specifically, rather than toward expected uncertainty or uncertainty broadly

(Chen \& Lovibond, 2016). Though all individuals exhibit a greater aversion to ambiguity, as compared to risk, when potential losses are high (Hsu, Bhatt, Adolphus, Tranel, \& Camerer, 2005), individuals with high IU may overvalue threat associated with ambiguity and delay or avoid decision-making as a result (Hartley \& Phelps, 2013).

Individual differences in cognitive control under uncertainty. Only one study has examined cognitive control among those with high IU, however, a large body of literature has emerged regarding cognitive control among those with anxiety disorders and may inform our understanding of cognitive control related to IU specifically.

However, these studies primarily rely on threat and neutral paradigms, leaving little know about cognitive processes under uncertainty. It is well established that individuals with 
anxiety disorders display characteristic attentional biases to threat (for a review see BarHaim, Lamy, Pergamin, Bakermans-Kranenburg, \& van IJzendoorn, 2007). Attentional biases are comprised of (1) facilitated attention toward threat, (2) difficulty in disengagement from threat once identified and (3) attentional avoidance of threat (Cisler $\&$ Koster, 2011). Attentional control and emotion regulation are the aspects of cognitive control underlying difficulty in disengagement and attentional avoidance, respectively. Attentional control is said to regulate bottom-up biases to threat, such that individuals with anxiety disorders have weaker attentional control and therefore more difficulty shifting attention away from threat once it has been identified (Derryberry \& Reed, 2002; Rueda, Posner, \& Rothbart, 2011). Threat can refer to external stimuli or internal cues, such as physiological and emotional experiences, or threatening imagery (Eysenck, Derakshan, Santos, \& Calvo, 2007). This weakened attentional control is present in neutral environments as well, and individuals with high trait anxiety are slower to attend to relevant cues when incongruent, but non-threatening, distractors are present (Bishop, 2009). Only one study has examined attentional differences in the context of IU. Participants in this study completed an Attention Network Task which demonstrated significant attentional differences between those with high and low IU such that individuals with high IU demonstrated increased attentional biases (Fergus \& Carleton, 2015).

\section{Individual differences in the cognitive control of emotion under uncertainty.}

Similarly, little is known about emotion regulation in the context of IU specifically. In the only study of IU and ER, IU was associated with experiential avoidance and distress about emotions even when controlling for negative affect, suggesting that worry and 
attentional avoidance may arise as a response to the internal states associated with uncertainty (Lee, Orsillo, Roemer, \& Allen, 2010). Emotion regulation among those with GAD, the disorder most closely related to IU, has been widely studied however. Individuals with anxiety disorders are much more likely to employ maladaptive emotion regulation strategies that serve to maintain or increase emotional experiences (Turk, Heimberg, Luterek, Mennin, \& Fresco, 2005). Specifically, those with GAD show increased intensity of emotions, greater reactivity to these emotions, and a reduced ability to self-soothe once emotions are experienced (Mennin, Heimberg, Turk, \& Fresco, 2005). As described previously, negative affect facilitates controlled information processing. In the case of highly anxious individuals, negative affect facilitates perseverative worry, rather than productive deliberation (Dash, Meeten, \& Davey, 2013). Worry has been conceptualized as a maladaptive problem-solving process, whereby individuals respond to problems with repetitive iterations of potential negative outcomes rather than productively engaging in solution generation and selection (Mennin, Heimberg, Turk, \& Fresco, 2002). Evidence also suggests that worry may increase negative affect among those with GAD (McLaughlin, Mennin, \& Farach, 2007) and maintain emotional disorders by preventing the productive processing of emotions (Newman, Llera, Erickson, Przeworski, \& Castonguay, 2013). Though individual differences in emotion regulation among those with high IU warrants further investigation, the characterization of emotion regulation among those with GAD may suggest that IU is also associated with reliance on maladaptive emotion regulation strategies.

Integrating uncertainty processing and IU. Figure 2 represents a proposed model through which dispositional IU contributes to maladaptive cognitive and emotional 
processing of uncertainty, increasing distress associated with uncertainty and reciprocally maintaining high IU levels. Unlike Figure 1, Figure 2 begins with (1) IU, a factor which increases vigilance toward uncertainty and (2) biases an individual's likelihood of perceiving uncertainty (Wever, Smeets, \& Sternheim, 2015) due in part to lagging base rate calculations of statistics in the environment. Therefore, (3) uncertainty may be perceived in situations when those without high IU would not continue to perceive uncertainty. As with all individuals, uncertainty leads to increased affect. In the case of individuals with high IU, this affect arises more frequently, and is more likely to increase negative affect in general and (4) anxiety specifically. Uncertainty increases anxiety, which reciprocally increases perceptions of uncertainty. For individuals with high IU who demonstrate difficulties with cognitive control and emotion regulation, uncertainty also leads to maladaptive cognitive processing. (5) Worry, emotional and cognitive avoidance, and emotional suppression arise in response to uncertainty and contribute to further increases in or maintenance of anxiety. The anxious response to uncertainty coupled with an increase in negative affect through maladaptive cognitive control and emotion regulation leads to symptoms of psychopathology (e.g., emotional reactivity, avoidance, repetitive negative thought) ultimately maintaining or increasing (1) intolerance of uncertainty. 


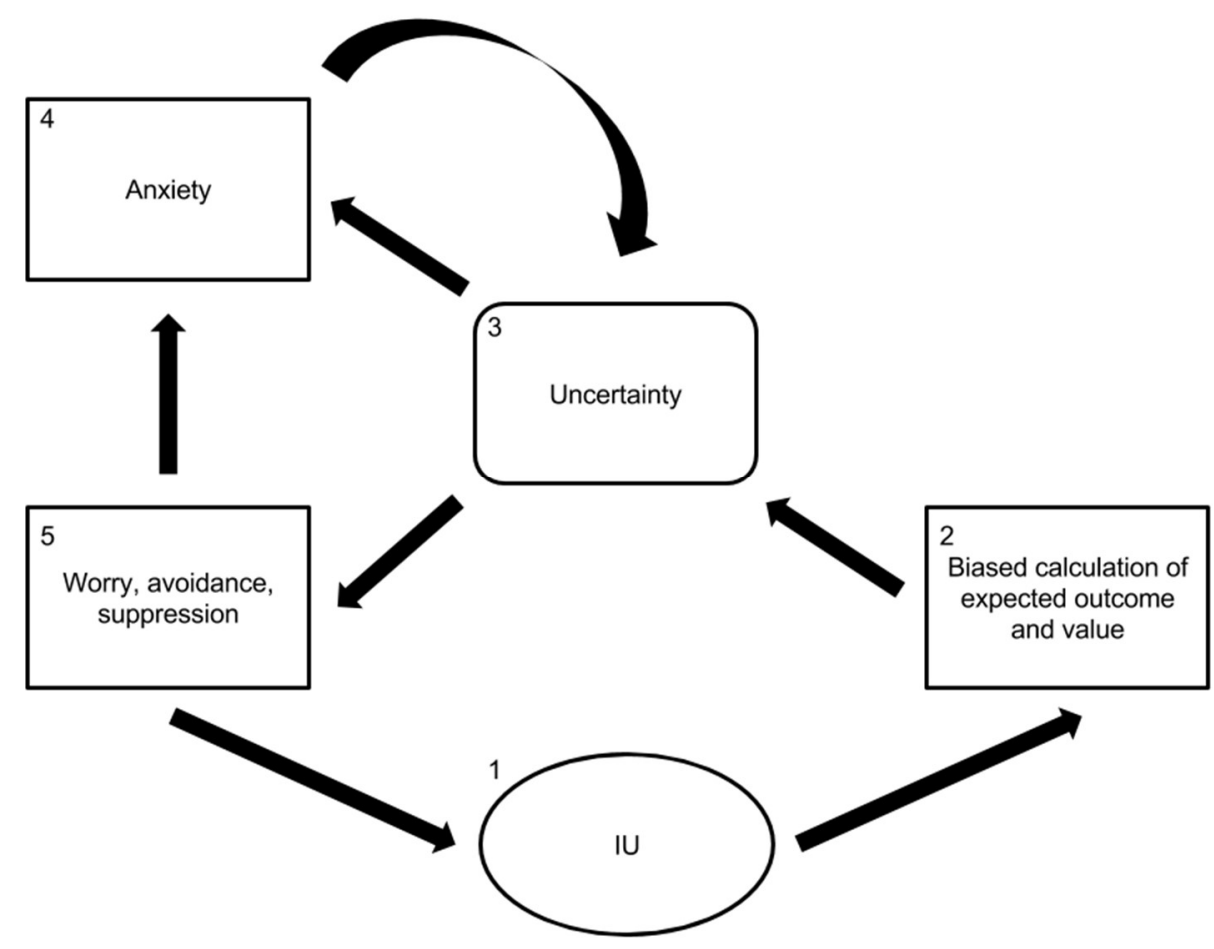

Figure 2. A proposed model of the conditions under which maladaptive uncertainty processing leads to the maintenance of IU.

\section{IU in Children}

Childhood IU is a relatively new field of study facilitated by the creation of the Intolerance of Uncertainty Scale for Children (IUSC; Comer et al., 2009).The IUSC is an adaptation of the IUS with child and parent report versions. Though the IUSC demonstrates acceptable reliability and validity, the measure may be difficult to complete for young children. One study found that significantly fewer six to eight-year-olds were able to complete the IUSC as compared to older children (Cowie, Clementi, \& Alfano, 2016) suggesting that younger children may not be able to adequately reflect on and report their reactions to uncertainty. This again highlights the methodological issue of reliance on questionnaires to examine IU. One group has attempted to address this issue 
by creating a parent report questionnaire aimed at assessing very young children's behavior in uncertain situations (Sanchez et al., 2017).

Child IU characteristics. High IU in childhood is associated with GAD and, to a lesser extent, other anxiety disorders as well (Hearn, Donovan, Spence, \& March, 2017). IUSC scores predict children's self-reported anxiety severity (Read, Comer, \& Kendall, 2013). A recent examination of the specific relation between childhood GAD and IU revealed that children with GAD and another comorbid anxiety disorder had the highest levels of IU as compared to children with pure GAD or another anxiety disorder. This study also found that worry but not GAD predicted increases in IU beyond the effects of overall anxiety (Cowie et al., 2016). This result suggests that IU in childhood may be more related to underlying cognitive and emotional processes, rather than to diagnoses themselves. Through development, IU may eventually relate directly to psychopathology, as is seen in adults with emotional disorders. However, given the association between IU and GAD found in previous studies, further research is required to test this hypothesis.

Studies of child IU in relation to cognitive and emotional processes have primarily focused on extending adult models of IU to child populations. These studies have found that, as in adults, child IU and worry are significantly and uniquely related as compared to similar psychological constructs (Fialko, Bolton, \& Perrin, 2012; Kertz \& Woodruff-Borden, 2013). Though IU seems to be a causal factor in anxiety symptoms among adults, the relation appears bidirectional among adolescents. A five-year longitudinal study of worry and IU among adolescents found that worry mediated IU over time and IU also mediated worry over time. Thus, IU and worry impact each other reciprocally in adolescence. Those who are still developing may learn worry as a 
response to uncertainty, while, reciprocally, worry makes uncertainty less tolerable (Dugas, Laugesen, \& Bukowski, 2012).

Beyond these studies, relatively little is known about children with high IU. Because high IU is associated with increases in anxiety severity we can hypothesize that uncertainty processing among children with greater anxiety may inform our understanding of uncertainty processing among children with greater IU. It is very likely that anxiety and IU, especially in childhood, are separable and arise from related but different pathways. However, given the dearth of research on childhood IU, uncertainty processing among children with high IU and anxious children are both examined here.

Individual differences in uncertainty processing among children. Converging evidence from multiple methodologies suggests that differences in uncertainty processing are associated with IU among children. Functional magnetic resonance imaging (fMRI) results from youth with high and low IU suggest that differences in neural pathways activated during uncertainty tasks are correlated with IU severity (Krain et al., 2008). This study also showed that, among anxious youth who differ in IU severity but not overall anxiety or worry levels, anxious youth with high IU show significantly delayed RTs on uncertain decision-making tasks and greater activity in brain areas associated with uncertainty processing than anxious youth with low IU. RTs on uncertainty tasks are predictive of IU levels but are not sufficiently predictive of anxiety symptoms among children (Brown et al., 2014). It is possible that differences in RTs are related to uncertainty processing differences rather than the interference of anxiety among anxious children. 
Child anxiety disorders and maladaptive uncertainty processing. Children with anxiety disorders experience characteristic emotional, emotion regulation and cognitive differences as compared to non-anxious children. Children with anxiety disorders tend to experience negative emotions more often than peers and are more reactive to these emotions (Tan et al., 2012). They experience difficulty regulating their emotions and are more likely to rely on suppression or avoidance rather than adaptive emotion regulation skills (Folk, Zeman, Poon, \& Dallaire, 2014). Emotion regulation has long been considered a predictor of general childhood psychopathology (Keenan, 2000) and reliance on suppression specifically in response to negative emotions causally contributes to increased anxiety symptoms (Folk et al., 2014). This difficulty with top-down control of emotions reflects difficulty with cognitive control overall for anxious children. Children with anxiety disorders show executive attention dysfunction on par with children diagnosed with Attention Deficit/Hyperactivity Disorder (Mogg et al., 2015). Individual differences in cognitive control early in life are predictive of outcomes in adulthood (Moffitt et al., 2011) and while cognitive control continues to develop into young adulthood, individual differences remain stable (Miyake \& Friedman, 2012). Thus, individual differences in cognitive control among children with high IU predict lifelong differences in cognitive control, and likely impact the development of psychopathology.

Child IU methods of study. IU in childhood is typically examined through use of the IUSC and questionnaire measures of related factors such as anxiety and worry. Child anxiety in these studies is quantified through use of questionnaires, such as the Revised Children's Manifest Anxiety Scale(RCMAS; Reynolds \& Richmond, 1997), or diagnostic interviews, such as the Anxiety Disorders Interview Schedule for DSM-IV, 
child and parent versions(ADIS-IV-C/P; Albano \& Silverman, 1996), while worry is best captured with the Penn State Worry Questionnaire - Child Version (PSWQ-C; Chorpita, Tracey, Brown, Collica, \& Barlow, 1997). Studies have primarily relied on crosssectional data to examine the relation between IU and psychopathology symptoms, and the characteristics of those with high IU (Osmanagaoglu, Creswell, \& Dodd, 2017). One study has examined IU and related factors longitudinally to test the dispositional nature of IU and the causal nature of IU in relation to psychopathology symptoms (Dugas et al., 2012). Only one study has employed an experimental task to examine the behavioral correlates of IU in children. Children in this study completed a decision-making game with varying uncertainty conditions, and were asked to rate their anxiety and subjective certainty following the game. This study also used functional Magnetic Resonance Imaging (fMRI) to identify separable patterns of neural activation related to uncertainty processing that distinguished children with high and low IU (Krain et al., 2008).

Other studies of uncertainty processing in childhood exist, but have not measured IU or examined individual differences in uncertainty processing. These studies typically employ decision-making paradigms that vary based on the following domains. Among decision-making studies that do not include emotional components, a task may be presented that varies based on the number of distractors or the salience of the cue. The task typically also contains a probabilistic component, whereby known and unknown probabilities are varied to measure differences between these conditions. When emotion is integrated into a decision-making study, emotion may be incidental or integral to the task. Incidental emotions are typically induced prior to decision-making, while integral emotions may involve making a decision about the value of threatening or neutral stimuli. 
Across these studies, measured outcomes include: RT and accuracy under varied conditions; neural activation associated with valuation or probabilistic computation; and eye-tracking data indicating how children attend to environments and process information when making decisions.

\section{The Current Study}

Though current studies have provided valuable evidence concerning the characteristics of children with high IU, several limitations are present. Little is known about how IU impacts individuals' behavior under uncertainty, and even less is known about how children with high IU behave under uncertainty. While the link between psychopathology and IU is well established, and interventions targeting IU have shown preliminary success in reducing psychopathology symptoms, it is yet unclear why this relation exists. It is likely that individuals with high IU employ maladaptive behavioral and cognitive processes when faced with uncertainty that contribute to the emergence of psychopathology (Shihata et al., 2016). However, this theory remains untested due to the paucity of research exploring the relations between IU and behavioral and cognitive processes associated with uncertainty resolution and decision-making.

Pre-adolescence appears to be a critical period for developing the ability to distinguish between threat and safety in the presence of ambiguous stimuli (Pine \& Fox, 2015), and learning to demarcate clear threat categories by inhibiting fear responses to ambiguous stimuli (J. Y. Lau et al., 2011). IU likely contributes to differences in uncertainty processing, which increase distress in the presence of uncertainty, and reciprocally maintain IU. Understanding how those with high IU respond to and process uncertainty and ambiguously threatening stimuli in childhood, prior to the maturation of 
cognitive control, may inform our understanding of how IU and broad psychopathology relate, and how clinical interventions can target IU across disorders and among those with comorbidities. The current study aims to begin addressing gaps in our knowledge of the individual differences in behaviors and cognitive processes associated with IU and psychopathology symptoms in childhood. As IU most strongly relates to anxiety

disorders, the proposed study examines IU in children with and without anxiety disorders, and related symptoms, specifically.

\section{Study aims and hypotheses.}

Aim 1. Examine the behavioral and cognitive correlates of high IU in children.

Hypothesis 1. Child IU will predict behavior and attention on a decision-making task, such that higher IU will be associated with slower RTs, more time spent looking at distractors, and more incorrect responses. Child IU will also predict differences in executive function and ER, such that high IU will be associated with weaker attentional and emotional control.

Aim 2. Understand how ambiguous threat affects behavior and cognition for children with high IU, as compared to overtly threatening or neutral conditions.

Hypothesis 2. Children with high IU will exhibit slower RTs, spend more time looking at distractors, and respond incorrectly more often in ambiguous environments as compared to overtly threatening or neutral conditions, while children with low IU will not experience differences by condition.

Aim 3. Test the hypothesized link between IU and anxiety disorder symptoms in childhood. 
Hypothesis $3 a$. Child IU will predict levels or worry and anxiety, such that higher IU corresponds to higher worry and anxiety.

Hypothesis $3 b$. The relation between child IU and psychopathology symptoms will be moderated by attentional and emotional control, such that higher IU will predict weaker attentional and emotional control, which will predict higher worry and anxiety levels. 


\section{METHOD}

\section{Recruitment}

This study was reviewed and approved by the University of Louisville's Internal Review Board (Approval \# 16.0054). Families were recruited from schools and throughout the Louisville community. Digital advertising was distributed through the University of Louisville's email announcement system. Flyers describing the study were distributed to Jefferson County Public Schools (JCPS) personnel to distribute to parents of children within the study's targeted age range. Flyers were also distributed to Catholic school personnel, other private school staff, and members of a local home-school cooperative. School personnel were encouraged to distribute flyers to parents of both anxious and non-anxious children, as the study aimed to recruit a community sample. Flyers were also posted in community locations such as coffee shops, libraries, and pediatrician's offices. Digital versions of study flyers were distributed on Facebook to Louisville parenting groups. Flyers contained information about the study including a brief description and study personnel contact information. To ensure recruitment of both anxious and non-anxious youth, one version of the flyer described the study as an investigation of worry in youth, while another version described the study as an investigation of decision-making and emotions.

The required sample size was calculated a priori using GPower version 3.0.1 (Faul, Erdfelder, Lang, \& Buchner, 2007). Regarding hypotheses 1 and 2, large effect sizes have been identified between measures of IU and decision-making behavioral tasks, 
including response latencies (Thibodeau, Carleton, Gómez-Pérez, \& Asmundson, 2013) and accuracy (Carleton et al., 2016). Medium effect sizes have been identified among children with anxiety disorders on go/no-go tasks measuring response inhibition (Wright, Lipszyc, Dupuis, Thayapararajah, \& Schachar, 2014). Medium effect sizes have also been identified among children with anxiety disorders when comparing attentional bias in threatening and neutral conditions (Dudeney, Sharpe, \& Hunt, 2015). Regarding hypothesis 3 , large effect sizes have been identified in studies predicting worry and anxiety from IUSC scores (Osmanagaoglu et al., 2017). To achieve power of .8, with $\alpha=$ .05 , a sample size of 42 was necessary to detect a medium to large effect size for Hypotheses 1 and 3. To achieve power of .8, with $\alpha=.05$, a sample size of 17 per IU group, for a total of 34 participants, was necessary to detect a medium effect size for Hypothesis 2. Thus, a total of 42 children were required for this study.

\section{Procedure}

Parents of eligible children were invited to schedule an appointment of approximately three hours duration in the study's research lab. Prior to their scheduled appointment, parents were emailed a link to the consent form explaining the study purpose and procedure. Study personnel contacted parents by telephone to explain the consent and answer any questions. Once parents electronically signed the consent they were directed to the study questionnaires and received a second email containing the study assent for their child to sign. After the child signed the study assent they were directed through the study questionnaires. Questionnaires were completed prior to the appointment to lessen the burden of time each family spent in the research lab. Study questionnaires and collected data were managed by REDCap, a HIPAA compliant 
research tool that allows each dyad's data to be linked to a study identification number for confidentiality. Questionnaires not completed at home were completed during the appointment.

When families arrived for their appointment, consents and questionnaires were checked for completeness, and questions about the measures were discussed. Confidentiality was explained to children at a developmentally appropriate level. During the appointment, children and parents individually completed the Anxiety Disorders Interview Schedule for DSM-IV, child and parent versions (ADIS-IV-C/P). These diagnostic interviews were administered by trained study personnel supervised by a licensed clinical psychologist to determine the presence or absence of anxiety and related disorders. Following the interviews, children completed an eye-tracking computer task. Families were compensated for their time with a report regarding the results of the diagnostic interviews, including the child's anxiety status and social and emotional functioning. Treatment referrals and recommendations were provided as appropriate for children meeting diagnostic criteria.

\section{Participants}

Participants were 47 children 7 to 13 years old $(M=9.21, S D=1.88)$ and their parents. Eligibility was limited to children with normal or corrected-to-normal vision and without any known developmental disabilities or delays or AttentionDeficit/Hyperactivity Disorder. Children were 21 boys (45\%) and 26 girls (55\%). The majority of children were European American (89\%) from households with a reported annual income of $\$ 60,000$ or more $(75 \%)$. Twenty-three $(50 \%)$ children met criteria for a primary anxiety disorder diagnosis and 15 of these children met criteria for a secondary 
anxiety disorder diagnosis. Of the primary anxiety disorder diagnoses, generalized anxiety disorder was the most common, $N=10$, followed by social anxiety disorder, $N=$ 6. Girls were significantly more likely to receive an anxiety disorder diagnosis, $X^{2}(1, \mathrm{~N}=$ $45)=5.02, p=.025$.

\section{Measures}

\section{Anxiety measures.}

\section{Anxiety Disorders Interview Schedule for DSM-IV, child and parent versions}

(ADIS-IV-C/P). Child diagnostic status was assessed using the ADIS-IV-C/P (Albano \& Silverman, 1996). The ADIS-IV-C/P assesses a broad range of anxiety, mood, and externalizing disorders in youth (ages 7-17) and screens for the presence of additional disorders including developmental, psychotic, and somatoform disorders. The ADIS-IV$\mathrm{C} / \mathrm{P}$ also assesses age of onset, impairment and avoidance and has been described as the premier instrument for assessing anxiety disorders in youth (Stallings \& March, 1995). Impairment ratings are generated for each diagnosis using the Clinician Severity Rating (CSR, range $=0-8 ; \geq 4$ required to assign a diagnosis). The ADIS-IV-C/P possesses the best psychometric profile for the diagnostic assessment of childhood anxiety disorders of available diagnostic measures (Silverman \& Nelles, 1988; Silverman, Saavedra, \& Pina, 2001) and is sensitive to prevention and treatment effects (Dadds, Atkinson, Turner, Blums, \& Lendich, 1999; Kendall et al., 1997). Diagnoses are derived by the interviewer based on child and parent report. Each ADIS-IV-C/P evaluation was supervised by a licensed clinical psychologist and discrepancies were reconciled during supervision.

Beck Anxiety Inventory-Youth (BAI-Y). The BAI-Y is an adaptation of the Beck Anxiety Inventory (BAI; Beck et al., 2005). The BAI-Y is a 20-item self-report 
scale measuring children's anxious beliefs (e.g., "I am afraid that I might get sick"), cognitions (e.g., "I worry I might go crazy"), and physiological responses (e.g., "My hands shake"). Each item asks the child to respond with whether they experienced the statement "never" "sometimes" "often" or "always" in the past two weeks. The BAI-Y produces a raw score, which is transformed to a T-score using the child's age and gender. BAI-Y T-scores were used for all calculations in this study. The BAI-Y has demonstrated convergent validity with other measures of anxiety in children, such as the RCMAS, as well as high test-retest reliability $(r=0.64-0.88)$. The possible range of T-scores on this measure is 31 to 100 . Higher scores indicate higher levels of anxiety.

Penn State Worry Questionnaire-Child Version (PSWQ-C). The PSWQ-C is an adaptation of the Penn State Worry Questionnaire (PSWQ; Chorpita, Tracey, Brown, Collica, \& Barlow, 1997). The PSWQ-C is a 14-item self-report scale measuring worry (e.g., "My worries really bother me," "Many things make me worry"). Each item asks the child to respond with whether a description is "never true," "sometimes true," "most times true," or "always true." The PSWQ-C has demonstrated convergent validity with other child worry measures, such as the Revised Children's Manifest Anxiety Scale Worry/Oversensitivity subscale, and high test-retest reliability $(r=.92)$. The PSWQ-C also demonstrates discriminant validity for children with and without clinical worry, and between children with GAD and other anxiety disorders. Children with GAD report significantly higher worry $(M=24.09)$ than children with other anxiety disorders $(M=18.89)$ and healthy controls ( $M=12.96$; Pestle, Chorpita, \& Schiffman, 2008). The possible range of scores on this measure is 0 to 42 . Higher scores on this scale indicate higher levels of worry. 
Temperament in Middle Childhood Questionnaire (TMCQ). The TMCQ is a paper-and-pencil parent-report of temperament in children 7-10 years of age. The TMCQ was based on the Children's Behavior Questionnaire (CBQ; Rothbart et al., 2001), a wellestablished caregiver report measure of temperament for children 3-7 years old. The TMCQ contains 16 scales comprised of 157 items and requires 20-25 minutes to complete. Internal consistency for the parent-report ranges from .63 to .90 . The Negative Affect (NA) subscale was calculated according to the methodology by Kotelnikova, Olino, Klein, Mackrell, and Hayden (2017).

\section{Executive function measure.}

Behavior Rating Inventory of Executive Function-Parent Form (BRIEF). The BRIEF is an 86-item questionnaire, consisting of eight subscales (Gioia, Isquith, Guy, \& Kenworthy, 2000). Each item asks the parent to respond with whether a description is "never true," "sometimes true" or "often true" for their child. The eight-item Shift subscale was used to measure attentional control. The Shift subscale measures the extent to which a child can move attention freely and flexibly from one situation or task to another (e.g., "Has a short attention span," "Thinks too much about the same topic"). Children low in Shift may experience more difficulty problem solving and be described as inflexible or rigid. This subscale shows high test-retest reliability in both clinical and normative samples. The possible range of scores on this scale is 8 to 24 and higher scores on this measure indicate greater difficulty shifting attention. The 10-item Emotional Control subscale was used to measure emotional control. The Emotional Control subscale measures how well a child can regulate their own emotional responses to situations (e.g., "Becomes tearful easily," "Angry or tearful outbursts are intense but end suddenly"). 
Children low in emotional control may display more frequent and dramatic mood changes. The possible range of scores on this scale is 10 to 30 , and higher scores indicate more difficulty with emotional control. Though a new version of the BRIEF was recently released, the updates to this measure primarily served to eliminate items that decreased the sensitivity and specificity of identifying youth with attention-deficit/hyperactivity disorder (BRIEF-2; Gioia, Isquith, Guy, \& Kenworthy, 2016). Thus, the original measure was used in the current study.

\section{Intolerance of Uncertainty measures.}

The Intolerance of Uncertainty Scale for Children (IUSC). The IUSC is an adaptation of the Intolerance of Uncertainty Scale (IUS; Comer et al., 2009). The IUSC is a 27-item self-report scale measuring negative emotional, cognitive and behavioral reactions to uncertain situations and events (e.g., "Not knowing what will happen in the future makes life hard, "Surprise events upset me greatly.") Each item asks the child to indicate how well a statement describes them on a scale from one to 5 , where one is "Not at all," three is "Somewhat," and five is "Very much." The IUSC has demonstrated convergent validity with measures of anxiety and worry including the Multidimensional Anxiety Scale for Children (MASC) and the PSWQ-C. The IUSC has also demonstrated acceptable utility in distinguishing youth with anxiety disorders from healthy controls, with a cut score of 50 to 54 correctly classifying $80 \%$ of youth with anxiety disorders (Comer et al., 2009). Youth with GAD tend to report higher levels of IU (M=66.61) than youth with other anxiety disorders ( $M=59.49$; Read et al., 2013). The possible range of scores on this measure 27 to 135 with higher scores indicating higher levels of IU (Comer et al., 2009). 
Modified attention task. A modified version of the Test Battery of Attention Performance — Child Version (KITAP; Zimmermann, Fimm, \& Gondan, 2002) was completed by children in this study. Children completed this task in front of a television screen positioned above a remote eye-tracker (EYE-TRAC 6 Desktop from Applied Science Laboratories) and view a calibration event prior to completing the task. The task, as adapted in Roebers, Schmid, and Roderer (2010), required children to respond (go) or inhibit response (no-go) based on a target stimuli, while ignoring distractor stimuli. The stimuli consisted of an underwater scene in which a submarine (containing the target) was attempting to return to the surface surrounded by sharks and dolphins (distractors). Past eye-tracking studies of attention and anxiety have used images of sharks to elicit emotion among both anxious and non-anxious adults and youth (Finucane \& Power, 2010; Kempe, Rookes, \& Swarbrigg, 2013; Allison M. Waters, Wharton, ZimmerGembeck, \& Craske, 2008). In this version of the KITAP, distractor stimuli were either neutral (two dolphins with happy faces), threatening (two sharks with angry faces) or ambiguous (one happy dolphin and one angry shark). Children were told to help the submarine return to the surface by pressing the space bar with their dominant hand as fast as they could when the porthole turned green, and waiting when the porthole turned red. Each trial began with a fixation period of $800 \mathrm{~ms}$ during which the scenery and submarine appeared, then a distractor period of $400 \mathrm{~ms}$ during which the two distractors were present, then a target period of $800 \mathrm{~ms}$ during which the porthole changed to green or red. Children had a chance to practice with 12 trials (four neutral, four threatening, four distractors) after instructions, then completed three blocks of 12 trials, of which half were "go" and half were "no-go". 
Accuracy and response latencies were recorded, as well as time spent looking at the areas of interest (AOIs; i.e., target, threatening distractor, neutral distractor). Though the original task examined only accuracy and response latencies, recent research suggests that eye tracking indices of attentional bias are more reliable indicators than RT (Gibb, Mcgeary, \& Beevers, 2016). Further, the use of both RTs and eye movement allows for examination of bias in both covert and overt attention (Weierich, Treat, \& Hollingworth, 2008). Dwell duration (i.e., time spent looking within an AOI) was examined as a proportion with the cumulative dwell duration for each AOI divided by the total dwell duration over the course of the task to account for individual differences in total dwell duration not related to the variables of interest (e.g., data lost due to blink, head shift, etc.). This approach to data reduction has been used previously in studies investigating controlled aspects of visual attention among anxious youth (Price et al., 2016; Shechner et al., 2017). 


\section{RESULTS}

\section{Preliminary Examination of Measures}

Eye gaze data did not record for five children total: four due to hardware failure and one due to prescription glasses worn during the study task that created a glare and prevented accurate eye gaze recording. Additionally, two parents did not complete the entire demographic questionnaire. Little's Missing Completely at Random (MCAR; Little, 1988) test was nonsignificant, $p=.40$, indicating that data were MCAR. Missing data were therefore addressed using pairwise deletion (Beaujean, 2012).

\section{Preliminary Analysis}

Descriptive statistics. Means and standard deviations for the current sample are displayed in Table 1. 
Table 1. Sample Characteristics and Independent Samples $T$ Tests Comparing Children with and without Anxiety Disorders on Study Measures

\begin{tabular}{lrrrr}
\hline & Sample Mean (SD) & Anxious (SD) & Non-anxious (SD) & \multicolumn{1}{l}{$T$} \\
\cline { 2 - 5 } IUS-C & $61.43(21.53)$ & $72.02(20.57)$ & $51.16(17.38)$ & $-3.90^{* * *}$ \\
BAI-Y-T & $51.22(10.54)$ & $56.17(7.89)$ & $46.36(10.89)$ & $-3.78^{* * *}$ \\
PSWQ-C & $18.83(9.10)$ & $24.83(5.90)$ & $13.05(7.80)$ & $-6.09^{* * *}$ \\
BRIEF-Shift & $13.77(3.95)$ & $15.72(3.49)$ & $11.72(3.40)$ & $-4.06^{* * *}$ \\
BRIEF-EC & $18.71(5.84)$ & $21.61(5.00)$ & $15.68(5.13)$ & $-4.07^{* * *}$ \\
TMCQ-NA & $2.44(0.55)$ & $2.66(0.38)$ & $2.24(0.61)$ & $-3.83^{* * *}$
\end{tabular}

Note. IUS-C = Intolerance of Uncertainty Questionnaire-Child; BAI-Y-T = Beck Anxiety Inventory for Youth T-score; PSWQ-C = Penn State Worry Questionnaire for Children; BRIEF = Behavior Rating Inventory of Executive Function; EC = Emotional Control; TMCQ-NA = Temperament in Middle Childhood Questionnaire-Negative Affect subscale.

$* * * p<.001$

The IUS-C demonstrated excellent reliability in the current sample (Cronbach's $\alpha$ $=.94)$. Children with anxiety disorders reported IUS-C scores somewhat higher than past investigations of children with any anxiety disorder (i.e., $M=64.97$ ) and comparable to studies of children with multiple comorbid anxiety disorders (i.e., $M=71.69$; Cowie, Clementi, \& Alfano, 2016) while the non-clinical children reported IUS-C scores comparable to non-anxious community youth (i.e., $M=52.81$; Comer et al., 2009). The BAI-Y demonstrated good reliability (Cronbach's $\alpha=.87$ ). Children with anxiety disorders reported BAI-Y T-scores comparable to past studies of children with a principal anxiety diagnosis (i.e., $M=59.00$ ) and non-clinical children reported scores comparable to past samples of non-anxious youth (i.e., $M=48.20$; Beck, Beck, Jolly, \& Steer, 2005). The PSWQ-C demonstrated excellent reliability in the current sample (Cronbach's $\alpha=$ .90). Children with anxiety disorders reported PSWQ-C scores comparable to past studies 
of youth with a diagnosis of generalized anxiety disorder (i.e., $M=24.09$ ) and nonclinical children reported scores comparable to past samples of youth without an anxiety diagnosis (i.e., $M=12.96$; Pestle, Chorpita, \& Schiffman, 2008).

The BRIEF demonstrated excellent reliability (Cronbach's $\alpha=.98)$ overall. The Shift subscale demonstrated good reliability (Cronbach's $\alpha=.84$ ) while the EC subscale demonstrated excellent reliability (Cronbach's $\alpha=.93$ ). No psychometric norms are available for anxious samples, however, the Shift (i.e., $M=11.34-11.99)$ and EC (i.e., $M$ $=14.81-16.39)$ subscale scores in the non-anxious group were comparable to community samples (Gioia et al., 2000). The TMCQ demonstrated excellent reliability (Cronbach's $\alpha$ $=.91$ ). No psychometric norms are available for the TMCQ, however, means in the current sample were comparable to community samples (i.e., $M=2.32-3.66$; Kotelnikova et al., 2017).

Independent samples t-tests indicated that child gender was related to PSWQ-C score such that girls reported significantly more worry than boys, $t(45)=-2.47, p=.017$. Child gender was also related to TMCQ and BRIEF-Shift scores such that girls demonstrated significantly greater negative affect, $t(45)=-2.32, p=.025$, and significantly greater difficulties with attentional control than boys, $t(45)=-2.03, p=.049$. Child gender was related to target dwell duration, $t(40)=-2.34, p=.032$, such that girls were relatively less likely to attend to the target and ignore distractors as compared to boys, and marginally related to $\mathrm{RT}, t(45)=-1.99, p=.053$, such that girls were relatively slower to respond than boys. Child age was not related to any study variables. Child gender was held as a covariate throughout hypothesis testing. 
Negative affect (NA) is considered a higher-order, temperamental trait that predicts IU (Carleton, 2016) and anxiety disorder symptoms (McEvoy \& Mahoney, 2012. Because temperament represents stable individual differences in emotion, cognition, and behavior across environments, NA was explored as a possible control variable. The relation between RT and NA was marginally significant, $r(45)=.28, p=.067$, however, when controlling for gender this relation became nonsignificant $p=.41$. NA did not predict any other task variables (i.e., dwell durations, accuracy) and so it was not used in further analyses.

Model assumptions. Normality of the variables was assessed by inspecting histograms and through use of skewness and kurtosis z-scores. All questionnaire scores (i.e., IUS-C, BAI-Y T, PSWQ-C, BRIEF, TMCQ) were normally distributed. RTs exhibited positive skew, which was appropriately reduced with logarithmic transformations. Dwell durations on distractors also exhibited positive skew, which was appropriately reduced with logarithmic transformations. Target dwell duration exhibited negative skew, which was appropriately reduced with an arcsine transformation. Transformed variables were used for hypothesis testing.

\section{Hypothesis Testing}

Hypothesis 1: IU predicts behavior and attention. Bivariate correlations conducted between IUS-C scores, covariates, and task outcome variables are displayed in Table 2. 
Table 2. Correlation Coefficients Between IUS-C, Task Outcomes, and Covariates

\begin{tabular}{|c|c|c|c|c|c|c|c|}
\hline & \multirow[b]{2}{*}{ IUS-C } & \multicolumn{2}{|c|}{ Behavior } & \multicolumn{3}{|c|}{ Attention } & Covariates \\
\hline & & Accuracy & RT & Target dwell & Threat dwell & Neutral dwell & Age Gender \\
\hline IUS-C & & & & & & & \\
\hline Accuracy & -.22 & & & & & & \\
\hline RT & $.36^{*}$ & .02 & & & & & \\
\hline Target dwell & $-.34^{*}$ & .03 & .08 & & & & \\
\hline Threat dwell & $.32 *$ & -.06 & .04 & $-.84 * *$ & & & \\
\hline Neutral dwell & .29 & -.09 & -.17 & $-.85^{* *}$ & $.58 * *$ & & \\
\hline Age & -.04 & .24 & -.25 & -.12 & .07 & .10 & \\
\hline Gender & .20 & .31 & $.31^{*}$ & .15 & -.17 & -.10 & -.16 \\
\hline
\end{tabular}

Note. IUS-C $=$ Intolerance of uncertainty questionnaire - child; RT = Overall average RT $* p<.05, * * p<.01$ 
IUS-C was related to average overall $\mathrm{RT}, r(47)=.36, p=.012$, target dwell duration, $r(42)=-.34, p=.015$, and threat dwell duration, $r(42)=.32, p=.043$.

Hierarchical linear regressions were conducted to explore these relations controlling for gender. IUS-C explained a significant proportion of variance in $\mathrm{RT}, R^{2}=.17, F(2,44)=$ $4.24, \beta=.32, p=.028$. IUS-C significantly predicted target dwell duration, $R^{2}=.097$, $F(2,39)=3.74, \beta=-.41, p=.011$, and threat dwell duration, $R^{2}=.10, F(2,39)=4.38, \beta$ $=.35, p=.029$.

Bivariate correlations conducted between IUS-C scores, BRIEF subscales, and covariates are displayed in Table 3.

Table 3. Correlation Coefficients between Study Measures and Covariates

\begin{tabular}{|c|c|c|c|c|c|c|c|}
\hline & \multirow[b]{2}{*}{ IUS-C } & \multicolumn{2}{|c|}{ Anxiety symptoms } & \multicolumn{2}{|c|}{ BRIEF } & \multicolumn{2}{|c|}{ Covariates } \\
\hline & & BAI-Y-T & PSWQ-C & Shift & $\mathrm{EC}$ & Age & Gender \\
\hline IUS-C & & & & & & & \\
\hline BAI-Y-T & $.71 * *$ & & & & & & \\
\hline PSWQ-C & $.66 * *$ & $.66 * *$ & & & & & \\
\hline Shift & $.44 * *$ & $.63^{* *}$ & $.44^{* *}$ & & & & \\
\hline $\mathrm{EC}$ & $.49 * *$ & $.59 * *$ & $.39 * *$ & $.76^{* *}$ & & & \\
\hline Age & -.04 & .02 & .05 & -.13 & -.10 & & \\
\hline Gender & .20 & .24 & $.02 *$ & $-.31 *$ & -.23 & -.16 & \\
\hline
\end{tabular}


IUS-C was related to Shift, $r(47)=.44, p=.003$, and EC, $r(47)=.49, p=.001$. Hierarchical linear regressions indicated that, when controlling for gender differences, IUS-C significantly predicted Shift, $R^{2}=.24, F(2,44)=6.71, \beta=.40, p=.005$, and EC, $R^{2}=.24, F(2,44)=13.29, \beta=.49, p=.001$.

\section{Hypothesis 2: High IU is associated with differences in attention and}

behavior under ambiguously threatening conditions. To test differences in attention and behavior by condition (i.e., threat, neutral, or ambiguous) for children with high and low IU, a mean split of IUS-C scores was used to create two groups. 23 children with an IUS-C score of 57 or below were coded as low IU and 24 children with an IUS-C score of 58 or above were coded as high IU. Children in these groups did not differ by age, $t(45)=0.47, p=.64$, or gender, $X^{2}(1, \mathrm{~N}=47)=1.02, p=.31$. A repeated measures mixed ANCOVA predicting RT from condition was not significant for the high, $F(2,68)$ $=0.21, p=.81$, or low IU groups, $F(2,65)=0.078, p=.93$. A repeated measures mixed ANCOVA predicting target dwell duration by condition yielded a main effect of condition in the high, $F(2,62)=4.17, p=.022$, but not low IU group, $F(2,56)=0.50, p$ $=.61$. Children in the high IU group were significantly more likely to attend to distractors during the ambiguous condition as compared to the neutral condition, $p=.026$. The difference between dwell duration in the ambiguous as compared to threat condition approached but did not reach statistical significance, $p=.080$. Estimated marginal means are presented in Figure 3. 


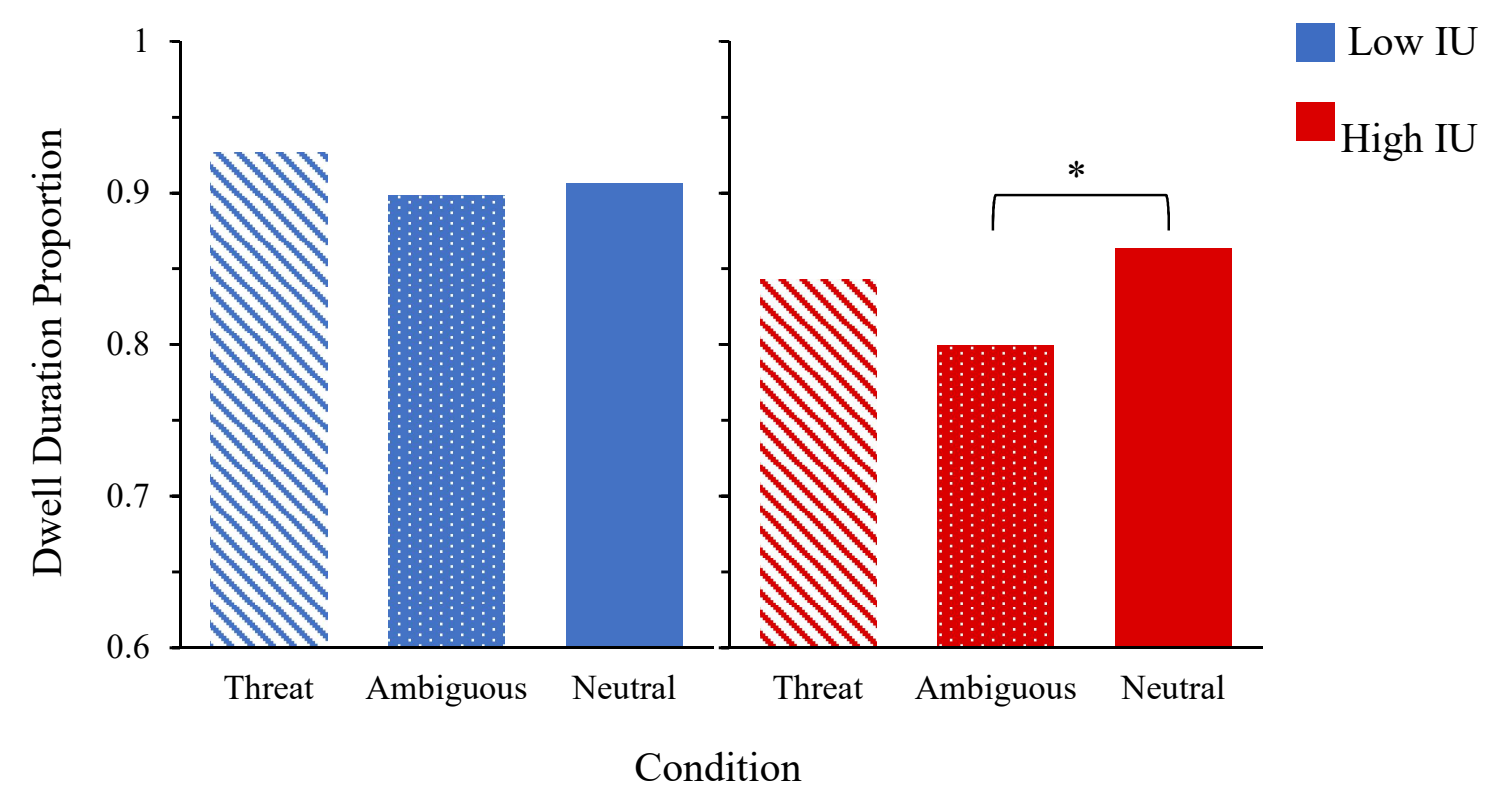

Figure 3. Graphical representation of dwell duration proportion predicted by condition for high and low IU groups.

Note. ${ }^{*} p<.05$

Hypothesis 3: IU predicts anxiety symptoms, moderated by attentional and emotional control. Bivariate correlations conducted between IUS-C scores, anxiety symptom scores, BRIEF subscales, and covariates are displayed in Table 3. IUS-C was related to BAI-Y T-score, $r(47)=.71, p<.001$, and PSWQ-C score, $r(47)=.66, p<$ .001. Hierarchical linear regressions indicated that IUS-C significantly predicted BAI-Y explained a significant proportion of variance in BAI-Y, $R^{2}=.51, F(1,45)=46.00, p<$ .001. When controlling for gender differences, IUS-C significantly predicted PSWQ-C, $\beta$ $=.65, p<.001$, and explained a significant proportion of variance in PSWQ-C, $R^{2}=.43$, $F(2,44)=16.70, p<.001$.

Moderational models were tested predicting anxiety symptoms from IUS-C with BRIEF subscales as moderators, with gender as a covariate. Shift, $\Delta R^{2}=.0023, F(1,42)$ 
$=0.19, p=.67$, and EC, $\Delta R^{2}=.028, F(1,42)=2.41, p=.13$, failed to moderate the relation between IUS-C and BAI-Y T-score. Shift, $\Delta R^{2}=.0036, F(1,42)=0.41, p=.52$, and $\mathrm{EC}, \Delta R^{2}=.0002, F(1,42)=0.016, p=.90$, also failed to moderate the relation between IUS-C and PSWQ-C.

\section{Exploratory Analyses}

Anxiety disorder symptoms. Given the significant relation between IUS-C and anxiety symptoms found in the current sample and in past studies (Osmanagaoglu et al., 2017), the relation between task outcome variables and anxiety symptoms was explored. Bivariate correlations conducted between BAI-Y T-scores, PSWQ-C scores, covariates, and task outcome variables are displayed in Table 4. 
Table 4. Correlation Coefficients between Anxiety Symptom Measures, Task Outcomes, and Covariates

\begin{tabular}{|c|c|c|c|c|c|c|c|c|}
\hline & \multicolumn{2}{|c|}{ Anxiety symptoms } & \multicolumn{2}{|c|}{ Behavior } & \multicolumn{3}{|c|}{ Attention } & Covariates \\
\hline & BAI-Y-T & PSWQ-C & Accuracy & RT & $\begin{array}{l}\text { Target } \\
\text { dwell }\end{array}$ & $\begin{array}{l}\text { Threat } \\
\text { dwell }\end{array}$ & $\begin{array}{l}\text { Neutral } \\
\text { dwell }\end{array}$ & Age Gender \\
\hline BAI-Y-T & & & & & & & & \\
\hline PSWQ-C & $.66 * *$ & & & & & & & \\
\hline Accuracy & -.03 & .08 & & & & & & \\
\hline RT & .20 & $.44 * *$ & .02 & & & & & \\
\hline Target dwell & -.23 & -.27 & .03 & .08 & & & & \\
\hline Threat dwell & .03 & .29 & -.06 & .04 & $-.84 * *$ & & & \\
\hline Neutral dwell & .26 & .22 & -.09 & -.17 & $-.85 * *$ & $.58 * *$ & & \\
\hline Age & -.02 & .05 & .24 & -.25 & -.12 & .07 & .10 & \\
\hline Gender & .24 & $.35^{*}$ & .31 & $.31 *$ & .15 & -.17 & -.10 & -.16 \\
\hline
\end{tabular}


PSWQ-C was related to average overall RT, $r(47)=.44, p=.002$. BAI-Y was not related to any task outcome variables. A hierarchical linear regression indicated that, when controlling for gender differences, PSWQ-C significantly predicted $\mathrm{RT}, R^{2}=.22$, $F(2,44)=6.14, \beta=.38, p=.011$.

A 2 (diagnostic group) x 3 (condition) repeated measures mixed ANCOVA yielded a main effect of diagnostic group, $F(1,141)=12.97, p<.001$, but not condition, $F(2,141)=0.12, p=.89$, on RT. The anxious group demonstrated significantly slower RTs across conditions as compared to the non-anxious group, $p<.001$. A 2 (diagnostic group) x 3 (condition) repeated measures mixed ANCOVA did not indicate a main effect for diagnostic group, $F(1,126)=0.21, p=.65$, or condition, $F(2,126)=1.10, p=.34$, on target dwell duration.

Correlations between IUS-C and task outcome variables were also investigated in the anxious and non-anxious groups separately. Pearson's $r$ values are displayed in Table 5.

Table 5. Correlations Coefficients between IUS-C and Task Outcomes by Group

\begin{tabular}{lll}
\hline & \multicolumn{2}{c}{ IUS-C } \\
\cline { 2 - 3 } Target dwell & Anxious & Non-anxious \\
\cline { 2 - 3 } Threat dwell & .17 & $-.52^{*}$ \\
Neutral dwell & .04 & .30 \\
Reaction time & .35 & $.44^{*}$ \\
\hline Note. ${ }^{*} p<.05$ & & -.02 \\
\hline
\end{tabular}


In the non-anxious group only IUS-C predicted target dwell duration, $r(22)=-.52$, $p=.017$, and dwell duration on neutral distractors, $r(22)=.44, p=.017$. No task variables were related to IUS-C in the anxious group.

Reaction time variability. Previous research has indicated that greater RT variability is associated with less effective cognitive control (Ode, Robinson, \& Hanson, 2011), including lapses in on-task attention (Vaurio, Simmonds, \& Mostofsky, 2009), and less efficient information processing (Karalunas \& Huang-Pollock, 2013). Because higher IUS-C score predicted increased distraction during the task, the relation between IUS-C score and RT variability was explored. Ex-Gaussian models were fit to each child's RT distribution using the 'retimes' package in R statistical software (Massidda, 2013). Tau $(\tau)$, a measure of variability due to increases in the distribution tail, was examined (Whelan, 2008). Increases in $\tau$ indicate longer infrequent RTs rather than overall slowed processing speed (Balota \& Yap, 2011). IUS-C score significantly predicted $\tau, R^{2}=.09, F(1,45)=4.68, p=.036, \beta=.31$. RT distributions for high and low IU groups are displayed in Figure 4. 


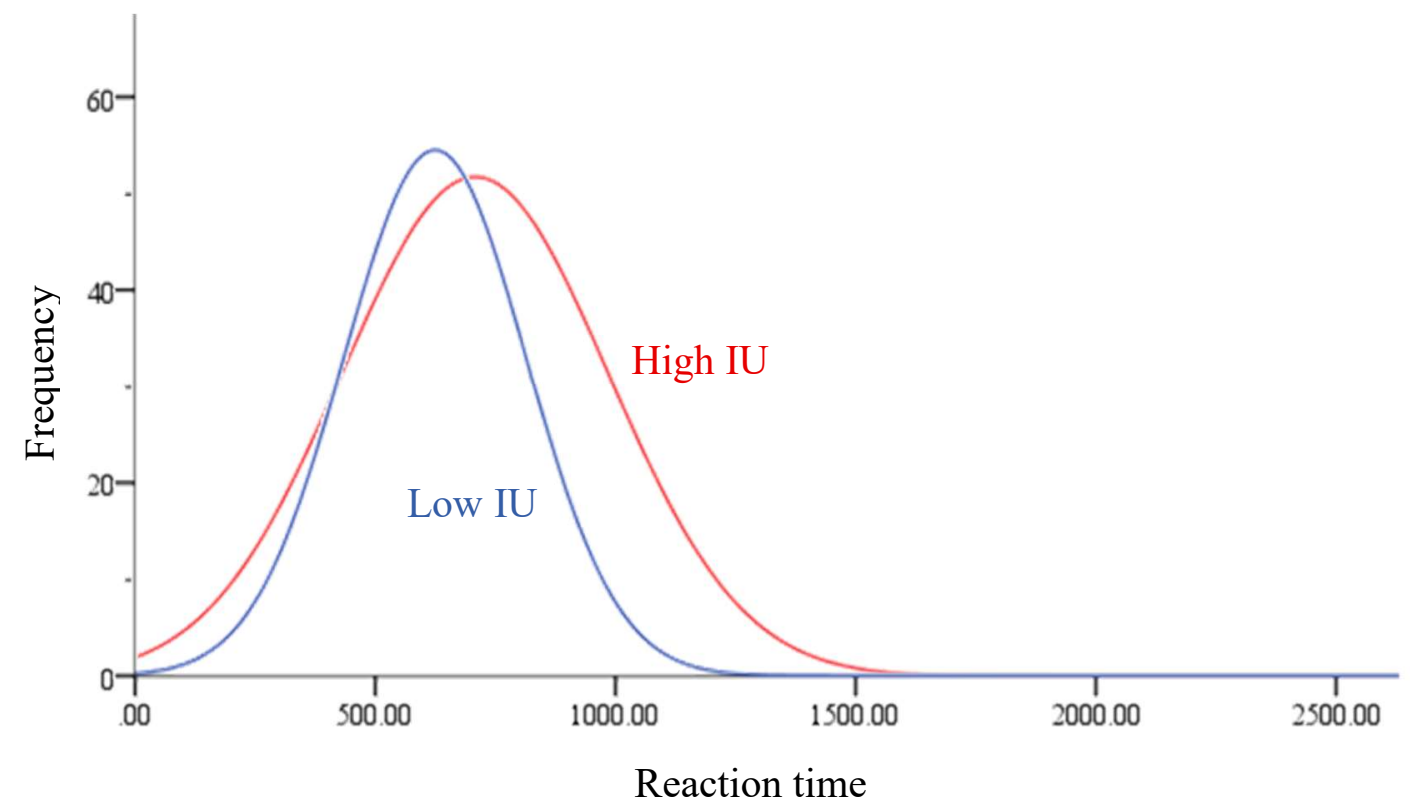

Figure 4. Reaction time distributions by IU group.

Fixation duration skewness. Skewness of fixation duration distributions is related to individual differences in task processing, where greater positive skewness indicates decreased cognitive control ability (Henderson, Choi, Luke, \& Schmidt, 2018) and less effortful cognitive processing of a scene (Luke \& Henderson, 2016), and lesser positive skewness indicates goal-oriented scene viewing (Hartwig, Schnitzspahn, Kliegel, Velichkovsky, \& Helmert, 2013). Because IUS-C and anxiety symptoms in the current sample were related to cognitive control measures, IUS-C and anxiety symptoms were examined in relation to the skewness value of each participant's fixation duration distribution. To control for multiple comparisons, a Bonferroni corrected alpha value of .017 (critical $\alpha$ level $=.05 / 3=.017)$ was used. PSWQ-C significantly predicted skew, $R^{2}=.16, F(1,40)=7.02, p=.012, \beta=.40$, such that higher PSWQ-C score predicted an increase in the number of short fixations, but IUS-C, $p=.53$, and BAI-Y, $p=.64$, did not. Fixation duration distributions for high and low worry groups are displayed in Figure 5. 


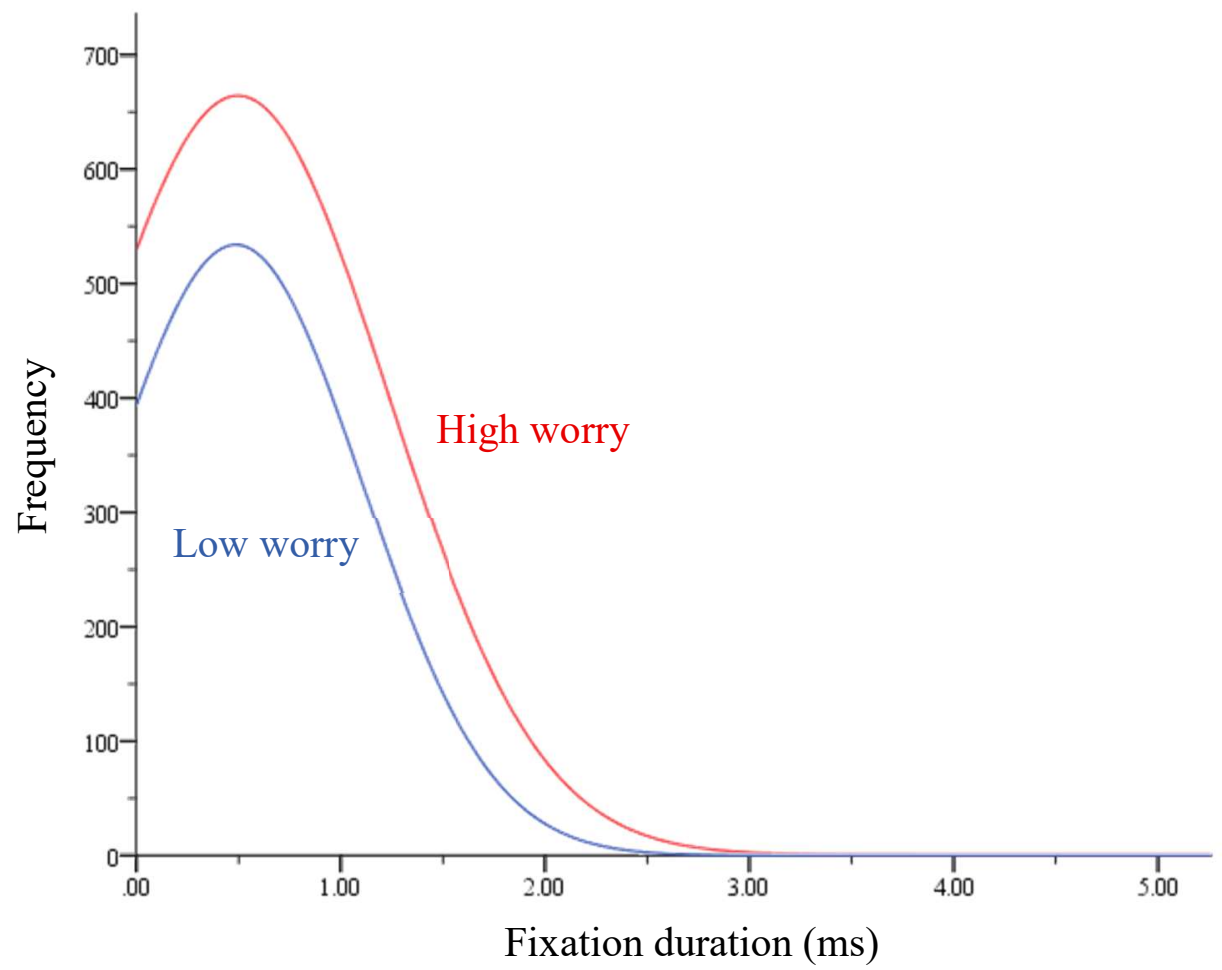

Figure 5. Fixation duration distribution for high and low worry groups.

IU and attention over time. To further explore information processing differences, dwell duration was separated into two time bins representing the first and second half of the task. Dwell duration proportion on target was calculated for each condition (i.e., ambiguous, threat, and neutral). A 2 (IU group) x 2 (time) repeated measures mixed ANCOVA predicting dwell duration proportion for ambiguous conditions yielded a significant interaction between IU group and time, $F(1,84)=4.053$, $p=.047$. Pairwise comparisons revealed that this interaction was driven by a significant difference in dwell during the first half of the task. The high IU group spent significantly more time attending to distractors in ambiguous conditions during the first half of the task as compared to the low IU group, $F(1,84)=16.61, p<.001$. The IU groups did not significantly differ in the second half of the task, $p=.074$. No significant main or interaction effects were identified when predicting dwell duration proportion during 
neutral or threat conditions, $p \mathrm{~s}>.084$. Estimated marginal means for dwell duration proportion in ambiguous conditions are presented in Figure 6.

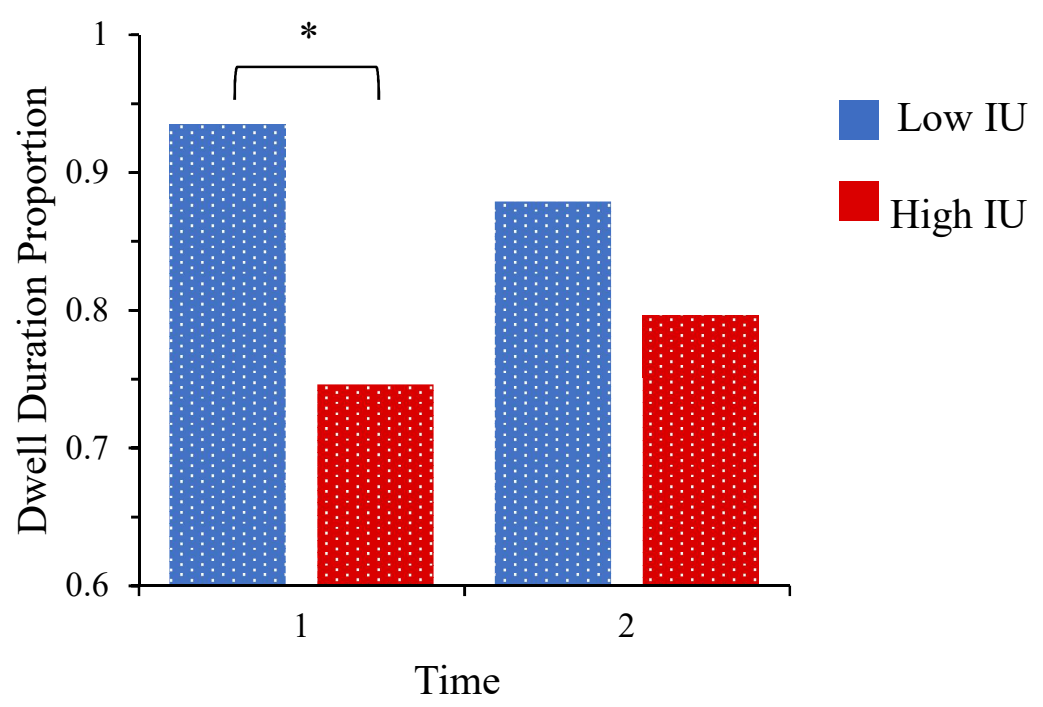

Figure 6. Graphical representation of dwell duration proportion in ambiguous conditions predicted by IU group by time.

Note. ${ }^{*} p<.05$ 


\section{DISCUSSION}

The current study examined the relation between IU and behavioral and cognitive aspects of decision-making among children with and without anxiety disorders. IU is a transdiagnostic, trait-like risk factor for the development of psychopathology and interventions that target IU have shown promise in effectively reducing disorder symptoms among those with emotional disorders and comorbid conditions. While it is well established that IU predicts a range of disorder symptoms, it is unclear what mechanisms drive this relation. This is likely due, in part, to the paucity of research examining correlates of IU at behavioral and physiological levels of analysis. Even fewer studies examining these aspects of IU in childhood exist, limiting our knowledge of the impact of IU on the development of cognitive and emotional processing differences that underlie emotional disorders (e.g., weaker attentional control, emotional dysregulation, etc.).

The aim of the current study was to begin addressing these gaps by examining how children with higher IU resolve uncertainty. The study hypothesized that IU is associated with individual differences in decision-making that may contribute to the development of psychopathology. Specifically, it was hypothesized that children with higher IU would exhibit increased evaluation of available information, delays in decisionmaking, and reduced accuracy, and that these differences would be greater in the presence of ambiguous information. It was also expected that IU would predict greater deficits in the aspects of higher-order cognitive control that support decision-making 
under uncertainty, namely emotional and attentional control, and these differences would moderate the relation between IU and disorder symptoms.

\section{Preliminary Analyses}

Preliminary analyses revealed that the current sample exhibited somewhat higher rates of GAD than expected within the anxiety disorder group. Previous epidemiological studies indicate that specific phobias, separation anxiety, and social anxiety are the most prevalent anxiety disorders diagnosed prior to age 14 (Merikangas et al., 2011), however, others indicate that GAD may be the most prevalent childhood anxiety disorder, followed by separation and panic disorders (Copeland, Angold, Shanahan, \& Costello, 2014). Increased prevalence of GAD in the current sample is likely due to recruitment procedures. Recruitment for the present study focused on identifying children with chronic and impairing worry, rather than anxiety broadly, as the present study was interested in recruiting children with a range of IU levels and IU exhibits a particularly strong association with worry, as compared to physiological or behavioral symptoms of anxiety (Donovan, Holmes, Farrell, \& Hearn, 2017). Some evidence exists for the separation of child anxiety disorders into distress (i.e., GAD) and fear (i.e., specific phobias, separation anxiety disorder, and social anxiety disorder) disorders based on findings that children with distress disorders exhibit hypervigilance towards threat, while children with fear disorders show attentional avoidance of threat (A. M. Waters, Bradley, \& Mogg, 2014). This is also consistent with the finding of increased attention to threatening distractors in the current study's sample. Results of the current study may be limited in their generalizability to fear disorders based on the sample characteristics. 
Preliminary analyses also revealed several gender differences in the current sample. Girls were more likely to meet criteria for an anxiety disorder. This is consistent with past examinations of gender differences among childhood anxiety disorders (Broeren, Muris, Diamantopoulou, \& Baker, 2013; Crocetti, Klimstra, Keijsers, Hale, \& Meeus, 2009). It is unclear why gender differences in childhood anxiety disorder prevalence exist, though it has been theorized that emotion socialization and other relevant parenting factors play a role (Zahn-Waxler, Shirtcliff, \& Marceau, 2008). Of note, gender differences have not been identified for the age of onset or chronicity of anxiety disorders in past studies (Mclean, Asnaani, Litz, \& G, 2011). Girls in the current sample also exhibited significantly higher levels of negative affect. Previous studies have not identified gender differences in negative affect (Hirshfeld-Becker et al., 2008), but it has been suggested that girls and boys with high negative affect may experience differential emotion socialization parenting practices that contribute to differences in the development of anxiety disorder symptoms (Brumariu \& Kerns, 2015). Girls in the current sample also exhibited significantly greater difficulties with attentional control. Small gender differences in attentional control have been identified in the opposite direction in previous studies, with boys having relatively greater attentional control difficulties than girls (Huizinga \& Smidts, 2011).

Gender differences in negative affect and attentional control in the current study are likely due to the gender differences in anxiety disorder rates. Gender was held as a covariate throughout hypothesis testing to account for these differences. Given the possible differences in parenting that interact with gender to predict disorder symptoms, it is possible that parenting interacts with gender in the relation between IU and disorder 
symptoms as well. That is, emotional socialization of girls with high IU may impact the pathway between uncertainty processing and the development of an anxiety disorder differently than the emotional socialization of boys with high IU. Examining parenting and gender in future studies of childhood IU may further explain the relation between this risk factor and disorder symptoms.

Age was not associated with any study variables, as expected, given the narrow age range used in this study. While inhibitory control and cognitive flexibility improve throughout childhood (Diamond, 2014) and, specifically, BRIEF Shift and Emotional Control scores decrease significantly, this tends to occur over a broader age range (i.e., from ages 5 to 14; Huizinga \& Smidts, 2011). The nonsignificant relation found here may indicate that a relatively restricted age range was used. Most participants in the current sample fell between the ages of 8 and 12. Identifying significant changes in emotional and attentional control may require the use of a broader age range. It is also possible that the impact of age on the executive function domains investigated here have small effect sizes that could not be detected by the current study's sample size.

\section{Hypothesis Testing}

Behavior and IU during decision-making. Behavior in the present study was operationalized as RT and accuracy on Go trials during the study task. With regard to behavior, the current study hypothesized that higher IU would be related to slower RTs and reduced accuracy. This hypothesis was partially supported. Increases in IU significantly predicted increases in RTs but not reductions in accuracy. The nonsignificant relation between accuracy and IU was likely due to the restricted range of errors on the study task. Of the 47 children who completed the task, 36 did not make any 
errors and the greatest number of errors made was 3 (i.e., $92 \%$ correct responses). This was likely due to the relatively slow pace of the study task. Previous studies examining accuracy and anxiety symptoms in children have reported similar issues and ultimately omitted accuracy from study analyses (Brown et al., 2014). Thus, accuracy was omitted from further analysis in the current study.

Past studies indicate that the presence of uncertainty engages bottom-up emotional arousal and top-down cognitive control to facilitate decision-making. Increases in uncertainty during experimental decision-making paradigms are associated with slowed RTs across individuals, as uncertainty signals the need for controlled cognitive processing rather than automatic responding (Fan et al., 2014). The degree to which an individual adapts to increases in uncertainty and resumes efficient responding (i.e., decreased RT) following changes in uncertainty depends, in part, on the individual's physiological responsiveness to environmental cues (de Berker et al., 2016). Physiological responses that accurately track uncertainty facilitate effective learning processes, which allow for reductions in future uncertainty (FeldmanHall et al., 2016). Individual differences in emotional and cognitive control responsiveness to uncertainty may predict individual differences in decision-making under uncertainty, including behavioral aspects of decision-making, such as RT. One study found that the relation between inhibitory control and RT during a decision-making task was attenuated by cue ambiguity, such that weaker inhibitory control predicted slower RTs only when decision-making cues were ambiguous (Kalanthroff, Linkovski, Henik, Wheaton, \& Anholt, 2016). Another study found that increases in uncertainty predicted increases in cognitive control, and, among youth specifically, IU predicted the magnitude of these 
increases. Youth with higher IU demonstrated increasing reactivity, rather than adaptive responsiveness, as uncertainty increased (Krain et al., 2006). Further, increases in IU are associated with diminished sensitivity of learning rates to outcome volatility during decision-making (Browning, Behrens, Jocham, O’Reilly, \& Bishop, 2015). In the present study, higher IU may predict slowed RT because children with higher IU are more emotionally reactive to uncertainty and less able to engage cognitive control processes that are responsive to task demands during decision-making, contributing to difficulty creating efficient response strategies during the task.

The current study also hypothesized that children with higher IU would exhibit behavioral differences under different threat conditions. Specifically, it was hypothesized that children with high IU would demonstrate significantly slower RTs for ambiguously threatening, as compared to neutral and overtly threatening, conditions. This hypothesis was not supported; children with high IU did not demonstrate differences in RT by condition. While increased uncertainty slows RTs, past studies indicate that this phenomenon is present regardless of the threat valence of uncertain cues (Speed, Jackson, Nelson, Infantolino, \& Hajcak, 2017). In the present study, individual differences in RT may not have been affected by uncertainty arising from the threat valence of cues (i.e., the presence of threatening and neutral distractors), but from the uncertain probability of seeing a Go cue (i.e., 50\%), which remained stable throughout the task.

To further explore the relation between IU and behavior, RT variability was examined. Given the hypothesized relation between IU and attention, and the relation between attention and RT variability in past studies (e.g., Antonini, Narad, Landberg, \& Epstein, 2013), the current study hypothesized that a significant positive relation would 
exist between IU and RT variability. The data supported this hypothesis. Higher IU predicted greater $\tau$, indicating that the slower average RTs identified among children with higher IU are due in part to increases in the RTs of the slowest, least frequent responses. No studies have examined IU and RT variability, however, past studies indicate that increases in $\tau$ are related to differences in attentional and emotional control (Sjöwall, Roth, Lindqvist, \& Thorell, 2013). $\tau$ is highly related to on-task behavior and successful on-task attention among typically developing children (Antonini et al., 2013). The speed of stimuli presented during a task also moderates the relation between $\tau$ and on-task behavior, such that $\tau$ is a better indicator of inattention when stimuli are presented at a relatively slower speed (Antonini et al., 2013), such as in the present study. Among adults, RT variability, corrected for overall average RT speed, is associated with less effective cognitive control and increases in negative emotion in daily life. Further, those with higher RT variability report experiencing more adverse effects related to attentional lapses in daily life (Ode et al., 2011). In the present study, the relation between IU and RT may be driven by RT variability rather than overall slowed processing speed. Children with higher IU may experience difficulty sustaining top-down goal directed attention through the duration of the task, leading to periodic attentional lapses that yield a small number of significantly slower responses, which ultimately increase their overall average RT.

\section{Behavior and anxiety symptoms during decision-making. Exploratory}

analyses indicated that worry and anxiety symptoms exhibited a similar relation to RT as that identified between RT and IU. Worry and anxiety symptoms predicted slower RTs, and children with anxiety disorders did not demonstrate differences in RT by condition. 
Current literature regarding anxiety and RT remains extremely mixed, though some studies suggest that slowed RTs only arise among anxious individuals in the presence of threatening distractors, as the presence of threat increases anxiety, which interferes with cognitive control (Van Bockstaele et al., 2014). As mentioned previously, studies of anxious children have yielded weak effect sizes when predicting RT from anxiety symptoms (Brown et al., 2014). One study found that attentional control and RT during a go/no-go task was associated with intolerance of distress independent of actual distress symptoms (i.e., anxiety and depressive symptoms; Macatee et al., 2018). Past studies have also not identified a relation between RT variability and anxiety (Antonini et al., 2013; Krain et al., 2008; Mogg et al., 2015).

Because past literature does not indicate that anxiety impacts RT, individual differences in RT in the present study may be primarily due to IU rather than anxiety. Further, past literature indicates that if differences in RT were driven by anxiety symptoms, RTs would be slowed in the presence of threatening distractors. Anxious children in the present study did not exhibit RT differences based on threat condition.

Attention and IU during decision-making. Attention in the present study was operationalized as the proportion of time spent looking at areas of interest during the task (i.e., dwell duration). With regard to attention, the current study hypothesized that higher IU would be related to greater distraction during the task. This hypothesis was supported; increases in IU predicted decreases in attention to the target and increases in attention to threatening distractors. In the non-anxious group specifically, increases in IU predicted increases in attention to neutral distractors. 
The current study also hypothesized that children with higher IU would exhibit attentional differences under different threat conditions; specifically, that children with high IU would demonstrate significantly greater distraction from the target during ambiguously threatening, as compared to neutral and overtly threatening, conditions. This hypothesis was supported, with children in the high IU group demonstrating significantly less attention to the target under ambiguous conditions as compared to neutral conditions. Attention to the target during ambiguous compared to threatening conditions trended toward, but did not reach, significance among children with high IU, and no significant differences were identified between attention to the target in threatening compared to neutral conditions for children with high IU.

The relation between attention and threat condition was also examined over time. It was hypothesized that children with high IU would be more distracted from the target during the first half of the task as compared to children with low IU. This hypothesis was supported for ambiguous conditions only. During ambiguously threatening trials, children with high IU were more distracted than children with low IU in the first half of the task, but not the second half of the task. There was no effect of time on attention between high and low IU groups for threatening or neutral conditions.

The learned predictiveness and learned value of information modulates both controlled and automatic visual attention (Le Pelley, Mitchell, Beesley, George, \& Wills, 2016). Healthy individuals suppress attention to areas of visual scenes known to have a high likelihood of containing distractors during decision-making so that the target can be identified and attended to efficiently (Wang \& Theeuwes, 2018a). Attentional suppression of distractors occurs when the decision-maker accurately tracks the 
probabilities of distractors appearing across the visual scene and uses this statistical map to identify locations most likely to contain distractors (Wang \& Theeuwes, 2018b). Faster RTs are associated with this type of distractor identification, while slower RTs are associated with top-down identification of distractors based on representations stored in working memory (Gaspar \& McDonald, 2014).

Evidence of slower RTs and greater distraction together in the current study may indicate that children with high IU are more reliant on stored representations of distractors to identify and suppress attention to these stimuli. Because IU is associated with difficulties learning the causal statistics of an environment, children with high IU in the current study may have been less able to rely on probability based attentional suppression and therefore more reliant on stored knowledge of visual cues. Increased attention toward a stimulus is associated with increased fixation and dwell duration on the stimulus (Orquin \& Mueller Loose, 2013). Visual stimuli matching stimuli stored in visual working memory automatically capture attention, however, this effect can be overcome by top-down attentional control (Kiss, Grubert, Petersen, \& Eimer, 2012; Sawaki \& Luck, 2011). Thus, increased dwell duration on distractors in the current study may indicate reliance on working memory representations of distractors coupled with weak attentional control.

Healthy individuals update prior representations of visual scenes with current information during repeated decision-making to accumulate knowledge and continually hone response strategies over time (Behrens et al., 2007). Stimuli salience directs early visual attention (Egeth, Leonard, \& Leber, 2011), and motivationally salient stimuli (i.e., stimuli that signal reward or punishment) capture early visual attention even when the 
stimuli are not physically salient or task-relevant (Le Pelley, Pearson, Griffiths, \& Beesley, 2015; Nissens, Failing, \& Theeuwes, 2017). As a task progresses, attentional selectivity, through cognitive control and accumulated knowledge of the scene, allows for a reduction in vulnerability to distraction (Theeuwes, 2010).

Children with higher IU may be particularly distracted by ambiguous information because it is more salient to them. Individuals with higher IU experience errors as more aversive, and, accordingly, more motivationally salient (Jackson, Nelson, \& Hajcak, 2016). Ambiguous information may be particularly salient to children with higher IU during early task trials because it serves as a cue for potential errors, and this motivational salience may interfere with information processing based on the task demands. Specifically, it may interfere with the process of identifying distractors as such. Children with higher IU may take longer to create representations of ambiguous environments because they have difficulty learning the value of information (i.e., whether a stimulus is integral or irrelevant to the task goal) so that distractors can be identified, and have more difficulty learning the statistical regularities of ambiguous environments so that attention to the identified distractors can be suppressed.

\section{Attention and anxiety symptoms during decision-making. Exploratory}

analyses indicated that anxiety and worry were not related to greater distraction in the current sample. This is consistent with current literature concerning anxiety and attention among youth. Past studies have identified a robust attentional bias toward threat among children with anxiety disorders (Puliafico \& Kendall, 2006). However, this bias is only identified during early attentional orienting (e.g., time to initial fixation) and has not been 
identified during sustained attentional processes (e.g., dwell duration; Shechner et al., 2013).

Exploratory analyses also indicated that worry, but not IU or anxiety, was related to fixation duration skewness, such that children who reported higher levels of worry exhibited a greater number of short fixations during the study task. While research concerning individual differences in fixation duration distribution is limited, evidence from eye-tracking studies of both scene viewing and reading suggests that greater fixation durations are under cognitive control, while shorter fixation durations are not (Henderson et al., 2018; Kardan et al., 2015; Luke \& Henderson, 2016). Evidence from eye-tracking studies of student attention and learning outcomes also indicates that increases in fixation duration skew are associated with mind wandering, where individuals begin to exhibit a greater number of shorter fixations just prior to an episode of off-task mind wandering (Hutt, Mills, White, Donnelly, \& D’Mello, 2016). Further, investigations of the functional connectivity differences between worry and anxiety indicate that, while anxiety is associated with impoverished attentional control, worry is uniquely related to differences in Default Mode functioning, the network of brain areas associated with offtask, self-referential thought, and specifically to mind-wandering (Forster, Elizalde, Castle, \& Bishop, 2015). While conclusions about this finding are preliminary, it is possible that the association between fixation duration skewness and worry may indicate that children who were distracted by their worries during the task exhibited gaze distributions similar to those associated with mind wandering.

IU, cognitive control, and anxiety symptoms. It was hypothesized that children with higher IU would have greater cognitive control difficulties and increased anxiety 
symptoms, and that cognitive control would moderate the relation between IU and anxiety symptoms. The first two of these hypotheses were supported; children in the current study who reported greater IU were rated by their parents as having greater difficulties with attentional and emotional control in daily life, and children who reported greater IU also reported increased worry and anxiety. The third hypothesis was not supported; attentional and emotional control did not moderate the relation between Cognitive and neuroimaging literature provides evidence for the role of brain areas associated with emotional and attentional control in decision-making under uncertainty (Mushtaq et al., 2011). The ability to use emotion as information (Marroquin, Boyle, Nolen-Hoeksema, \& Stanton, 2016) and deploy adequate attention to incoming, task-relevant information (Kool, Shenhav, \& Botvinick, 2017) supports learning under uncertainty (Abrahamse, Braem, Notebaert, \& Verguts, 2016). Brain areas associated with the processing and regulation of somatic-emotional cues are associated with subjective perceptions of uncertainty specifically (Stern, Gonzalez, Welsh, \& Taylor, 2010). Difficulties with attentional and emotional control may contribute to increased perceptions of uncertainty and difficulty resolving uncertainty, which drive the aversive reactions to and negative beliefs about uncertainty that underlie IU (Grupe \& Nitschke, 2013).

IU in the current study was associated with individual differences in decisionmaking processes under uncertainty. The differences in behavior and attention identified among children with higher IU in the current study may arise because these children have difficulty with higher order attentional and emotional control. Specifically, difficulty regulating the emotional reactions elicited by uncertainty may diminish the use of 
emotions as information in decision-making and increase perceptions of uncertainty, reciprocally increasing emotional reactivity (Chin, Nelson, Jackson, \& Hajcak, 2016). Biased uncertainty calculations coupled with weaker attentional control may interfere with the ability to update learning rates according to task demands, allow for lapses in ontask attention toward task-irrelevant information, and ultimately result in inefficient decision-making behaviors.

The relation between IU and anxiety symptoms among youth is a robust finding (Osmanagaoglu et al., 2017) that was replicated in the current study. Cognitive control did not moderate this relation. Previous studies have established that childhood anxiety disorders are characterized by deficits in emotion regulation (Bender, Reinholdt-Dunne, Esbjørn, \& Pons, 2012; Carthy, Horesh, Apter, \& Gross, 2010) and attentional control (Kertz, Belden, Tillman, \& Luby, 2016; Lau \& Waters, 2017). It is possible that attentional and emotional control play a mediational role in the relation between IU and anxiety, where IU predicts anxiety symptoms because it is associated with emotional and attentional weaknesses, however, the current study's cross-sectional design precludes testing this hypothesis.

\section{Implications for the Impact of IU on Development and Anxiety Symptoms}

Results of the current study have implications for models of IU across development. Past studies show that the cognitive and emotional processing of uncertainty is separable from the processing of threat (Grupe \& Nitschke, 2013). IU likely arises from individual differences in uncertainty processing specifically, which contribute to distress in the presence of uncertainty even in the absence of threat (Pepperdine, Lomax, \& Freeston, 2018). In non-threatening, uncertain environments 
individuals with anxiety disorders have difficulty determining whether an unexpected outcome is due to a true change in the likelihood of a cue-outcome relationship or whether it represents statistical randomness (Huang, Thompson, \& Paulus, 2017). As a result, they tend to adjust learning rates based on irrelevant outcomes and have difficulty creating accurate representations of uncertain environments, contributing to uncertainty about uncertainty (Bach, Hulme, Penny, \& Dolan, 2011). During decision-making, these adults tend to avoid information-poor options (Bishop \& Gagne, 2018) and reduce time spent evaluating options under uncertainty (Luhmann, Ishida, \& Hajcak, 2011), indicating that IU may be related to avoidance of uncertainty.

If IU is related to uncertainty avoidance, IU in childhood may interfere with the development of uncertainty processing skills by restricting children's opportunities to identify and resolve uncertainty. Children with high IU in the current study spent more time evaluating available information and were particularly likely to attend to ambiguous information. Higher IU among children without an anxiety disorder was also associated with attentional differences in the present study. It is possible that over-processing of ambiguous and task-irrelevant information among children with higher IU represents avoidance of uncertainty. Greater emotional reactivity and difficulty with emotional control associated with IU may increase subjective perceptions of uncertainty regardless of the true availability of information. Further, uncertainty about uncertainty, or underconfidence about statistical estimates and value judgements, increases the tendency to rely on short-term information, despite environmental stability. This delays the accumulation of relevant knowledge and allows for continued attention to irrelevant information, which increases the subjective perception of uncertainty and prevents 
efficient decision-making (Bishop \& Gagne, 2018). Children with higher IU may spend more time attending to ambiguous information because they require more information to sufficiently reduce perceived uncertainty. Over time, inefficient processing of and reactivity to uncertainty may contribute to top-down representations of uncertainty as aversive, and lead to adult IU patterns of uncertainty avoidance.

Results of the current study may also have implications for models of IU as a risk factor for anxiety disorder symptoms. While IU may contribute to difficulty processing ambiguous stimuli generally, exposure to a threatening learning experience (e.g., a significant life stressor, anxious parenting, etc.) may create a specific difficulty determining the valence of ambiguous information (i.e.., categorizing ambiguous stimuli as threatening or neutral). Children who have difficulty accurately categorizing stimuli fail to learn to inhibit fear responses to ambiguous stimuli over the course of development (Lau et al., 2011). The inefficient processing of uncertainty associated with IU may also contribute to inaccurate predictions of the likelihood of future threat and prevent flexible updating of threat representations based on new information. One study has shown that increased predictability attenuates startle reactions to threat, while unpredictability increases startle reactions among children with anxiety disorders, supporting the hypothesis that an interaction between uncertainty processing and threat processing exists among those with anxiety disorders (Nelson \& Hajcak, 2017). Together, the overgeneralization of fear responses to ambiguity, biased calculations of threat outcomes under uncertainty, and rigid responding to perceived threat cues may contribute to the development of an anxiety disorder. 


\section{Limitations of the Current Study}

The current study has several limitations which require consideration. First, the cross-sectional nature of this study prevents drawing causal conclusions about the results. While the results were considered in the context of developmental models of emotional and cognitive control and developmental psychopathology, longitudinal investigations of IU will be required to establish causation between the outcomes examined. Specifically, it is unclear whether IU contributes to weaknesses in executive functioning or if executive functioning deficits contribute to IU. Longitudinal studies will be particularly important in determining how IU and early temperamental risk factors, such as behavioral inhibition and negative affect, relate. Given the nonsignificant relation between age and other variables in the current study, a broader age range may also be useful in determining how IU impacts the development of uncertainty across childhood and into adulthood.

Second, while the current study focused on two aspects of executive functioning (i.e., emotional and attentional control) there are other relevant functions involved in uncertainty processing that warrant consideration in the study of IU. Working memory is a key aspect of executive function associated with decision-making under uncertainty (Cui et al., 2015). Deficits in working memory ability have been implicated in the development of psychopathology broadly (Huang-Pollock, Shapiro, Galloway-Long, \& Weigard, 2017; Vytal, Arkin, Overstreet, Lieberman, \& Grillon, 2016) and anxiety disorders specifically (Bishop, 2009). In the current study, distractors in the ambiguous condition may have represented higher working memory load, as the scene contained two different distractors rather than two of the same image. While executive functions are 
separable constructs, deficits in one area are often related to deficits in others (Chevalier, 2015), and it is possible that the attentional and emotional control difficulties identified among children with high IU in the current study represent difficulties with executive functioning more broadly, or are related to a different specific executive function difficulty, such as working memory.

Third, the study task relied on distractors that represented both threat ambiguity and statistical uncertainty. This may limit the ability to draw conclusions about the relation between IU and uncertainty or threat processing individually. As anxiety disorder development likely results from differences in both uncertainty and threat processing, it will be important for future studies to vary the degree of uncertainty and threat within the experimental paradigm independently to examine how differences in each pathway contribute to anxiety disorders. For example, examining differences in physiological (e.g., pupil dilation, startle-blink, skin conductance) and behavioral (e.g., avoidance, perseveration, distractibility) responses to a cue that signals an aversive outcome in low uncertainty, high uncertainty, and volatile conditions, holding the objective aversiveness of the outcome constant, and comparing this to responses when the cue-outcome statistics are stable but the aversiveness varies.

Finally, the current study drew conclusions about attention from measures of eyegaze, which are related to overt, behavioral aspects of attention, but not necessarily covert attention (Gibb et al., 2016). While these measures can provide important information about what and how children attend to visual scenes, they do not capture the full range of attentional processes. Most studies examining biased attention in anxiety disorders employ dot-probe paradigms to examine differences in covert attention to threat (Kruijt, 
Field, \& Fox, 2016). However, these studies are limited in the conclusions that can be made about attentional differences over time and in naturalistic settings (Gamble \& Rapee, 2009). Examinations of attentional differences in IU may be strengthened by the use of paradigms that engage overt and covert attention independently, such as gazecontingent masking (Hermans \& De Houwer, 2010).

\section{Summary and Future Directions}

IU is associated with increased attention toward off-task distractors and increased RT during decision-making due to greater variability in responding. Children with higher IU are particularly distracted by ambiguously threatening stimuli and take longer to suppress attention to distractors in ambiguous conditions than children with lower IU. The relation between IU and distraction is present among both children with and without anxiety disorders. The current study is one of the first to examine the relation between childhood IU and attention and behavior under uncertainty. Children with higher IU are more likely to engage in over-processing of ambiguous stimuli and experience off-task attentional lapses during decision-making. In real world situations, children with higher IU may spend more time considering irrelevant information when attempting to make a decision and may be particularly likely to engage in this behavior when they are less certain about a decision, have less experience with the decision they are making, or are underconfident about their ability to make an adequate decision. They may become easily distracted by unimportant details and subsequently delay decision-making because their subjective uncertainty remains high due to time spent processing extraneous information that does not reduce true levels of uncertainty. These decision-making difficulties may ultimately contribute to beliefs that uncertainty is unfair and avoidance of decision- 
making through adherence to rigid patterns of behavior and distress when confronted with unexpected change.

IU has been consistently identified as a risk factor for the development of anxiety disorders, but research concerning attentional patterns among youth with and at risk for these disorders has yielded conflicting results. A large body of literature indicates that anxiety, in clinical and community samples, is associated with attentional bias toward threat (Puliafico \& Kendall, 2006). This finding is based primarily on studies of attentional orienting, however, and studies examining sustained attention indicate that anxiety is associated with attentional avoidance of threat (Sonuga-Barke, Cortese, Fairchild, \& Stringaris, 2016). Future studies should seek to examine multiple aspects of attention, namely sustained attention, attentional orienting, and executive attention, in both threatening and uncertain environments to inform models of information processing biases associated with the development of anxiety disorders.

Mixed findings are likely also due to the inclusion of clinically and sub-clinically anxious children in these studies. Children at risk for developing anxiety disorders do not show the same information processing biases as children with anxiety disorders in past studies (Ewing et al., 2016). In the present study, IU was associated with increased distractibility to neutral distractors only among children without anxiety disorders. It is possible that information processing among children at risk for developing an anxiety disorder is not representative of information processing biases among clinically anxious youth. The current study posits that IU represents individual differences in uncertainty processing that interact with aberrant threat processing to give rise to anxiety disorders. Thus, future studies should seek to differentiate attention and behavior associated with IU 
from that associated with chronic anxiety by examining children with anxiety disorders, children at-risk for anxiety disorders, and typically developing children.

The current study also identified a relation between worry, but not IU or anxiety, and fixation duration skewness. Increases in fixation duration skewness precede episodes of mind-wandering, and worry is associated with increased functional connectivity between brain areas associated with decision-making and those associated with mindwandering. The finding in the current study was exploratory, however, fixation duration distribution may serve as an indicator of worry. Further, as IU is typically a robust predictor of worry, the nonsignificant relation between IU and fixation duration distribution may suggest that this skewness reflects a cognitive vulnerability for worry independent from maladaptive uncertainty processing. Future studies should seek to investigate the relation between risk factors for anxiety disorders, including IU and worry, in relation to multiple characteristics of eye-gaze, including distribution and frequency.

Finally, future studies should investigate whether IU can be targeted prior to the development of a psychological disorder as a preventative intervention. The current results suggest that IU among both anxious and non-anxious children contributes to attentional and behavioral differences during decision-making. Use of measures such as the IUSC could help identify children who are at-risk for developing the disorders associated with IU. Because IU is associated with a broad range of disorders, the IUSC may be a more efficient predictor of future difficulties, rather than screening for the presence of each disorder symptom separately. Interventions could target decisionmaking difficulties broadly, including prolonged perseveration on ambiguous 
information, difficulty identifying and using the emotional valence of information in decision-making, inaccurate probability estimation of outcomes, and emotion dysregulation specifically related to incorrect choices. Future studies should examine the utility of measures such as the IUSC for identifying children who later develop psychological disorders, and the usefulness of treatments that target behaviors related to IU. In settings where children are more likely to experience threatening events that could interact with IU to produce disorder symptoms (e.g., chronically ill children in pediatric settings), the IUSC may serve as a useful tool for identifying vulnerable children. 


\section{REFERENCES}

Abrahamse, E., Braem, S., Notebaert, W., \& Verguts, T. (2016). Grounding cognitive control in associative learning. Psychological Bulletin, 142(7), 693-728. https://doi.org/10.1037/bul0000047

Albano, A. M., \& Silverman, W. K. (1996). The Anxiety Disorders Interview Schedule for Children for DSM-IV: Clinician manual (child and parent versions). San Antonio, TX: Psychological Corporation.

Antonini, T. N., Narad, M. E., Landberg, J. M., \& Epstein, J. N. (2013). Behavioral correlates of reaction time variability in children with and without ADHD. Neuropsychology, 27(2), 201-209. https://doi.org/10.1037/a0032071.Behavioral

Bach, D. R., Hulme, O., Penny, W. D., \& Dolan, R. J. (2011). The Known Unknowns: Neural Representation of Second-Order Uncertainty, and Ambiguity. Journal of Neuroscience, 31(13), 4811-4820. https://doi.org/10.1523/JNEUROSCI.145210.2011

Balota, D. A., \& Yap, M. J. (2011). Moving beyond the mean in studies of mental chronometry: The power of RT distributional analyses. Current Directions in Psychological Science, 20(3), 160-166. https://doi.org/10.1177/0963721411408885

Bar-Anan, Y., Wilson, T. D., \& Gilbert, D. T. (2009). The Feeling of Uncertainty Intensifies Affective Reactions. Emotion, 9(1), 123-127. https://doi.org/10.1037/a0014607 
Bar-Haim, Y., Lamy, D., Pergamin, L., Bakermans-Kranenburg, M. J., \& Van Ijzendoorn, M. H. (2007). Threat-related attentional bias in anxious and nonanxious individuals: A meta-analytic study. Psychological Bulletin, 133(1), 1-24. https://doi.org/10.1037/0033-2909.133.1.1

Beck, J. S., Beck, A. T., Jolly, J. B., \& Steer, R. A. (2005). Beck youth inventories: for children and adolescents. Psychological Corporation.

Behrens, T. E. J., Woolrich, M. W., Walton, M. E., \& Rushworth, M. F. S. (2007). Learning the value of information in an uncertain world. Nature Neuroscience, 10(9), 1214-1221. https://doi.org/10.1038/nn1954

Bender, P. K., Reinholdt-Dunne, M. L., Esbjørn, B. H., \& Pons, F. (2012). Emotion dysregulation and anxiety in children and adolescents: Gender differences. Personality and Individual Differences, 53(3), 284-288.

https://doi.org/10.1016/j.paid.2012.03.027

Birrell, J., Meares, K., Wilkinson, A., \& Freeston, M. (2011). Toward a definition of intolerance of uncertainty: A review of factor analytical studies of the Intolerance of Uncertainty Scale. Clinical Psychology Review, 31(7), 1198-1208. https://doi.org/10.1016/j.cpr.2011.07.009

Bishop, S. J. (2009). Trait anxiety and impoverished prefrontal control of attention. Nature Neuroscience, 12(1), 92-98. https://doi.org/10.1038/nn.2242

Bishop, S. J., \& Gagne, C. (2018). Anxiety, Depression, and Decision Making : A Computational Perspective, (April), 371-388.

Bland, A. R., \& Schaefer, A. (2012). Different varieties of uncertainty in human decisionmaking. Frontiers in Neuroscience, $6(\mathrm{JUN}), 1-11$. 
https://doi.org/10.3389/fnins.2012.00085

Boelen, P. A., \& Reijntjes, A. (2009). Intolerance of uncertainty and social anxiety. Journal of Anxiety Disorders, 29, 130-135.

Bomyea, J., Ramsawh, H., Ball, T. M., Taylor, C. T., Paulus, M. P., Lang, A. J., \& Stein, M. B. (2015). Intolerance of uncertainty as a mediator of reductions in worry in a cognitive behavioral treatment program for generalized anxiety disorder. Journal of Anxiety Disorders, 33, 90-94. https://doi.org/10.1016/j.janxdis.2015.05.004

Boswell, J. F., Thompson-Hollands, J., Farchione, T. J., \& Barlow, D. H. (2013). Intolerance of Uncertainty: A Common Factor in the Treatment of Emotional Disorders. Journal of Clinical Psychology, 69(6), 1-16. https://doi.org/10.1002/jclp.21965

Botvinick, M. M., Braver, T. S., Barch, D. M., Carter, C. S., \& Cohen, J. D. (2001). Conflict monitoring and cognitive control. Psychological Review, 108(3), 624-652. https://doi.org/10.1037/0033-295X.108.3.624

Braver, T. S., Gray, J. R., \& Burgess, G. C. (2012). Explaining the Many Varieties of Working Memory Variation: Dual Mechanisms of Cognitive Control. In Variation in Working Memory. https://doi.org/10.1093/acprof:oso/9780195168648.003.0004

Broeren, S., Muris, P., Diamantopoulou, S., \& Baker, J. R. (2013). The course of childhood anxiety symptoms: Developmental trajectories and child-related factors in normal children. Journal of Abnormal Child Psychology, 41(1), 81-95. https://doi.org/10.1007/s10802-012-9669-9

Brown, H. M., Eley, T. C., Broeren, S., MacLeod, C., Rinck, M., Hadwin, J. A., \& Lester, K. J. (2014). Psychometric properties of reaction time based experimental 
paradigms measuring anxiety-related information-processing biases in children. Journal of Anxiety Disorders, 28(1), 97-107.

https://doi.org/10.1016/j.janxdis.2013.11.004

Brown, J. W., \& Braver, T. S. (2005). Learned predictions of error likelihood in the anterior cingulate cortex. Science (New York, N.Y.), 307(5712), 1118-21. https://doi.org/10.1126/science.1105783

Browning, M., Behrens, T. E., Jocham, G., O’Reilly, J. X., \& Bishop, S. J. (2015). Anxious individuals have difficulty learning the causal statistics of aversive environments. Nat Neurosci, 18(4), 590-596. https://doi.org/10.1038/nn.3961

Brumariu, L. E., \& Kerns, K. A. (2015). Mother - child emotion communication and childhood anxiety symptoms. Cognition and Emotion, 29(3), 416-431. https://doi.org/10.1080/02699931.2014.917070

Buhr, K., \& Dugas, M. J. (2006). Investigating the construct validity of intolerance of uncertainty and its unique relationship with worry. Journal of Anxiety Disorders, 20(2), 222-236. https://doi.org/10.1016/j.janxdis.2004.12.004

Carleton, R. N. (2012). The intolerance of uncertainty construct in the context of anxiety disorders: Theoretical and practical perspectives. Expert Review of Neurotherapeutics, 12(8), 937-947. https://doi.org/10.1586/ern.12.82

Carleton, R. N. (2016). Into the unknown: A review and synthesis of contemporary models involving uncertainty. Journal of Anxiety Disorders, 39, 30-43. https://doi.org/10.1016/j.janxdis.2016.02.007

Carleton, R. N., Duranceau, S., Shulman, E. P., Zerff, M., Gonzales, J., \& Mishra, S. (2016). Self-reported intolerance of uncertainty and behavioural decisions. Journal 
of Behavior Therapy and Experimental Psychiatry, 51, 58-65.

https://doi.org/10.1016/j.jbtep.2015.12.004

Carleton, R. N., Norton, M. A. P. J., \& Asmundson, G. J. G. (2007). Fearing the unknown: A short version of the Intolerance of Uncertainty Scale. Journal of Anxiety Disorders, 2l(1), 105-117. https://doi.org/10.1016/j.janxdis.2006.03.014

Carlson, S. M., Zelazo, P. D., \& Faja, S. (2013). Executive function. In Oxford handbook of developmental psychology (Vol. 1, pp. 706-742).

Carthy, T., Horesh, N., Apter, A., \& Gross, J. J. (2010). Patterns of emotional reactivity and regulation in children with anxiety disorders. Journal of Psychopathology and Behavioral Assessment, 32(1), 23-36. https://doi.org/10.1007/s10862-009-9167-8

Cauffman, E., Shulman, E. P., Steinberg, L., Claus, E., Banich, M. T., Graham, S., \& Woolard, J. (2010). Age Differences in Affective Decision Making as Indexed by Performance on the Iowa Gambling Task. Developmental Psychology, 46(1), 193207. https://doi.org/10.1037/a0016128

Chen, J. T. H., \& Lovibond, P. F. (2016). Intolerance of Uncertainty Is Associated With Increased Threat Appraisal and Negative Affect Under Ambiguity but Not Uncertainty. Behavior Therapy, 47(1), 42-53.

https://doi.org/10.1016/j.beth.2015.09.004

Chevalier, N. (2015). Executive function development: Making sense of the environment to behave adaptively. Current Directions in Psychological Science, 24(5), 363-368. https://doi.org/10.1177/0963721415593724

Chevalier, N., \& Blaye, A. (2009). Setting Goals to Switch Between Tasks: Effect of Cue Transparency on Children's Cognitive Flexibility. Developmental Psychology, 
45(3), 782-797. https://doi.org/10.1037/a0015409

Chin, B., Nelson, B. D., Jackson, F., \& Hajcak, G. (2016). Intolerance of uncertainty and startle potentiation in relation to different threat reinforcement rates. International Journal of Psychophysiology, 99, 79-84. https://doi.org/10.1016/j.jpsycho.2015.11.006

Chorpita, B. F., Tracey, S. A., Brown, T. A., Collica, T. J., \& Barlow, D. H. (1997). Assessment of worry in children and adolescents: An adaptation of the Penn State Worry Questionnaire. Behaviour Research and Therapy, 35(6), 569-581. https://doi.org/10.1016/S0005-7967(96)00116-7

Chrysikou, E. G., Weber, M. J., \& Thompson-Schill, S. L. (2014). A Matched Filter Hypothesis for Cognitve Control. Neuropsychologia, 62, 341-355. https://doi.org/10.1038/jid.2014.371

Cisler, J. M., \& Koster, E. H. W. (2011). Mechanisms of attentional biases towards threat in anxiety disorder: An integrative review, 30(2), 1-29. https://doi.org/10.1016/j.cpr.2009.11.003.Mechanisms

Cohen, J., \& Aston-Jones, G. (2005). Decision amid uncertainty. Nature, 436, $1977-$ 1981. https://doi.org/10.1002/adma.200401726

Comer, J. S., Roy, A. K., Ph, D., Furr, J. M., Gotimer, K., Beidas, R. S., ... Ph, D. (2009). The Intolerance of Uncertainty Scale for Children: A Psychometric Evaluation, 21(3), 402-411. https://doi.org/10.1037/a0016719.The

Copeland, W. E., Angold, A., Shanahan, L., \& Costello, E. J. (2014). Longitudinal Patterns of Anxiety From Childhood to Adulthood: The Great Smoky Mountains Study. J Am Acad Child Adolesc Psychiatry, 53(1), 21-33. 
https://doi.org/10.1016/j.str.2010.08.012.Structure

Cowie, J., Clementi, M. A., \& Alfano, C. A. (2016). Examination of the Intolerance of Uncertainty Construct in Youth With Generalized Anxiety Disorder. Journal of Clinical Child \& Adolescent Psychology, 1-9.

Crocetti, E., Klimstra, T., Keijsers, L., Hale, W. W., \& Meeus, W. (2009). Anxiety trajectories and identity development in adolescence: A five-wave longitudinal study. Journal of Youth and Adolescence, 38(6), 839-849. https://doi.org/10.1007/s10964-008-9302-y

Cui, J. F., Wang, Y., Shi, H. S., Liu, L. L., Chen, X. J., \& Chen, Y. H. (2015). Effects of working memory load on uncertain decision-making: Evidence from the Iowa Gambling Task. Frontiers in Psychology, 6(FEB), 1-9. https://doi.org/10.3389/fpsyg.2015.00162

Cuthbert, B. N., \& Insel, T. R. (2013). Toward the future of psychiatric diagnosis: The seven pillars of RDoC. BMC Medicine, 11(1). https://doi.org/10.1186/1741-7015$11-126$

Dadds, M. R., Atkinson, E., Turner, C., Blums, G. J., \& Lendich, B. (1999). Family conflict and child adjustment: Evidence for a cognitive-contextual model of intergenerational transmission. Journal of Family Psychology, 13(2), 194-208. https://doi.org/10.1037/0893-3200.13.2.194

Dash, S. R., Meeten, F., \& Davey, G. C. L. (2013). Systematic information processing style and perseverative worry. Clinical Psychology Review. Elsevier Ltd. https://doi.org/10.1016/j.cpr.2013.08.007

De Berker, A. O., Rutledge, R. B., Mathys, C., Marshall, L., Cross, G. F., Dolan, R. J., \& 
Bestmann, S. (2016). Computations of uncertainty mediate acute stress responses in humans. Nature Communications, 7, 1-11. https://doi.org/10.1038/ncomms10996

Derryberry, D., \& Reed, M. a. (2002). Anxiety-related attentional biases and their regulation by attentional control. Journal of Abnormal Psychology, 111(2), 225236. https://doi.org/10.1037/0021-843X.111.2.225

Diamond, A. (2014). Executive Functions. Annual Review of Clinical PsychologyPsychol., 64, 135-168. https://doi.org/10.1146/annurev-psych-113011143750.Executive

Donovan, C. L., Holmes, M. C., Farrell, L. J., \& Hearn, C. S. (2017). Thinking about worry: Investigation of the cognitive components of worry in children. Journal of Affective Disorders, 208(September 2016), 230-237.

https://doi.org/10.1016/j.jad.2016.09.061

Dudeney, J., Sharpe, L., \& Hunt, C. (2015). Attentional bias towards threatening stimuli in children with anxiety: A meta-analysis. Clinical Psychology Review, 40(June), 66-75. https://doi.org/10.1016/j.cpr.2015.05.007

Dugas, M. J., Freeston, M. H., \& Ladouceur, R. (1997). Intolerance of uncertainty and problem orientation in worry. Cognitive Therapy and Research, 21(6), 593-606. https://doi.org/10.1023/A:1021890322153

Dugas, M. J., Laugesen, N., \& Bukowski, W. M. (2012). Intolerance of uncertainty, fear of anxiety, and adolescent worry. Journal of Abnormal Child Psychology, 40, 863870. https://doi.org/10.1007/s10802-012-9611-1

Durston, S., Davidson, M. C., Tottenham, N., Galvan, A., Spicer, J., Fossella, J. A., \& Casey, B. J. (2006). A shift from diffuse to focal cortical activity with development. 
Developmental Science, 9(1), 18-20. https://doi.org/10.1111/j.14677687.2005.00454.x

Egeth, H. E., Leonard, C. J., \& Leber, A. B. (2011). Why Salience is Not Enough: Reflections on Top-Down Selection in Vision. Acta Psychologica, 135(2), 130-132. https://doi.org/10.1016/j.actpsy.2010.05.012.Why

Einstein, D. A. (2014). Extension of the Transdiagnostic Model to Focus on Intolerance of Uncertainty: A Review of the Literature and Implications for Treatment. Clinical Psychology: Science and Practice, 21(3), 280-300. https://doi.org/10.1111/cpsp.12077

Ewing, D. L., Dash, S., Thompson, E. J., Hazell, C. M., Hughes, Z., Lester, K. J., \& Cartwright-Hatton, S. (2016). No Significant Evidence of Cognitive Biases for Emotional Stimuli in Children At-Risk of Developing Anxiety Disorders. Journal of Abnormal Child Psychology, 44(7), 1243-1252. https://doi.org/10.1007/s10802-015$0122-8$

Eysenck, M. W., Derakshan, N., Santos, R., \& Calvo, M. G. (2007). Anxiety and cognitive performance: Attentional control theory. Emotion, 7(2), 336-353. https://doi.org/10.1037/1528-3542.7.2.336

Fan, J., Van Dam, N. T., Gu, X., Liu, X., Wang, H., Tang, C. Y., \& Hof, P. R. (2014). Quantitative Characterization of Functional Anatomical Contributions to Cognitive Control under Uncertainty. Journal of Cognitive Neuroscience, 26(7), 1490-1506. https://doi.org/10.1162/jocn

Faul, F., Erdfelder, E., Lang, A.-G., \& Buchner, A. (2007). G*Power 3: a flexible statistical power analysis program for the social, behavioral, and biomedical 
sciences. Behavior Research Methods, 39(2), 175-191.

https://doi.org/10.3758/BF03193146

FeldmanHall, O., Glimcher, P., Baker, A. L., \& Phelps, E. A. (2016). Emotion and decision-making under uncertainty: Physiological arousal predicts increased gambling during ambiguity but not risk. Journal of Experimental Psychology:

General, 145(10), 1255-1262. https://doi.org/10.1037/xge0000205

Fergus, T. A., \& Carleton, R. N. (2015). Intolerance of uncertainty and attentional networks: Unique associations with alerting. Journal of Anxiety Disorders, 41, 5964. https://doi.org/10.1016/j.janxdis.2016.03.010

Fetzner, M. G., Horswill, S. C., Boelen, P. A., \& Carleton, R. N. (2013). Intolerance of uncertainty and PTSD symptoms: Exploring the construct relationship in a community sample with a heterogeneous trauma history. Cognitive Therapy and Research, 37(4), 725-734. https://doi.org/10.1007/s10608-013-9531-6

Fialko, L., Bolton, D., \& Perrin, S. (2012). Applicability of a cognitive model of worry to children and adolescents. Behaviour Research and Therapy, 50(5), 341-9. https://doi.org/10.1016/j.brat.2012.02.003

Finucane, A. M., \& Power, M. J. (2010). The effect of fear on attentional processing in a sample of healthy females. Journal of Anxiety Disorders, 24(1), 42-48. https://doi.org/10.1016/j.janxdis.2009.08.005

Folk, J. B., Zeman, J. L., Poon, J. A., \& Dallaire, D. H. (2014). A longitudinal examination of emotion regulation: Pathways to anxiety and depressive symptoms in Urban minority youth. Child and Adolescent Mental Health, 19(4), 243-250. https://doi.org/10.1111/camh.12058 
Forster, S., Elizalde, A. O. N., Castle, E., \& Bishop, S. J. (2015). Unraveling the anxious mind: Anxiety, worry, and frontal engagement in sustained attention versus off-task processing. Cerebral Cortex, 25(3), 609-618. https://doi.org/10.1093/cercor/bht248

Freeston, M. H., Rhéaume, J., Letarte, H., Dugas, M. J., \& Ladouceur, R. (1994). Why do people worry? Personality and Individual Differences, 17(6), 791-802. https://doi.org/10.1016/0191-8869(94)90048-5

Frey, R., Hertwig, R., \& Rieskamp, J. (2014). Fear shapes information acquisition in decisions from experience. Cognition, 132(1), 90-99. https://doi.org/10.1016/j.cognition.2014.03.009

Fritz, J., \& Dreisbach, G. (2013). Conflicts as aversive signals: Conflict priming increases negative judgments for neutral stimuli. Cognitive, Affective and Behavioral Neuroscience, 13(2), 311-317. https://doi.org/10.3758/s13415-012-0147-1

Gamble, A. L., \& Rapee, R. M. (2009). The time-course of attentional bias in anxious children and adolescents. Journal of Anxiety Disorders, 23(7), 841-847. https://doi.org/10.1016/j.janxdis.2009.04.001

Gaspar, J. M., \& McDonald, J. J. (2014). Suppression of Salient Objects Prevents Distraction in Visual Search. Journal of Neuroscience, 34(16), 5658-5666. https://doi.org/10.1523/JNEUROSCI.4161-13.2014

Gentes, E. L., \& Ruscio, A. M. (2011). A meta-analysis of the relation of intolerance of uncertainty to symptoms of generalized anxiety disorder, major depressive disorder, and obsessive-compulsive disorder. Clinical Psychology Review, 31(6), 923-933. https://doi.org/10.1016/j.cpr.2011.05.001

Gibb, B. E., Mcgeary, J. E., \& Beevers, C. G. (2016). Attentional biases to emotional 
stimuli: Key components of the RDoC constructs of sustained threat and loss. American Journal of Medical Genetics, Part B: Neuropsychiatric Genetics, 171(1), 65-80. https://doi.org/10.1002/ajmg.b.32383

Gioia, G. A., Isquith, P. K., Guy, S. C., \& Kenworthy, L. (2016). Behavior rating inventory of executive function, (BRIEF-2). Lutz, FL: Psychological Assessment Resource.

Grupe, D. W., \& Nitschke, J. B. (2013). Uncertainty and Anticipation in Anxiety: An integrated neurobiological and psychological perspective Dan. Nature Reviews Neuroscience, 14(7), 488-501. https://doi.org/10.1038/jid.2014.371

Gullone, E., Hughes, E. K., King, N. J., \& Tonge, B. (2010). The normative development of emotion regulation strategy use in children and adolescents: A 2-year follow-up study. Journal of Child Psychology and Psychiatry and Allied Disciplines, 51(5), 567-574. https://doi.org/10.1111/j.1469-7610.2009.02183.x

Hartley, C. A., \& Phelps, E. A. (2013). Anxiety and Decision-Making. Biol Psychiatry, 72(2). https://doi.org/10.1016/j.biopsych.2011.12.027.Anxiety

Hartwig, J., Schnitzspahn, K. M., Kliegel, M., Velichkovsky, B. M., \& Helmert, J. R. (2013). I see you remembering: What eye movements can reveal about process characteristics of prospective memory. International Journal of Psychophysiology, 88(2), 193-199. https://doi.org/10.1016/j.ijpsycho.2013.03.020

Hearn, C. S., Donovan, C. L., Spence, S. H., \& March, S. (2017). A worrying trend in Social Anxiety: To what degree are worry and its cognitive factors associated with youth Social Anxiety Disorder? Journal of Affective Disorders, 208(October 2016), 33-40. https://doi.org/10.1016/j.jad.2016.09.052 
Heilman, R. M., Crişan, L. G., Houser, D., Miclea, M., \& Miu, A. C. (2010). Emotion Regulation and Decision Making Under Risk and Uncertainty. Emotion, 10(2), 257265. https://doi.org/10.1037/a0018489

Henderson, J. M., Choi, W., Luke, S. G., \& Schmidt, J. (2018). Neural correlates of individual differences in fixation duration during natural reading. Quarterly Journal of Experimental Psychology, 71(1 Special Issue), 314-323. https://doi.org/10.1080/17470218.2017.1329322

Hermans, D., \& De Houwer, J. (2010). Cognition \& Emotion: Reviews of Current Research and Theories. Cognition \& Emotion Reviews of Current Research and Theories (Vol. 1). New York: Psychology Press. https://doi.org/10.1017/CBO9781107415324.004

Hirshfeld-Becker, D. R., Micco, J., Henin, A., Bloomfield, A., Biederman, J., \& Rosenbaum, J. (2008). Behavioral inhibition. Depression and Anxiety, 25(4), 357367. https://doi.org/10.1002/da.20490

Hsu, M., Bhatt, M., Adolphus, R., Tranel, D., \& Camerer, C. F. (2005). Neural Systems Responding to Degrees of Uncertainty in Human Decision-Making. Science, 310(5754), 1680-1683. https://doi.org/10.1126/science.1115327

Huang-Pollock, C., Shapiro, Z., Galloway-Long, H., \& Weigard, A. (2017). Is Poor Working Memory a Transdiagnostic Risk Factor for Psychopathology? Journal of Abnormal Child Psychology, 45(8), 1477-1490. https://doi.org/10.1007/s10802-016$0219-8$

Huang, H., Thompson, W., \& Paulus, M. P. (2017). Computational Dysfunctions in Anxiety: Failure to Differentiate Signal From Noise. Biological Psychiatry, 82(6), 
440-446. https://doi.org/10.1016/j.biopsych.2017.07.007

Huettel, S. A., Song, A. W., \& McCarthy, G. (2005). Decisions under Uncertainty: Probabilistic Context Influences Activation of Prefrontal and Parietal Cortices. Journal of Neuroscience, 25(13), 3304-3311. https://doi.org/10.1523/JNEUROSCI.5070-04.2005

Huizinga, M., \& Smidts, D. P. (2011). Age-related changes in executive function: A normative study with the dutch version of the Behavior Rating Inventory of Executive Function (BRIEF). Child Neuropsychology, 17(1), 51-66. https://doi.org/10.1080/09297049.2010.509715

Hutt, S., Mills, C., White, S., Donnelly, P. J., \& D 'Mello, S. K. (2016). The Eyes Have It: Gaze-based Detection of Mind Wandering during Learning with an Intelligent Tutoring System. Proceedings of the 9th International Conference on Educational Data Mining. International Educational Data Mining Society., 86-93.

Inzlicht, M., Bartholow, B. D., \& Hirsh, J. B. (2015). Emotional foundations of cognitive control. Trends in Cognitive Sciences, 19(3), 126-132. https://doi.org/10.1016/j.tics.2015.01.004.Emotional Jackson, F., Nelson, B. D., \& Hajcak, G. (2016). The uncertainty of errors: Intolerance of uncertainty is associated with error-related brain activity. Biological Psychology, 113, 52-58. https://doi.org/10.1016/j.biopsycho.2015.11.007

Kalanthroff, E., Linkovski, O., Henik, A., Wheaton, M. G., \& Anholt, G. E. (2016). Inhibiting uncertainty: Priming inhibition promotes reduction of uncertainty. Neuropsychologia, 92(January), 142-146. https://doi.org/10.1016/j.neuropsychologia.2015.11.020 
Karalunas, S. L., \& Huang-Pollock, C. L. (2013). Integrating impairments in reaction time and executive function using a diffusion model framework. Journal of Abnormal Child Psychology, 41(5), 837-850. https://doi.org/10.1007/s10439-0110452-9.Engineering

Kardan, O., Berman, M. G., Yourganov, G., Schmidt, J., Henderson, J. M., \& Henderson, J. M. (2015). Classifying Mental States From Eye Movements During Scene Viewing. Journal of Experimental Psychology: Human Perception and Performance.

Keenan, K. (2000). Emotion dysregulation as a risk factor for child psychopathology. Clinical Psychology: Science and Practice, 418-434.

Kempe, V., Rookes, M., \& Swarbrigg, L. (2013). Speaker emotion can affect ambiguity production. Language and Cognitive Processes, 28(10), 1579-1590. https://doi.org/10.1080/01690965.2012.755555

Kendall, P. C., Flannery-Schroeder, E., Panichelli-Mindel, S. M., Southam-Gerow, M., Henin, A., \& Warman, M. (1997). Therapy for youths with anxiety disorders: A second randomized clincal trial. Journal of Consulting and Clinical Psychology, 65(3), 366-380. https://doi.org/10.1037/0022-006X.65.3.366

Kertz, S. J., Belden, A. C., Tillman, R., \& Luby, J. (2016). Cognitive Control Deficits in Shifting and Inhibition in Preschool Age Children are Associated with Increased Depression and Anxiety Over 7.5 Years of Development. Journal of Abnormal Child Psychology, 44(6), 1185-1196. https://doi.org/10.1007/s10802-015-0101-0

Kertz, S., \& Woodruff-Borden, J. (2013). The role of metacognition, intolerance of uncertainty, and negative problem orientation in children's worry. Behavioural and 
Cognitive Psychotherapy, 41(2), 243-8.

https://doi.org/10.1017/S1352465812000641

Kiss, M., Grubert, A., Petersen, A., \& Eimer, M. (2012). Attentional Capture by Salient Distractors during Visual Search Is Determined by Temporal Task Demands. Journal of Cognitive Neuroscience, 24(3), 749-759. https://doi.org/10.1162/jocn_a_00127

Koerner, N., \& Dugas, M. J. (2008). An investigation of appraisals in individuals vulnerable to excessive worry: The role of intolerance of uncertainty. Cognitive Therapy and Research, 32(5), 619-638. https://doi.org/10.1007/s10608-007-9125-2

Kool, W., Shenhav, A., \& Botvinick, M. M. (2017). Cognitive Control as Cost-Benefit Decision Making. In T. Egner (Ed.), The Wiley Handbook of Cognitive Control (1st ed., pp. 167-189). John Wiley \& Sons Ltd.

Krain, A. L., Gotimer, K., Hefton, S., Ernst, M., Castellanos, F. X., Pine, D. S., \& Milham, M. P. (2008). A Functional Magnetic Resonance Imaging Investigation of Uncertainty in Adolescents with Anxiety Disorders. Biological Psychiatry, 63(6), 563-568. https://doi.org/10.1016/j.biopsych.2007.06.011

Krain, A. L., Hefton, S., Pine, D. S., Ernst, M., Xavier Castellanos, F., Klein, R. G., \& Milham, M. P. (2006). An fMRI examination of developmental differences in the neural correlates of uncertainty and decision-making. Journal of Child Psychology and Psychiatry and Allied Disciplines, 47(10), 1023-1030. https://doi.org/10.1111/j.1469-7610.2006.01677.x

Kruijt, A. W., Field, A. P., \& Fox, E. (2016). Capturing dynamics of biased attention: Are new attention variability measures the way forward. PLoS ONE, 11(11), 1-22. 
https://doi.org/10.1371/journal.pone.0166600

Lagattuta, K. H., \& Sayfan, L. (2011). Developmental changes in children's understanding of future likelihood and uncertainty. Cognitive Development, 26(4), 315-330. https://doi.org/10.1016/j.cogdev.2011.09.004

Lagattuta, K. H., \& Sayfan, L. (2013). Not all past events are equal: biased attention and emerging heuristics in children's past-to-future forecasting. Child Development, 84(6), 2094-111. https://doi.org/10.1111/cdev.12082

Larissa Z. Tiedens, S. L. (2001). Judgement Under Emotional Certainty and Uncertainty:The Effects of Specific Emotions on Information Processing. Journal of Personality and Social Psychology, 81(6), 973-988. https://doi.org/10.1037/00223514.81.6.973

Lau, J. Y., Britton, J. C., Nelson, E. E., Angold, A., Ernst, M., Goldwin, M., ... Pine, D. S. (2011). Distinct neural signatures of threat learning in adolescents and adults. Proceedings of the National Academy of Sciences, 108(11), 4500-4505. https://doi.org/10.1073/pnas.1005494108

Lau, J. Y. F., \& Waters, A. M. (2017). Annual Research Review: An expanded account of information-processing mechanisms in risk for child and adolescent anxiety and depression. Journal of Child Psychology and Psychiatry and Allied Disciplines, 58(4), 387-407. https://doi.org/10.1111/jcpp.12653

Le Pelley, M. E., Mitchell, C. J., Beesley, T., George, D. N., \& Wills, A. J. (2016). Attention and associative learning in humans : An integrative review. Psychological Bulletin. https://doi.org/http://dx.doi.org/10.1037/bul0000064

Le Pelley, M. E., Pearson, D., Griffiths, O., \& Beesley, T. (2015). When goals conflict 
with values: Counterproductive attentional and oculomotor capture by rewardrelated stimuli. Journal of Experimental Psychology: General, 144(1), 158-171. https://doi.org/10.1037/xge0000037

Lee, J. K., Orsillo, S. M., Roemer, L., \& Allen, L. B. (2010). Distress and avoidance in generalized anxiety disorder: exploring the relationships with intolerance of uncertainty and worry. Cognitive Behaviour Therapy, 39(2), 126-136. https://doi.org/10.1080/16506070902966918

Lench, H. C., Flores, S. A., \& Bench, S. W. (2011). Discrete emotions predict changes in cognition, judgment, experience, behavior, and physiology: A meta-analysis of experimental emotion elicitations. Psychological Bulletin, 137(5), 834-855. https://doi.org/10.1037/a0024244

Lerner, J. S., Li, Y., Valdesolo, P., \& Kassam, K. S. (2015). Emotion and Decision Making. Annual Review of Psychology, 66(1), 799-823. https://doi.org/10.1146/annurev-psych-010213-115043

Lewis, M. D. (2013). The Development of Emotion Regulation: Integrating Normative and Individual Differences Through Developmental Neuroscience. In The Oxford Handbook of Developmental Psychology (pp. 81-97). Oxford: Oxford University Press.

Little, R. J. A. (1988). A test of missing completely at random for multivariate data with missing values. Journal of the American Statistical Association, 83(404), 11981202. https://doi.org/10.1080/01621459.1988.10478722

Logan, G. D., \& Schneider, D. W. (2006). Interpreting instructional cues in task switching procedures: the role of mediator retrieval. Journal of Experimental 
Psychology. Learning, Memory, and Cognition, 32(2), 347-363.

https://doi.org/10.1037/0278-7393.32.3.347

Luhmann, C. C., Ishida, K., \& Hajcak, G. (2011). Intolerance of uncertainty and decisions about delayed, probabilistic rewards. Behavior Therapy, 42(3), 378-386. https://doi.org/10.1016/j.beth.2010.09.002

Luke, S. G., \& Henderson, J. M. (2016). The influence of content meaningfulness on eye movements across tasks: Evidence from scene viewing and reading. Frontiers in Psychology, 7(MAR), 1-10. https://doi.org/10.3389/fpsyg.2016.00257

Macatee, R. J., Albanese, B. J., Clancy, K., Allan, N. P., Bernat, E. M., Cougle, J. R., \& Schmidt, N. B. (2018). Distress intolerance modulation of neurophysiological markers of cognitive control during a complex Go/No-Go task. Journal of Abnormal Psychology, 127(1), 12-29. https://doi.org/10.1037/abn0000323

Marroquin, B., Boyle, C. C., Nolen-Hoeksema, S., \& Stanton, A. L. (2016). Using Emotion as Information in Future-Oriented Cognition: Individual Differences in the Context of State Negative Affect. Personality and Individual Differences, 95, 121126. https://doi.org/10.1016/j.jad.2015.06.025.Associations

McEvoy, P. M., \& Mahoney, A. E. J. (2012). To Be Sure, To Be Sure: Intolerance of Uncertainty Mediates Symptoms of Various Anxiety Disorders and Depression. Behavior Therapy, 43(3), 533-545. https://doi.org/10.1016/j.beth.2011.02.007

McEvoy, P. M., \& Mahoney, A. E. J. (2013). Intolerance of uncertainty and negative metacognitive beliefs as transdiagnostic mediators of repetitive negative thinking in a clinical sample with anxiety disorders. Journal of Anxiety Disorders, 27(2), 216224. https://doi.org/10.1016/j.janxdis.2013.01.006 
McLaughlin, K. a, Mennin, D. S., \& Farach, F. J. (2007). The contributory role of worry in emotion generation and dysregulation in generalized anxiety disorder. Behaviour Research and Therapy, 45(8), 1735-52. https://doi.org/10.1016/j.brat.2006.12.004

Mclean, C. P., Asnaani, A., Litz, B. T., \& G, H. S. (2011). Gender differences in anxiety disorders: Prevalence, course of illness, comorbidity and burden of illness. Journal of Psychiatric Research, 45(8), 1027-1035. https://doi.org/10.1016/j.jpsychires.2011.03.006.Gender

Mennin, D. S., Heimberg, R. G., Turk, C. L., \& Fresco, D. M. (2002). Applying an emotion regulation framework to integrative approaches to generalized anxiety disorder. Clinical Psychology: Science and Practice. https://doi.org/10.1093/clipsy/9.1.85

Mennin, D. S., Heimberg, R. G., Turk, C. L., \& Fresco, D. M. (2005). Preliminary evidence for an emotion dysregulation model of generalized anxiety disorder. Behaviour Research and Therapy, 43(10), 1281-310. https://doi.org/10.1016/j.brat.2004.08.008

Merikangas, K., Jian-ping, H., Burstein, M., Swanson, S., Avenevoli, S., Lihong, C., ... Swendsen, J. (2011). Lifetime Prevalence of Mental Disorders in US Adolescents: Results from the National Comorbidity Study-Adolescent Supplement. Journal of the American Academy Children Adolescent Psychiatry, 49(10), 980-989. https://doi.org/10.1016/j.jaac.2010.05.017.Lifetime

Miyake, A., \& Friedman, N. P. (2012). The Nature and Organisation of Individual Differences in Executive Functions : Four General Conclusions. Current Directions in Psychological Science, 21(1), 8-14. 
https://doi.org/10.1177/0963721411429458.The

Miyake, A., Friedman, N. P., Emerson, M. J., Witzki, A. H., Howerter, A., \& Wager, T. D. (2000). The unity and diversity of executive functions and their contributions to complex \&quot;Frontal Lobe\&quot; tasks: a latent variable analysis. Cognitive Psychology, 41(1), 49-100. https://doi.org/10.1006/cogp.1999.0734

Moffitt, T. E., Arseneault, L., Belsky, D., Dickson, N., Hancox, R. J., Harrington, H., ... Caspi, A. (2011). A gradient of childhood self-control predicts health, wealth, and public safety. Proceedings of the National Academy of Sciences of the United States of America, 108, 2693-2698. https://doi.org/10.1073/pnas.1010076108

Mogg, K., Salum, G. A., Bradley, B. P., Gadelha, A., Pan, P., Alvarenga, P., ... Manfro, G. G. (2015). Attention network functioning in children with anxiety disorders, attention-deficit/hyperactivity disorder and non-clinical anxiety. Psychological Medicine, 45(12), 2633-2646. https://doi.org/10.1017/S0033291715000586

Morriss, J., Christakou, A., \& van Reekum, C. M. (2016). Nothing is safe: Intolerance of uncertainty is associated with compromised fear extinction learning. Biological Psychology, 121, 187-193. https://doi.org/10.1016/j.biopsycho.2016.05.001

Mushtaq, F., Bland, A. R., \& Schaefer, A. (2011). Uncertainty and cognitive control. Frontiers in Psychology, 2(SEP), 1-14. https://doi.org/10.3389/fpsyg.2011.00249

Nelson, B. D., \& Hajcak, G. (2017). Anxiety and Depression Symptom Dimensions Demonstrate Unique Relationships with the Startle Reflex in Anticipation of Unpredictable Threat in 8 to 14 Year-Old Girls. Journal of Abnormal Child Psychology, 45(2), 397-410. https://doi.org/10.1016/j.coviro.2015.09.001.Human Newman, M. G., Llera, S. J., Erickson, T. M., Przeworski, A., \& Castonguay, L. G. 
(2013). Worry and generalized anxiety disorder: a review and theoretical synthesis of evidence on nature, etiology, mechanisms, and treatment. Annual Review of Clinical Psychology, 9, 275-97. https://doi.org/10.1146/annurev-clinpsy-050212185544

Nissens, T., Failing, M., \& Theeuwes, J. (2017). People look at the object they fear: oculomotor capture by stimuli that signal threat. Cognition and Emotion, 31(8), 1707-1714. https://doi.org/10.1080/02699931.2016.1248905

Ochsner, K. N., \& Gross, J. J. (2005). The cognitive control of emotion. Trends in Cognitive Sciences, 9(5), 242-249. https://doi.org/10.1016/j.tics.2005.03.010

Ode, S., Robinson, M. D., \& Hanson, D. M. (2011). Cognitive-emotional dysfunction among noisy minds: Predictions from individual differences in reaction time variability. Cognition and Emotion, 25(2), 307-327.

https://doi.org/10.1080/02699931.2010.494387

Oglesby, M. E., Raines, A. M., Short, N. A., Capron, D. W., \& Schmidt, N. B. (2016). Interpretation bias for uncertain threat: A replication and extension. Journal of Behavior Therapy and Experimental Psychiatry, 51, 35-42. https://doi.org/10.1016/j.jbtep.2015.12.006

Oppenheimer, D. M., \& Kelso, E. (2015). Information Processing as a Paradigm for Decision Making. Annual Review of Psychology, 66(1), 277-294. https://doi.org/10.1146/annurev-psych-010814-015148

Orquin, J. L., \& Mueller Loose, S. (2013). Attention and choice: A review on eye movements in decision making. Acta Psychologica, 144(1), 190-206. https://doi.org/10.1016/j.actpsy.2013.06.003 
Osmanagaoglu, N., Creswell, C., \& Dodd, H. F. (2017). Intolerance of Uncertainty, Anxiety, and Worry in Children and Adolescents: A Meta-Analysis. Journal of Affective Disorders. https://doi.org/10.1016/j.jad.2017.07.035

Payzan-LeNestour, E., Dunne, S., Bossaerts, P., \& O’Doherty, J. (2013). The Neural Representation of Unexpected Uncertainty during Value-Based Decision Making. Neuron, 79(1), 191-201. https://doi.org/10.1016/j.neuron.2013.04.037

Pepperdine, E., Lomax, C., \& Freeston, M. H. (2018). Disentangling intolerance of uncertainty and threat appraisal in everyday situations. Journal of Anxiety Disorders, (April), 0-1. https://doi.org/10.1016/j.janxdis.2018.04.002

Pestle, S. L., Chorpita, B. F., \& Schiffman, J. (2008). Psychometric properties of the Penn State worry questionnaire for children in a large clinical sample. Journal of Clinical Child and Adolescent Psychology, 37(2), 465-471. https://doi.org/10.1080/15374410801955896

Pine, D. S., \& Fox, N. A. (2015). Childhood Antecedents and Risk for Adult Mental Disorders. Annual Review of Psychology, 66(1), 459-485. https://doi.org/10.1146/annurev-psych-010814-015038

Prencipe, A., Kesek, A., Cohen, J., Lamm, C., Lewis, M. D., \& Zelazo, P. D. (2011). Development of hot and cool executive function during the transition to adolescence. Journal of Experimental Child Psychology, 108(3), 621-637. https://doi.org/10.1016/j.jecp.2010.09.008

Price, R. B., Rosen, D., Siegle, G. J., Ladouceur, C. D., Tang, K., Allen, K. B., .. Silk, J. S. (2016). From Anxious Youth to Depressed Adolescents: Prospective Prediction of 2-year Depression Symptoms via Attentional Bias Measures. Journal of Abormal 
Psychology, 125(2), 267-278. https://doi.org/10.1016/j.coviro.2015.09.001.Human

Puliafico, A. C., \& Kendall, P. C. (2006). Threat-related attentional bias in anxious youth: a review. Clinical Child and Family Psychology Review, 9(3-4), 162-80. https://doi.org/10.1007/s10567-006-0009-x

Read, K. L., Comer, J. S., \& Kendall, P. C. (2013). The intolerance of uncertainty scale for children (IUSC): Discriminating principal anxiety diagnoses and severity. Psychological Assessment, 25(3), 722-729. https://doi.org/10.1037/a0032392

Reynolds, C. R., \& Richmond, B. O. (1997). Revised Children's Manifest Anxiety Scale Manual. Journal of Abnormal Child Psychology, 6(2), 271-280. https://doi.org/10.1037/t00514-

Roderer, T., \& Roebers, C. M. (2010). Explicit and implicit confidence judgments and developmental differences in metamemory: An eye-tracking approach. Metacognition and Learning, 5(100014), 229-250. https://doi.org/10.1007/s11409$010-9059-\mathrm{z}$

Roebers, C. M., Schmid, C., \& Roderer, T. (2010). Encoding Strategies in Primary School Children: Insights From an Eye-Tracking Approach and the Role of Individual Differences in Attentional Control. The Journal of Genetic Psychology, 171(1), 1-21. https://doi.org/10.1080/00221320903300361

Rueda, M. R., Posner, M. I., \& Rothbart, M. K. (2011). Attentional control and selfregulation. In Handbook of self-regulation: Research, theory, and applications (2nd ed., pp. 284-299). New York: Guilford Press.

Russell, J. A. (2003). Core affect and the psychological construction of emotion. Psychological Review, 110(1), 145-72. https://doi.org/10.1037/0033- 
295X.110.1.145

Sanchez, A. L., Cornacchio, D., Chou, T., Lewfer, O., Coxe, S., Pincus, D., \& Comer, J. S. (2017). Development of a scale to evaluate young children's responses to uncertainty and low environmental structure. Journal of Anxiety Disorders, 45, 17 23.

Sanislow, C. A., Pine, D. S., Quinn, K. J., Kozak, M. J., Garvey, M. A., Heinssen, R. K., ... Cuthbert, B. N. (2010). Developing constructs for psychopathology research: Research domain criteria. Journal of Abnormal Psychology, 119(4), 631-639. https://doi.org/10.1037/a0020909

Sawaki, R., \& Luck, S. J. (2011). Active suppression of distractors that match the contents of visual working memory. Visual Cognition, 19(7), 956-972. https://doi.org/10.1080/13506285.2011.603709.Active

Shechner, T., Jarcho, J. M., Britton, J. C., Leibenluft, E., Pine, D. S., \& Nelson, E. E. (2013). Attention bias of anxious youth during extended exposure of emotional face Pairs: An eye-tracking study. Depression and Anxiety, 30(1), 14-21. https://doi.org/10.1002/da.21986

Shechner, T., Jarcho, J. M., Wong, S., Leibenluft, E., Pine, D. S., \& Nelson, E. E. (2017). Threats, rewards, and attention deployment in anxious youth and adults: An eye tracking study. Biological Psychiatry, (122), 121-129. https://doi.org/10.1038/nsmb.1793.A

Shihata, S., McEvoy, P. M., Mullan, B. A., \& Carleton, R. N. (2016). Intolerance of uncertainty in emotional disorders: What uncertainties remain? Journal of Anxiety Disorders, 41, 115-124. https://doi.org/10.1016/j.janxdis.2016.05.001 
Silverman, W. K., \& Nelles, W. B. (1988). The Anxiety Disorders Interview Schedule for Children. Journal of the American Academy of Child \& Adolescent Psychiatry, 27(6), 772-778. https://doi.org/10.1097/00004583-198811000-00019

Silverman, W. K., Saavedra, L. M., \& Pina, A. A. (2001). Test-retest reliability of anxiety symptoms and diagnoses with the Anxiety Disorders Interview Schedule for DSMIV: child and parent versions. Journal of the American Academy of Child and Adolescent Psychiatry, 40(8), 937-44. https://doi.org/10.1097/00004583200108000-00016

Sjöwall, D., Roth, L., Lindqvist, S., \& Thorell, L. B. (2013). Multiple deficits in ADHD: Executive dysfunction, delay aversion, reaction time variability, and emotional deficits. Journal of Child Psychology and Psychiatry and Allied Disciplines, 54(6), 619-627. https://doi.org/10.1111/jcpp.12006

Sonuga-Barke, E. J. S., Cortese, S., Fairchild, G., \& Stringaris, A. (2016). Annual Research Review: Transdiagnostic neuroscience of child and adolescent mental disorders - differentiating decision making in attention-deficit/hyperactivity disorder, conduct disorder, depression, and anxiety. Journal of Child Psychology and Psychiatry, 57(3), 321-349. https://doi.org/10.1111/jcpp.12496

Speed, B. C., Jackson, F., Nelson, B. D., Infantolino, Z. P., \& Hajcak, G. (2017). Unpredictability increases the error-related negativity in children and adolescents. Brain and Cognition, 119(September), 25-31. https://doi.org/10.1016/j.bandc.2017.09.006

Stallings, P., \& March, J. S. (1995). Assessment. In J. S. March (Ed.), Anxiety disorders in children and adolescents (pp. 125-147). New York: Guilford Press. 
Stern, E. R., Gonzalez, R., Welsh, R. C., \& Taylor, S. F. (2010). Updating beliefs for a decision: neural correlates of uncertainty and underconfidence. The Journal of Neuroscience : The Official Journal of the Society for Neuroscience, 30(23), 803241. https://doi.org/10.1523/JNEUROSCI.4729-09.2010

Tan, P. Z., Forbes, E. E., Dahl, R. E., Ryan, N. D., Siegle, G. J., Ladouceur, C. D., \& Silk, J. S. (2012). Emotional reactivity and regulation in anxious and nonanxious youth: A cell-phone ecological momentary assessment study. Journal of Child Psychology and Psychiatry and Allied Disciplines, 53(2), 197-206. https://doi.org/10.1111/j.1469-7610.2011.02469.x

Theeuwes, J. (2010). Top-down and bottom-up control of visual selection. Acta Psychologica, 135(2), 77-99. https://doi.org/10.1016/j.actpsy.2010.02.006

Thibodeau, M. a., Carleton, R. N., Gómez-Pérez, L., \& Asmundson, G. J. G. (2013). “What If I Make a Mistake?” Intolerance of Uncertainty Is Associated With Poor Behavioral Performance. The Journal of Nervous and Mental Disease, 201(9), 760766. https://doi.org/10.1097/NMD.0b013e3182a21298

Tolin, D. F., Abramowitz, J. S., Brigidi, B. D., \& Foa, E. B. (2003). Intolerance of uncertainty in obsessive-compulsive disorder. Journal of Anxiety Disorders, 17(2), 233-242. https://doi.org/10.1016/S0887-6185(02)00182-2

Turk, C. L., Heimberg, R. G., Luterek, J. a., Mennin, D. S., \& Fresco, D. M. (2005). Emotion Dysregulation in Generalized Anxiety Disorder: A Comparison with Social Anxiety Disorder. Cognitive Therapy and Research, 29(1), 89-106. https://doi.org/10.1007/s10608-005-1651-1

Van Bockstaele, B., Verschuere, B., Tibboel, H., De Houwer, J., Crombez, G., \& Koster, 
E. H. W. (2014). A review of current evidence for the causal impact of attentional bias on fear and anxiety. Psychological Bulletin, 140(3), 682-721. https://doi.org/10.1037/a0034834

Vaurio, R. G., Simmonds, D. J., \& Mostofsky, S. H. (2009). Increased intra-individual reaction time variability in attention-deficit/hyperactivity disorder across response inhibition tasks with different cognitive demands. Neuropsychologia, 47(12), 23892396. https://doi.org/doi:10.1016/j.neuropsychologia.2009.01.022

Vytal, K. E., Arkin, N. E., Overstreet, C., Lieberman, L., \& Grillon, C. (2016). Inducedanxiety differentially disrupts working memory in generalized anxiety disorder. BMC Psychiatry, 16(1), 1-9. https://doi.org/10.1186/s12888-016-0748-2

Wang, B., \& Theeuwes, J. (2018a). How to inhibit a distractor location? Statistical learning versus active, top-down suppression. Attention, Perception, and Psychophysics, (February), 1-11. https://doi.org/10.3758/s13414-018-1493-z Wang, B., \& Theeuwes, J. (2018b). Statistical regularities modulate attentional capture. Journal of Experimental Psychology: Human Perception and Performance, 44(1), 13-17. https://doi.org/10.1037/xhp0000472

Waters, A. M., Bradley, B. P., \& Mogg, K. (2014). Biased attention to threat in paediatric anxiety disorders (generalized anxiety disorder, social phobia, specific phobia, separation anxiety disorder) as a function of "distress" versus "fear" diagnostic categorization. Psychological Medicine, 44(3), 607-616. https://doi.org/10.1017/S0033291713000779

Waters, A. M., Wharton, T. A., Zimmer-Gembeck, M. J., \& Craske, M. G. (2008). Threat-based cognitive biases in anxious children: Comparison with non-anxious 
children before and after cognitive behavioural treatment. Behaviour Research and Therapy, 46(3), 358-374. https://doi.org/10.1016/j.brat.2008.01.002

Weierich, M. R., Treat, T. A., \& Hollingworth, A. (2008). Theories and measurement of visual attentional processing in anxiety. Cognition and Emotion (Vol. 22). https://doi.org/10.1080/02699930701597601

Wever, M., Smeets, P., \& Sternheim, L. (2015). Neural Correlates of Intolerance of Uncertainty in Clinical Disorders. The Journal of Neuropsychiatry and Clinical Neurosciences, 27(4), 345-353. https://doi.org/10.1176/appi.neuropsych.14120387

Whelan, R. (2008). Effective analysis of reaction time data. The Psychological Record, $58,475-482$.

Winkielman, P., Knutson, B., Paulus, M., \& Trujillo, J. L. (2007). Affective Influence on Judgments and Decisions: Moving Towards Core Mechanisms. Review of General Psychology, 11(2), 179-192. https://doi.org/10.1037/1089-2680.11.2.179

Wright, L., Lipszyc, J., Dupuis, A., Thayapararajah, S. W., \& Schachar, R. (2014). Response inhibition and psychopathology: A meta-analysis of Go/No-Go task performance. Journal of Abnormal Psychology, 123(2), 429-439. https://doi.org/10.1037/a0036295

Yeung, N., \& Cohen, J. D. (2006). The impact of cognitive deficits on conflict monitoring predictable dissociations between the error-related negativity and $\mathrm{N} 2$. Psychological Science, 17(2), 164-171. https://doi.org/10.1111/j.14679280.2006.01680.x

Yook, K., Kim, K. H., Suh, S. Y., \& Lee, K. S. (2010). Intolerance of uncertainty, worry, and rumination in major depressive disorder and generalized anxiety disorder. 
Journal of Anxiety Disorders, 24(6), 623-628.

https://doi.org/10.1016/j.janxdis.2010.04.003

Yu, A. J., \& Dayan, P. (2003). Expected and unexpected uncertainty: ACh and NE in the neocortex. Advances in Neural Information Processing ..., 15, 157-164. https://doi.org/citeulike-article-id:496920

Yu, A. J., \& Dayan, P. (2005). Uncertainty, neuromodulation, and attention. Neuron, 46(4), 681-692. https://doi.org/10.1016/j.neuron.2005.04.026

Zahn-Waxler, C., Shirtcliff, E. A., \& Marceau, K. (2008). Disorders of Childhood and Adolescence: Gender and Psychopathology. Annual Review of Clinical Psychology, 4(1), 275-303. https://doi.org/10.1146/annurev.clinpsy.3.022806.091358

Zelazo, P. D., \& Carlson, S. M. (2012). Hot and Cool Executive Function in Childhood and Adolescence: Development and Plasticity. Child Development Perspectives, 6(4), 354-360. https://doi.org/10.1111/j.1750-8606.2012.00246.x

Zelazo, P. D., \& Müller, U. (2010). Executive Function in Typical and Atypical Development. In Handbook of Childhood Cognitive Development (pp. 574-603). https://doi.org/10.1002/9781444325485.ch22

Zimmermann, P., Fimm, B., \& Gondan, M. (2002). Testbatterie zur Aufmerksamkeitsprüfung für Kinder (KITAP) [Children Version Test-battery of Attention Performance (KITAP)]. Psytest. 


\section{CURRICULUM VITAE}

Colette Gramszlo, M.S. (Szabo-Long)

Department of Psychological and Brain Sciences

University of Louisville | Louisville, KY 40292

Colette.gramszlo@louisville.edu |(610)348-7722

EDUCATION:

Doctor of Philosophy, Clinical Psychology (Anticipated 2019)

Advisor: Janet Woodruff-Borden, Ph.D.

University of Louisville, Louisville, KY

Master of Science, Clinical Psychology (December 2016)

Advisor: Janet Woodruff-Borden, Ph.D.

University of Louisville, Louisville, KY

Bachelor of Arts, Double major in Cognitive Science and Psychology (May 2013)

Advisors: Paul Smolensky, Ph.D., Stephen Drigotas Ph.D.

Johns Hopkins University, Baltimore, MD

DISSERTATION:

Title: $\quad$ Behavioral and cognitive correlates of Intolerance of Uncertainty in children with and without anxiety disorders

Chair: Janet Woodruff-Borden, Ph.D.

CLINICAL EXPERIENCE:

\section{Anxiety Research and Treatment Team}

\section{Noble H. Kelley Psychological Services Center, Louisville, KY}

August 2014-August 2016; January 2018-Present

Supervisor: Janet Woodruff-Borden, Ph.D.

- Conducted therapy intake evaluations for adults and children with anxiety disorders and related symptoms; wrote diagnostic evaluations and evidence-based case conceptualizations

- Administered cognitive behavioral treatments for disorders including: GAD, $\mathrm{SAD}$, selective mutism, panic disorder, OCD, MDD and Tourette syndrome

- Met weekly for group supervision and biweekly for individual supervision; provided peer supervision 


\section{Children with ADHD and Related Difficulties Team}

Noble H. Kelley Psychological Services Center, Louisville, KY

University of Louisville, Louisville, KY

March 2016-December 2017

Supervisor: Paul J. Rosen, Ph.D.

- Conducted therapy intake evaluations for children ages 3-17 with ADHD and comorbid externalizing and internalizing disorders

- Administered evidence-based treatments including PCIT, Collaborative Problem Solving, Defiant Child, Organization Skills Training, and behavior management

- Led the Managing Frustration for Children (MFC) group, a manualized treatment designed for children ages 8-11 with emotion regulation and related behavioral difficulties; led the MFC parenting group, a manualized companion treatment for parents of children with ADHD and related emotional difficulties

- Met weekly for group supervision and individual supervision; provided peer supervision

\section{Child Assessment and Testing Practicum}

Noble H. Kelley Psychological Services Center

August 2015-Present

Supervisor: Bernadette Walter, Ph.D.

- Administered psychological test batteries for children and adolescents ages 5-17

- Assessed for concerns including ADHD, LDs, anxiety and mood disorders; recommended accommodations to school staff and consulted with school counselors to implement recommendations

- Completed achievement testing for Jefferson County Public School students

- Utilized assessment tools including: WISC-V, WAIS-IV, WMS-IV, CAARS, CPT, WJ-III, MMPI

\section{Pediatric Psychology Inpatient Consultation/Liaison Service \\ Norton Children's Hospital, Louisville, KY}

\section{University of Louisville Department of Pediatrics, Louisville, KY}

July 2016-August 2017

Supervisor: Bryan Carter, Ph.D.

- Evaluated children with acute and chronic medical illnesses at the request of attending physicians to assist with coping, adherence and communication between children, families and hospital staff

- Implemented evidence-based interventions for children and their families undergoing long-term hospitalizations to promote healthy development and optimal functioning post-discharge

- Conducted psycho-social pre-transplant evaluation, participated in heart failure team meetings and care conferences, and provided ongoing inpatient care for children awaiting solid organ and bone marrow transplants 
- Completed risk assessments for suicidal patients with dispositions for psychiatric care following medical stabilization

- Received weekly one-to-one supervision including live supervision

\section{Pediatric Psychology Outpatient Clinic}

Bingham Child Guidance Clinic

University of Louisville Department of Pediatrics, Louisville, KY

July 2016-August 2017

Supervisor: Bryan Carter, Ph.D.

- Provided short-term after-care for medically ill children following hospital discharge to promote recovery and facilitate continuity of care

- Implemented evidence-based therapy on an outpatient basis for children with chronic medical conditions and chronic pain, psychosomatic disorders, and related anxiety and mood symptoms

- Co-led the Children's Health and Illness Recovery Program (CHIRP), a manualized therapy for adolescents managing chronic illnesses and pain, and related stress symptoms

PROFESSIONAL ORGANIZATIONS:

2017-Present Society for Pediatric Psychology

Graduate student member

2015-Present Anxiety and Depression Association of America

Graduate student member

Child and Adolescent Anxiety SIG

2015-2016 Vice Chair

2014-Present

American Psychological Association

Graduate student member

2014-Present

Association of Behavioral and Cognitive Therapies

Graduate student member

Child and Adolescent Anxiety SIG

Oppression and Resilience Minority Health SIG-in-

formation

AWARDS AND SCHOLARSHIPS:

2014-2016 Research Fellowship, College of Arts and Sciences,

University of Louisville

June 2017 Preliminary Qualifying Examination: Distinguished Pass

May $2016 \quad$ Excellence in Research Award-University of Louisville

Department of Psychological and Brain Sciences

TEACHING EXPERIENCE:

\section{Graduate Teaching Assistant}

University of Louisville, Louisville, KY 
- Social Psychology, Lead Instructor: Lora Haynes, Ph.D. August 2016-December 2016

- Abnormal Psychology, Lead Instructor: Tamara Newton, Ph.D. January 2017-May 2017

- Social Psychology, Lead Instructor: Lora Haynes, Ph.D. August 2017-Present

RESEARCH EXPERIENCE:

Anxiety and Stress in Kids (ASK) Lab University of Louisville, Louisville, KY

Supervisor: Janet Woodruff-Borden, Ph.D.

July 2014-July 2016, Research fellow; July 2016-Present, Study coordinator

- Produced and submitted an IRB application investigating the cognitive development of children with anxiety and related disorders in middle childhood; managed IRB correspondence and continuing reviews for multiple studies

- Administered the ADIS-IV-C/P and the ADIS-5-Client; wrote diagnostic evaluations for children based on data obtained from structured interviews and assessment measures; provided feedback and recommendations to parents

- Conducted data cleaning and analysis using SPSS, AMOS, PROCESS, R, and REDCap; Collected physiological data including heartrate variability, respiration, and eye movement

- Trained and supervised undergraduate research assistants and beginning graduate students in assessment administration and data analysis

\section{Child Anxiety Prevention Study (CAPS)}

Johns Hopkins Hospital, Baltimore, MD

Supervisor: Golda Ginsburg, Ph.D.

June 2010-December 2013, Research assistant

- Administered questionnaires and behavioral tasks to families as part of a multisite R01 funded study investigating the prevention of anxiety disorders in at-risk children

- Prepared and analyzed data using SPSS; coded behavioral tasks

- Reviewed literature and contributed to the writing and revision of grant applications, manuscripts and poster abstracts

- Conducted follow-up phone screenings and brief clinical interviews with enrolled families

GRANTS:

2016-2017

$2015-2016$

GSC Travel Grant, University of Louisville (\$350)

$2015-2016$

GSC Research Grant, University of Louisville (\$300)

2014-2015

GSC Travel Grant, University of Louisville (\$350)

GSC Travel Grant, University of Louisville (\$350) 
CONFERENCE TALKS:

Gramszlo, C., \& Woodruff-Borden, J., (October, 2016) How does Intolerance of Uncertainty Influence the Development of Worry? Association for Behavioral and Cognitive Therapies, New York, NY.

Poster PRESENTATIONS:

Drazdowski, T. K., Szabo-Long, C., \& Ginsburg, G. S. (2011) Predictors of parent-child discrepancies of child anxiety symptoms. Presented at the Anxiety Disorders Association of America $31^{\text {st }}$ Annual Convention, New Orleans, LA.

Szabo-Long, C. \& Woodruff-Borden, J. (2014) The Role of Emotional and Attentional Control in the Relation between Emotional Reactivity and Child Worry. Presented at the Association of Behavioral and Cognitive Therapies $48^{\text {th }}$ Annual Convention, Philadelphia, P.A.

Szabo-Long, C., Richards, A., Petrie, J. \& Woodruff-Borden, J. (2015) Culturally Protective Factors in the Relation Between Child Emotionality and Worry Symptoms. Presented at the Anxiety and Depression Association of America 35th Annual Convention, Miami, FL.

Gramszlo, C., Arellano, B. \& Woodruff-Borden, J. (2015) Two Temperamental Vulnerabilities and Their Contributions to Childhood Anxiety Symptoms. Presented at the Association of Behavioral and Cognitive Therapies $49^{\text {th }}$ Annual Convention, Chicago, IL.

Geronimi, E. M. C., Gramszlo, C., Patterson, H., Affrunti, N.W., Richards, A., \& Woodruff-Borden, J. (2015) Understanding Worry in Adolescents: Linguistic Features of Theoretical Worry Models. Presented at the Association of Behavioral and Cognitive Therapies $49^{\text {th }}$ Annual Convention, Chicago, IL.

Patterson, H., Affrunti, N., Geronimi, E., Richards, A., Szabo-Long, C. \& WoodruffBorden, J. (2015). Preliminary evidence for a physiological avoidance mechanism in children: comparison with adult research on heart rate variability and worry. Presented at the Association for Behavioral and Cognitive Therapies $49^{\text {th }}$ Annual Convention, Chicago, IL.

Affrunti, N.W., Bortoleto, E.G., Szabo-Long, C., Patterson, H., Richards, A., \& Woodruff-Borden, J. (2015) The effect of maternal psychopathology on parentchild agreement of child anxiety symptoms: A hierarchical linear modeling approach. Presented at the Association for Behavioral and Cognitive Therapies $49^{\text {th }}$ Annual Convention, Chicago, IL.

Affrunti, N.W., Bortoleto, E.G., Szabo-Long, C., Patterson, H., Richards, A., \& 
Woodruff-Borden, J. (2015) Fearful temperament moderates the relation between perfectionism and child worry and anxiety. Presented at the Association for Behavioral and Cognitive Therapies $49^{\text {th }}$ Annual Convention, Chicago, IL.

Affrunti, N.W., Bortoleto, E.G., Gramszlo, C., Arellano, B., \& Woodruff-Borden, J. (2016) Negative Affect, Perfectionism, and Intolerance of Uncertainty in a Model of Risk for Child Anxiety Diagnostic Status. Presented at the Association for Behavioral and Cognitive Therapies $50^{\text {th }}$ Annual Convention, New York, NY.

Bortoleto, E.G., Gramszlo, C., Arellano, B., Affrunti, N.W., \& Woodruff-Borden, J. (2016) Temperament and Mindfulness in Children: The Mediating Role of Intolerance of Uncertainty. Presented at the Association for Behavioral and Cognitive Therapies $50^{\text {th }}$ Annual Convention, New York, NY.

Arellano, B., Woodruff-Borden, J., Affrunti, N.W., Bortoleto, E.G., \& Gramszlo, C. (2016). GAD Severity Predicts Parenting Behavior During a Mildly Stressful Task. Presented at the Association for Behavioral and Cognitive Therapies $50^{\text {th }}$ Annual Convention, New York, NY.

Arellano, B., Gramszlo, C., Mier-Chairez, J., Lee, A. \& Woodruff-Borden, J. (2017) Emotional Control and Child Anxiety: The Moderating Role of Supportive Emotion Socialization. Presented at the Anxiety and Depression Association of America Annual Convention, San Diego, CA.

Gramszlo, C., Fogleman, N.D., Rosen, P.J., \& Woodruff-Borden, J. (2017) Intolerance of Uncertainty in Children with ADHD. Presented at the Association for Behavioral and Cognitive Therapies $51^{\text {st }}$ Annual Convention, San Diego, CA.

Fogleman, N.D., Gramszlo, C., Rosen, P.J., \& Woodruff-Borden, J. (2017) Relation between intolerance of uncertainty and emotion regulation among children with ADHD. Presented at the Association for Behavioral and Cognitive Therapies $51^{\text {st }}$ Annual Convention, San Diego, CA.

Mier-Chairez, J., Richards, A., Gramszlo, C., Geronimi, E.M.C., \& Woodruff-Borden, J. (2018). Cognitive Features Associated with Worry among Low Income African American Youth. Submitted to the Association for Behavioral and Cognitive Therapies $52^{\text {nd }}$ Annual Convention, Washington, D.C.

Gramszlo, C., Lee, A., Dixon, K., Cashon, C., \& Woodruff-Borden, J. (2018) Pupillary Differences During Decision-Making are Associated with Intolerance of Uncertainty. Submitted to the Association for Behavioral and Cognitive Therapies $52^{\text {nd }}$ Annual Convention, Washington, D.C.

MANUSCRIPTS, PUblished AND In PRESS:

Gramszlo, C., \& Woodruff-Borden, J. (2015). Emotional reactivity and executive 
control: A pathway of risk for the development of childhood worry. Journal of Anxiety Disorders, 35, 35-41. doi:10.1016/j.janxdis.2015.07.005

Affrunti, N.W., Gramszlo, C., \& Woodruff-Borden, J. (2016). Executive function moderates the association between fearful temperament and dimensions of perfectionism. Personality and Individual Differences, 89, 117-122. doi:10.1016/j.paid.2015.10.012

Gramszlo, C., Geronimi, E.M.C., Arellano, B., \& Woodruff-Borden, J. (2017). Testing a cognitive pathway between temperament and childhood anxiety. Journal of Child and Family Studies, 1-11. doi: 10.1007/s10826-017-0914-2

Arellano, B., Gramszlo, C., \& Woodruff-Borden, J. (2017). Parental reactions to children's negative affect: The moderating role of parental GAD. Journal of Anxiety Disorders.

Gramszlo, C.*, Fogleman, N.*, Rosen, P., \& Woodruff-Borden, J. (2017). Intolerance of uncertainty in children with Attention-Deficit/Hyperactivity Disorder. $A D H D$ Attention Deficit and Hyperactivity Disorders. *Authors contributed to this work equally.

MANUSCRIPTS, UNDER ReVIEW AND In PROGRESS:

Richards, A., Geronimi, E.M.C., Gramszlo, C., \& Woodruff-Borden, J. (Under review). Cognitive Features Associated with Worry among African American Youth. Journal of Black Psychology.

Lee, A., Gramszlo, C., \& Woodruff-Borden, J. (Under review). Impact of Parental Anxiety on Parenting Behaviors Across Child Development. Parenting: Science and Practice.

\section{BOOK CHAPTERS:}

Woodruff-Borden, J., Lee, A. \& Gramszlo, C. (2018). Anxiety disorders In D. C. Beidel $\&$ B.C. Frueh (Eds.) Adult Psychopathology and Diagnosis ( $\left.8^{\text {th }} e d.\right)$. Hoboken, NJ: Wiley.

PEeR-REVIEW EXPERIENCE:

\begin{tabular}{ll}
\hline 2017 & Ad-Hoc Peer Reviewer (Child \& Youth Care Forum) \\
2016 & Ad-Hoc Peer Reviewer (Journal of Abnormal Child Psychology) \\
2016 & Ad-Hoc Peer Reviewer (Journal of Child and Family Studies)
\end{tabular}

